\title{
WestVirginiaUniversity
}

THE RESEARCH REPOSITORY @ WVU

Graduate Theses, Dissertations, and Problem Reports

2015

\section{Emotion Regulation Flexibility and Illicit Substance Use among Adolescents}

Chit Yuen Yi

Follow this and additional works at: https://researchrepository.wvu.edu/etd

\section{Recommended Citation}

Yi, Chit Yuen, "Emotion Regulation Flexibility and Illicit Substance Use among Adolescents" (2015). Graduate Theses, Dissertations, and Problem Reports. 7006.

https://researchrepository.wvu.edu/etd/7006

This Dissertation is protected by copyright and/or related rights. It has been brought to you by the The Research Repository @ WVU with permission from the rights-holder(s). You are free to use this Dissertation in any way that is permitted by the copyright and related rights legislation that applies to your use. For other uses you must obtain permission from the rights-holder(s) directly, unless additional rights are indicated by a Creative Commons license in the record and/ or on the work itself. This Dissertation has been accepted for inclusion in WVU Graduate Theses, Dissertations, and Problem Reports collection by an authorized administrator of The Research Repository @ WVU.

For more information, please contact researchrepository@mail.wvu.edu. 
Emotion Regulation Flexibility and Illicit Substance Use among Adolescents

\title{
Chit Yuen Yi
}

\author{
Dissertation submitted to the \\ Eberly College of Arts and Sciences \\ at West Virginia University \\ in partial fulfillment of the requirementsfor the degree of \\ Doctor of Philosophyin \\ Psychology
}
Amy Gentzler, Ph.D., Chair Aaron Metzger, Ph.D.
Sara Anderson, Ph.D.
Karen Anderson, Ph.D.
Alfgeir Kristjansson, Ph.D.

Department of Psychology

Morgantown, West Virginia

2015

Keywords: regulatory flexibility, illicit substance use, adolescents, mood, emotionality, urgency

Copyright 2015 Chit Yuen Yi 


\begin{abstract}
Emotion Regulation Flexibility and Illicit Substance Use among Adolescents
\end{abstract}

\title{
Chit Yuen Yi
}

The purpose of the present study was to investigate how emotion regulation (ER) flexibility was related to illicit substance use among adolescents. The hypotheses were that higher levels of ER flexibility (indicated by higher levels of context sensitivity, a larger ER repertoire, and higher levels of responsiveness tofeedback about ER) would be associated with lower levels of substance use, fewer substance-related problems, and lower tendency to use substances in emotion-laden situations. In an online survey, adolescent participants (aged 18-20; $M=19.00$; $S D=0.74 ; 77.1 \%$ female) answeredquestions about emotion regulation, illicit substance involvement and other emotion-relevant characteristics. Various indices of ER flexibility were created and their associations with levels of substance use, substance-related problems, and tendency to use substances in emotion-laden situations were examined. Moderation analyses were also performed to identifyemotion-relevant factors (i.e., mood, temperament reactivity, and urgency to act rashly in response to intense emotional experiences) that might impact the aforementioned associations. Additional indices of ER flexibility were also explored post-hoc. Results were analyzed using structural equation modeling. Counter to expectations, a larger ER repertoire for negative emotionswas associated with more substance-related problems, whereas a larger ER repertoire for positive emotions was associated with higher levels of substances but lower tendency to use substances in positive situations. Furthermore, some of these associations were moderated by negative urgency and positive emotionality such that a larger ER repertoire for negative emotions was associated with more substance-related problems among individuals with higher levels of negative urgency, whereas a larger ERfor positive emotions was related to lower tendency to use substances in positive situations for individuals with lower levels of positive emotionality. Another moderating effect, which was consistent with hypotheses, indicated that higher levels of responsiveness to feedback about positive ER was associated with lower levels of substance use for individuals who reported higher levels (but not lower levels) of positive mood. Overall, most of the findings were not consistent with the hypotheses, suggesting that there might be other factors (e.g., peer influence) that more strongly predict illicit substance use in the current sample or that there may be better ways to assess ER flexibility. 


\section{ACKNOWLEDGEMENTS}

I would like express my appreciation tomy dissertation committee for their advice and assistance on this project. I would also like to thank my advisor, Dr. Amy Gentzler, for challenging me to succeed and for providing invaluable guidance and support over the past five years. I am grateful for her flexibility in accommodating my academic and career aspirations. Without her encouragement and understanding, my academic journey would have been different. I also appreciate my fellow lab members Jennifer Morey, Cara Palmer, Meagan Ramsey, Elizabeth Yale-Babskie, Karena Moran, and Katelyn Black for their continuous support and friendship. Finally, I would not have accomplished this if not for the unconditional love and care from my parents and my significant other, AD. Thank you for making this accomplishment a possibility. 


\section{TABLE OF CONTENTS}

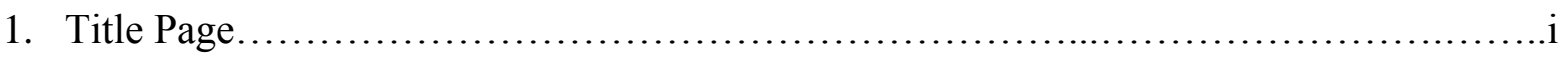

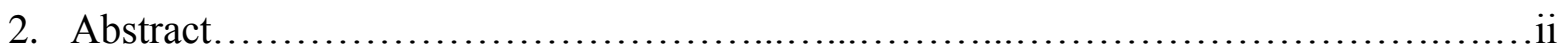

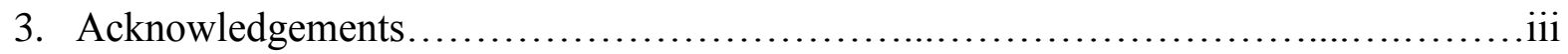

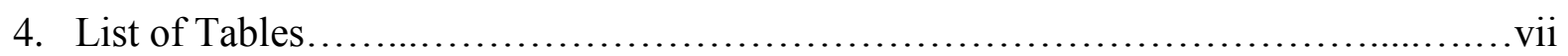

5. List of Figures.............................................................................

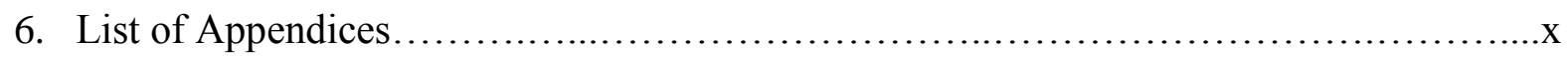

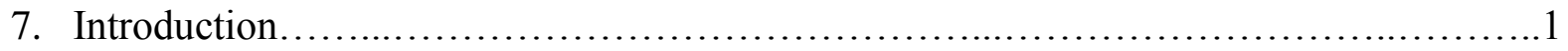

7.1 Emotion Regulation and Substance Use.........................................

7.1.1 Coping and Negative Emotion Regulation................................4

7.1.2 Positive Emotion Regulation........................................... 8

7.2 ER Flexibility and Adolescent Substance Use...................................11

7.3 Individual Differences in Vulnerability to Substance Use..............................14

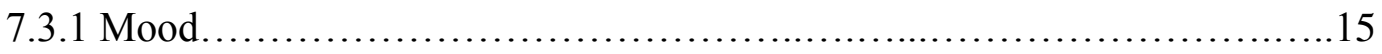

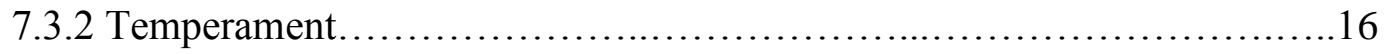

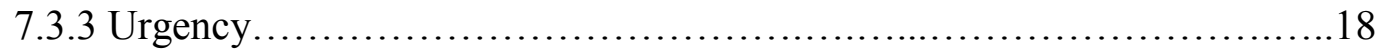

7.4 The Present Study ............................................................ 18

7.4.1 Research Questions and Hypotheses.......................................19

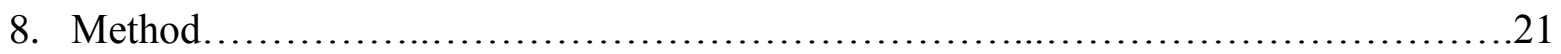

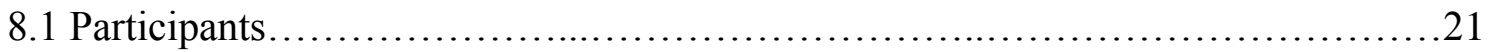

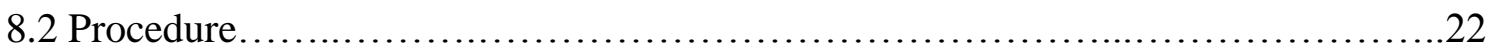

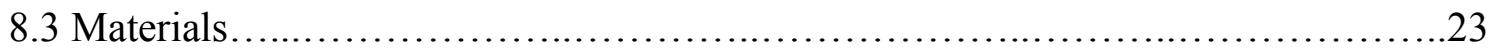

8.3.1 Demographic and Background Information............................23 
8.3.2 ER Flexibility: Context Sensitivity...................................24

8.3.3 ER Flexibility: Repertoire..........................................25

8.3.4 ER Flexibility: Responsiveness to Feedback about ER..................26

8.3.5 Substance Use....................................................27

8.3.6 Substance-Taking Situations......................................28

8.3.7 Typical Mood States..............................................28

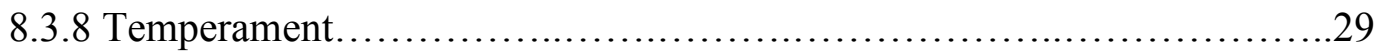

8.3 .9 Urgency...................................................... 30

8.3.10 Depressive Symptoms..........................................30

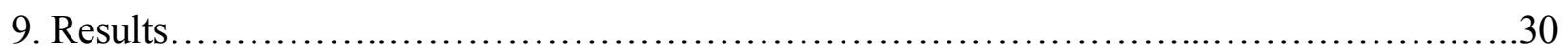

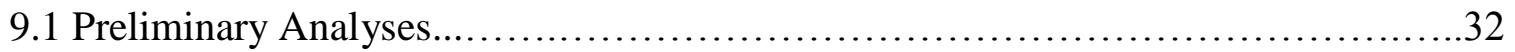

9.2 Research Question 1: What are the Components of ER Flexibility?..........................34

9.3 Research Question 2: How is ER Flexibility Related to Illicit Substance Use among

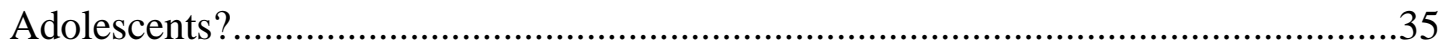

9.4 Research Question 3: Is the Association between ER Flexibility and Severity of Adolescent Substance Use Moderated by Other Emotion-Relevant Factors?............37

9.5 Exploratory Analyses.................................................... 39

9.5.1 Adaptive and Maladaptive ER Repertoire for Negative Emotions ...........39

9.5.2 Adaptive and Maladaptive ER Repertoire for Positive Emotions ...........40

9.5.3 Other Indices of ER Flexibility.....................................40

9.5.4 New Model for Negative ER Flexibility...............................41

9.5.5 New Model for Positive ER Flexibility.............................41

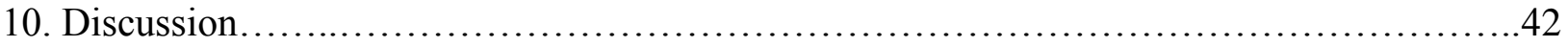


10. 1 Testing of the Measurement Model.......................................43

10.2 Context Sensitivity and Illicit Substance Use.................................44

10.3 ER Repertoire and Illicit Substance Use.................................45

10.4 Responsiveness to Feedback about ER and Illicit Substance Use..................48

10. 5 Other Emotion-relevant Characteristics and Illicit Substance Use................49

10.6 Discussion of Exploratory Findings...................................... 52

10.7 Limitations and Future Directions...........................................55

11. References.................................................................6

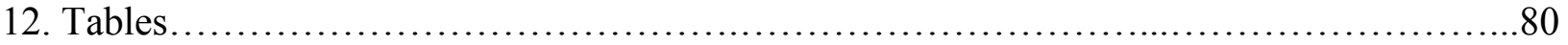

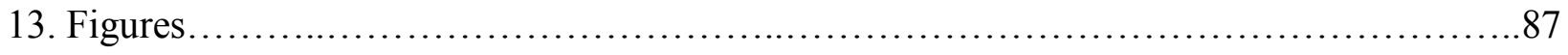

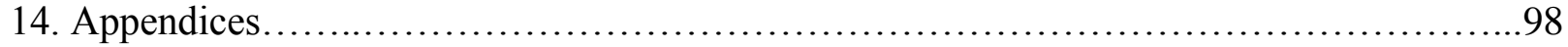




\section{LIST OF TABLES}

1. Table 1: Prevalence of Lifetime Use of Illicit Substances............................80

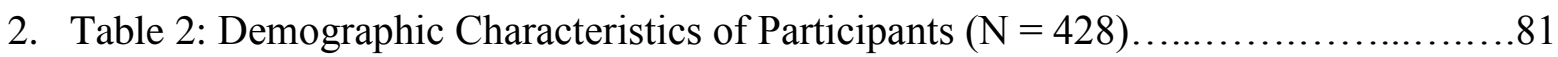

3. Table 3: Means, Standard Deviations, and Ranges for Main Study Variables............82

4. Table 4: Bivariate Correlations among Demographic Characteristics and Substance Use Outcomes................................................................ 83

5. Table 5: Bivariate Correlations among ER Flexibility Predictors and Substance Use

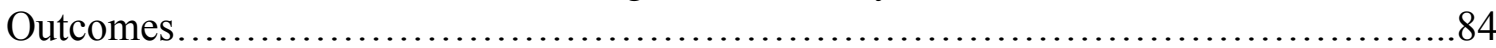

6. Table 6: Bivariate Correlations among Moderators and Substance Use Outcomes.......85

7. Table 7: Bivariate Correlations among ER Flexibility Predictors and Moderators.......86 


\section{LIST OF FIGURES}

1. Figure 1: Conceptual Model for Negatively Valenced Emotion (NA) Variables..............87

2. Figure 2: Conceptual Model for Positively Valenced Emotion (PA) Variables..................88

3. Figure 3: Full Measurement Model.................................................. 89

4. Figure 4: Full Model for Negative Emotion Regulation Flexibility and Illicit Substance Use

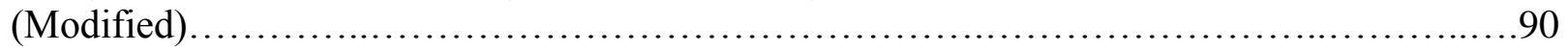

5. Figure 5: Full Model for Positive Emotion Regulation Flexibility and Illicit Substance Use.

6. Figure 6: Additive Model for Negative Emotion Regulation Flexibility, the Three Negatively Valenced Moderators, and Illicit Substance Use (Modified)..............................92

7. Figure 7: Additive Model for Positive Emotion Regulation Flexibility, the Three Positively Valenced Moderators, and Illicit Substance Use (Modified).

8. Figure 8: Full Model for Adaptive and Maladaptive Repertoire of Negative Emotion Regulation and Illicit Substance Use.

9. Figure 9: Full Model for Adaptive and Maladaptive Repertoire of Positive Emotion Regulation and Illicit Substance Use.

10. Figure 10: Full Model for New Indices of Negative Emotion Regulation Flexibility and Illicit

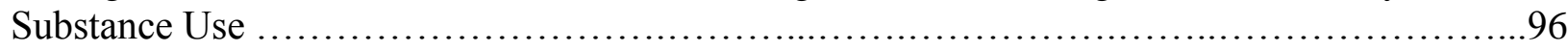

11. Figure 11: Full Model for New Indices of Positive Emotion Regulation Flexibility and Illicit

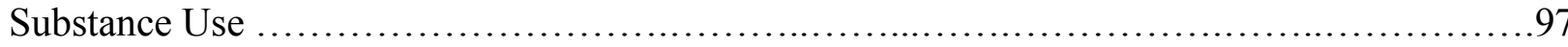

12. Figure J1: Model for Moderation by Negative Urgency on Negative Emotion Regulation Flexibility and Illicit Substance Use (Modified).................................... 137

13. Figure J2: Negative Urgency by Repertoire for Negative Emotion Regulation Interaction on Substance-Related Problems......................................................... 138

14. Figure J3: Model for Moderation by Positive Mood on Positive Emotion Regulation Flexibility and Illicit Substance Use

15. Figure J4: Positive Mood by Responsiveness to Feedback about Positive Emotion Regulation Interaction on Levels of Substance Use.

16. Figure J5: Model for Moderation by Positive Emotionality on Positive Emotion Regulation Flexibility and Illicit Substance Use.... 
17. Figure J6: Positive Emotionality by Repertoire for Positive Emotion Regulation Interaction

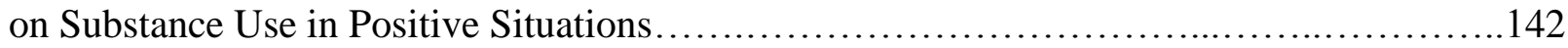




\section{LIST OF APPENDICES}

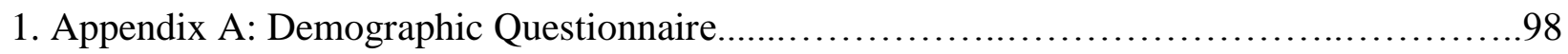

2. Appendix B: Emotion Regulation Profile- Revised..............................................99

3. Appendix C: Adapted Emotion Regulation Flexibility Scale................................116

4. Appendix D: Alcohol, Smoking, and Substance Involvement Screening Test................117

5. Appendix E: Inventory of Drug-Taking Situations....................................... 124

6. Appendix F: Typical Mood Survey................................................... 127

7. Appendix G: Adult Temperament Questionnaire.......................................128

8. Appendix H: UPPS-P Impulsive Behavior Scale........................................131

9. Appendix I: Center for Epidemiologic Studies Depression Scale..............................133

10. Appendix J: Supplementary Moderation Analyses......................................134 


\section{Emotion Regulation Flexibility and Illicit Substance Use among Adolescents}

Illicit substance use among adolescents may have adverse short-term and long-term implications for their health (Hawkins, Catelano, \& Miller, 1992; Tapert, Granholm, Leedy, \& Brown. 2002). In 2013, approximately $8.8 \%$ of younger adolescents (aged $12-17$ ) and $22.6 \%$ older adolescents (aged $18-20$ ) were illicit substance users. In addition, about 8.7 million people aged 12 to 20 (22.7\% of this age group) were underage drinkers (SAMHSA, 2014).Past research hasshown that there is an increase in illicit substance use and alcohol useamong older adolescents after college entry (Suerken et al., 2013). Although the rates of illicit substance use among college and non-college adolescents are comparable (22.3 and 23\%, respectively), college students tend to report higher rates of underage drinking compared to their non-college counterparts $(59,4 \%$ and $50.6 \%$, respectively, SAMHSA, 2014). The present study selectively focused on the correlates of illicit substance use (including alcohol, which is illicit for individuals aged 21 years or below) among college-age adolescents (aged 18 -20) because the transition to college may free adolescents of relatively restrictive social control from parents and schools.Furthermore, experimentation with substances may be viewed as normative in college. Both of these psychosocial changes during this developmental period may promote autonomous decisions about substance use (Staton et al., 1999). Although not all adolescent users will persist to more problematic use that requires treatment, a better understanding of the correlate of illicit substance use in college can inform prevention and intervention efforts.

Emotion regulation (ER) is the process by which individuals modulate the intensity, duration, and expression of their emotional responses in some emotion-eliciting situations (Gross, 1998). ER is inextricably related to substance use under the assumptions that people may be motivated to use substances to enhance positive emotions and reduce negative emotions 
(Kassel \& Veilleux, 2010). Past research with adolescents in high school and college has shown that individuals whose emotional states fluctuate frequently are at greater risk of more severe patterns of substance use, suggesting that poor regulation of emotions may be a risk factor of substance use (Simons \& Carey, 2002; Simons, Gaher, Correia, Hansen, \& Christopher, 2005; Wills, Walker, Mendoza, \& Ainette, 2006). However, past research on ER and substance useoften reports mixed results in linking a specific ER strategy to severity of substance use among adolescents aged 15 -20 (e.g., Dashora, Erdem, \& Slesnick, 2011; Nyamathi et al., 2010; Wills, Sandy, \& Yaeger, 2002). One explanation may be that these studies largely focused on adolescents' tendency to deploy a single category of strategies. This categorical perspective on ER strategies does not necessarily capture adolescents' full repertoire of regulatory strategies and their ability to flexibly draw on different strategies to modulate their emotions based on the situation. Having an adequate repertoire of ER responses and flexibility in using them within and across situations are key ingredients to psychological well-being (e.g., Cheng, 2001; Kashdan \& Rottenberg, 2010; Lougheed \& Hollenstein, 2012). As suggested by Bonnano and Burton (2013), research on ER and adjustment should shift focus from the categorical perspective of ER and emphasize individuals' flexibility in regulating emotions across different emotion-eliciting situations. This emphasis on ER flexibility can also be applied to research on adolescent substance use to better understand the dynamic interplay between ER and substance use.In addition, there may be important emotion-related individual differences in adolescents' vulnerability to substance use. For instance, daily mood states, temperamental reactivity (i.e., propensity to exhibit certain emotional reactions; Rothbart \& Bates, 1998), and urgency to act rashly when experiencing intense emotions could all impact adolescents' tendency to use substances (Adams, Kaiser, Lynam, Charnigo, \& Milich, 2012; Measelle, Stice, \& Springer, 
2006; Rankin \& Maggs, 2006). Therefore, the goals of the present study were 1) to test a measurement model of Bonnano and Burton (2013)'s conceptualization of ER flexibility, 2) to examine whether ER flexibility is negatively associated with adolescents' severity of illicit substance use and their tendency to useinpositive and negative situations, and 3) to investigate whether the association between ER flexibility and severity of adolescent substance use varies as a function of other emotion-related variables.

\section{Emotion Regulation and Substance Use}

Although adolescents may use illicit substances for non-emotional reasons (e.g., conforming to social norm, curiosity; Buckner, 2013; Garnier-Dykstra, Caldeira, Vincent, O'Grady, \& Arria, 2012), the present study specifically focused on emotion-related aspects of illicit substance use because major theoretical perspectives on substance use have focused on emotion regulation as one of the main motivation for substance-using behaviors. For example, self-medication hypothesis (Khantzian, 1997) and stress-coping model (Wills\& Shiffman, 1985) posit that the instantaneous mood-altering effects of substances would reinforce continuous use as quick and immediate relief for emotional distress among substance users with higher levels of stress and low levels of positive emotions. Furthermore, human studies on the neurobiological and subjective effects of psychoactive drugs suggest that the pharmacological effects of certain substances (e.g., cocaine, amphetamine) on the reward-seeking center of the brain correspond to self-reported feelings of euphoria and well-being that resemble naturally occurring positive emotions (Nelson et al., 2006, Voruganti \& Awad, 2005). These euphorigenic effects of substances may then function as positive reinforcers to increase the likelihood of substance use (de Wit \& Phan, 2010). In other words, people may use substances for the purpose of experiencing positive emotions, even when they are not stressed. 
Despite the intuitive appeal of these theoretical perspectives, mixed results have been found in studies that linked specific coping and regulatory strategies to adolescent substance use among high-school and college students (e.g., Boujut, Bruchon-Schweitzer, \& Dombrowski, 2012;Fromme \& Rivet, 1994; Hamdan-Mansour, Puskar, \& Sereika, 2007). One plausible explanation is that these studies use questionnaires that only access individuals' general preference for certain coping and regulatory strategies, which may overlook their propensity to use adaptive ER assessed in a different way (i.e., selecting different strategies across various stressful contexts and making adjustmentsbased on changes inthe emotion-eliciting situations). Also, although enhancement of positive emotions has been identified as one of the motives for substance use (Cooper, 1994; Cooper, Frone, Russel, \& Mudar, 1995; Lee, Neighbors, \& Woods, 2007; Simons, Correia, Carey, \& Corsari, 1998), relatively little is known about how regulatory responses to positive emotions would relate to adolescent substance use. With the use of a vignette-based questionnaire, the present study was designed to extend past literature by accessing adolescents' repertoire of ER strategies for positive and negative emotions, as well as their flexibility in using different ER strategies across various emotion-eliciting situations.

Coping and Negative Emotion Regulation. Coping consists of behavioral and cognitive strategies that aim to change the stressful situations and the associated emotional responses to stress (Gross \& Thomas, 2007; Lazarus \& Folkman, 1984; Wang \& Saudino, 2011). Although they are related constructs, ER is distinguished from coping by its emotion-specific emphasis on modulating the internal feelings and overt expressions of both positive and negative emotions (Gross, 1998; Lazarus \& Folkman, 1984).Given the close overlap and that both constructs relate to substance use, research on coping and negative ER will both be discussed.

A number of studies have identified specific coping strategies that may impact 
vulnerability to substance use among college-ageadolescents, with the assumption that adaptive coping strategies would be protective and maladaptive strategies would be detrimental (e.g., Boujut et al., 2012; Britton, 2004; Fromme \&Rivet, 1994). Although there are many ways to classify coping strategies (Skinner, Edge, Altman, \& Sherwood, 2003), coping is commonly conceptualized as consisting of three broad categories. Problem-focused coping (e.g., changing a stressful situation or one's appraisal of the situation) and emotion-focused coping (e.g., modulating negative emotional reactions to a stressful situation) are considered as adaptive because they are characterized by effort to seek resolution to emotional distress. On the other hand, avoidance coping (e.g., ignoring or disengaging oneself from a stressful situation) is considered maladaptive because it prevents direct confrontation of the emotional distress and development of a resolution, leading to accumulation of stress over time (Britton, 2004; Carver, Scheier, \& Weintraub, 1989). Reliance on maladaptive strategies may make adolescents more prone to seeking quick and immediate relief of their stress through substance use at the expense of long-term negative consequences (Wills \& Hirky, 1996).

Because coping and negative emotion regulation have been related to all stages of substance use (i.e., initiation of substance use, problematic use characterized by increased amount and frequency of use, and vulnerability to substance use disorder; Cheetham, Allen, Yücel,\& Lubman, 2010), past literature regarding both normative and at-risk youth population were reviewed. In addition, the indices of substance use in the present study were assessed as continuous variables, with higher levels indicative of more severe illicit substance use, and thus, this sample could include individuals with severe substance abuse problems (i.e., meeting the diagnostic criteria for substance dependence or substance use disorder). However, it is important to note that the findings from prior research on high-risk youth (e.g., Dashora et al., 2011; 
Nyamathi et al., 2010) may not necessarily generalize to the college students in the present study.

Previous research on coping has focused on two indices of substance use among adolescents and college students: 1) their levels of substance use, as indicated by quantityfrequency measure, and 2), the extent to which they experience health, psychosocial, and legal problems as a result of their substance use. Although problem-focused coping (e.g., behavioral engagement, planning) and emotion-focused coping (e.g. seeking emotional support, venting) are often considered as adaptive and are expected to be inversely related to substance use, past research on the association between these strategies and indices of substance use has been inconsistent. Some studies have found that greater use of problem-focused coping was concurrently associated with lower mean levels of tobacco, marijuana and alcohol use, and fewer substance-related problems among adolescents aged 15 -21 (Rafnsson, Jonsson, \& Windle, 2006; Wills et al., 2002). However, other studies have reported that active coping (conceptually similar to problem-solving coping; Carver et al. 1989) was unrelated to frequency of alcohol consumptionin college (Britton, 2004) and the use of other substances among at-risk adolescents (Dashora et al., 2011; Nyamathi et al., 2010). With regard to emotion-focused coping, some studies have found that lower levels of emotion-focused coping predicted heavy drinking and more alcohol-related problems among college-age adolescents (Fromme \& Rivet, 1994; Britton, 2004). Other studies with homeless youth (age 15 -25) have not supported an association between emotion-focused coping and severity of adolescent substance use, including alcohol and illicit substance use (Dashora et al., 2011; Nyamathi et al., 2010).

More sporadic results were found for avoidance coping (e.g., not thinking about the stressful situation and denial of problem). For example, greater use of avoidance coping has been linked to more frequent and heavy use of alcohol in both rural and urban samples of 
adolescentsbetween the age of 14 - 20 (Hamdan-Mansour et al., 2007; Rafnsson et al., 2006). Similarly, Wills and his associates (Wills et al., 2002) also reported a positive association between avoidance coping and frequent use of tobacco, marijuana and alcohol among highschool adolescents. Avoidance coping strategies have also been linked to frequent marijuana use and use-related consequences among incarcerated adolescent offenders between the ages of 15 20 (Eftekhari, Turner, \& Larimer, 2004). On the other hand, Britton (2004) found that avoidance coping strategies were unrelated to alcohol consumption in college students (aged 18 -20), but predicted more alcohol-related problems. However, another study did not find associations between avoidance coping and college-age adolescents' use of tobacco, marijuana and alcohol (Boujut et al., 2012). In other studies with college students (Fromme \& Rivet, 1994) and homeless adolescents (Dashora et al., 2011), higher levels of avoidance coping were associated with less frequent alcohol use. Possible explanations for these mixed results are that the sample characteristics and the strategies that comprise the avoidance coping category were different across the studies, making direct comparisons difficult. In line with ER flexibility, it is also plausible that the adaptiveness of a singular strategy or a certain category of strategies may not be universal across all stressful conditions. Thus, a higher tendency of using a certain strategy (even ones traditionally considered maladaptive) may not alwaysbe associated withnegative outcomes.

An ER strategy that is closely related to avoidant coping is emotion suppression, which involves active avoidance of experiences or expressions of emotions (Gross, 1998). A recent study revealed that emotion suppression was associated with earlier initiation and higher frequency of illicit drug use among high-risk youth between the age of 16 and 25 (Wong et al., 2013). However, Wills and his colleagues (2006) found that anger suppression, but not sadness 
suppression, was associated with frequent use of alcohol, tobacco and marijuana in a sample of high-school students, suggesting that specific regulatory techniques within the same category of ER can be differentially related to substance use outcomes.

Positive Emotion Regulation. With the emergence of research on positive psychology, a growing number of studies uncover ways that people can enhance or attenuate their positive emotions (e.g., Bryant, 1989; Feldman, Joormann, \& Johnson, 2008, Langston, 1994). Strategies that up-regulate or increase positive emotions are called savoring, maximizing, or capitalizing. These are generally considered adaptive because they are linked to overall emotional well-being and life-satisfaction in adults (Bryant, 2003; Livingstone \& Srivastava, 2012; Quoidabach, Berry, Hansenne, \& Mikolajczak, 2010), and to sustained positive feelings about positive events in younger adolescents (age 10 -14) and adults (Gentzler, Morey, Palmer,\& Yi, 2013; Langston, 1994). These findings suggest that attempts to maximize one's positive experiences may allow adolescents to incur more benefits from those experiences. Given that low levels of positive affect have been linked to frequent substance use among school-age adolescents (age 12 -18) and college students (Allen \& Holder, 2014; Colder \& Chassin, 1997), the attempt to make the best of ones' positive experiences could be protective in sense that it allows adolescents to maintain or increase their positive emotions in ways that do not include substance use. According to Fredrickson's broaden and build model (1998), the broadening effects of positive emotions on individuals' thoughts and behaviors promote ready engagement in the social environment, and in turn help the individuals to build enduring social resources. Thus, experiencing sustained positive emotions may prevent adolescents from using substances to up-regulate their positive emotions because the positive experiences allow adolescents to broaden the scopes of their thoughts and consider a wider range of activity options, and build social resources to sustain 
them through difficult time.

With regard to down-regulating or decreasing positive emotions, certain regulatory strategies that attenuate positive emotions are generally considered as maladaptive. These strategies are collectively called minimizing or dampening (Gentzler, Kerns, \& Keener, 2010; Quoidbach et al., 2010; Wood, Heimpel, \& Michela, 2003), which pertain to behaviors that inhibit the expression of positive emotions, downplay the importance of one's positive experiences, deny personal credits for the occurrence of these positive experiences, or think that the positive feelings will not last. Past research with adults indicates that reliance of these minimizing strategies is associated with lower overall positive mood and life satisfaction (Quoidbach et al., 2010), worse mood the day after a personal achievement and low self-esteem (Wood et al., 2010), and increased depressive symptoms (Raes, Smets, \& Schoof, 2012). With younger adolescents (age 10 -14), greater use of minimizing strategies has been linked to social adjustment problems, including externalizing behaviors (Gentzler et al., 2013), suggesting that those who have trouble maintaining positive emotions may be more likely to engage in counterproductive rule-breaking behaviors. Thus, adolescents who rely on minimizing strategies may be tempted to increase positive emotions through the use of mood-altering substances because they tend to experience less positive emotions in general and even in response to positive events.

It is worth noting, however, that up-regulating strategies are not uniformly adaptive and that there are situations that call for the use of certain minimizing strategies, such as inhibition of positive emotions. In a recent study (Livingstone \& Srivastava, 2012), reward-focused upregulating strategies (e.g., going out drinking or partying, fantasize or daydream) were related to higher levels of momentary positive emotions, but were also linked to more depressive symptoms and lower life satisfaction when they were used in isolation with other up-regulating 
strategies that promote social engagement (e.g., look on the bright side of things, share positive emotions with others) and personal growth (e.g., think about how to become a better person). These findings suggest that adolescents who solely rely on reward-focused strategies may be tempted to seek immediate enhancement of positive emotions through substance use. Similarly, minimizing strategies are not uniformly maladaptive. For example, minimizing highly intense positive emotional expressions (e.g., a hysterical laugh) is more common in workplace settings(Diefendorff \& Greguras, 2009). Tamir (2009) also suggested that minimizing positive emotional experiences may be important when people are preparing for a competitive task. Therefore, adolescents who have trouble minimizing their positive emotional experiences as needed may also be at risk for substance use because they may have poor control of their positive emotions. Indeed, past research with adolescents and young adults indicated that intense experiences of positive emotions were associated with reduced risk perception for drinking and smoking (Haase \& Silbereisen, 2011) and reckless engagement in risky behaviors (e.g., using substances to get high; Roberts, Dimsdale, East, \& Friedman, 1998). These studies suggest that being unable to flexibly minimize positive emotions when needed could be a risk factor for substance use.

Taken together, previous research on coping and ER of negative and positive emotions seems to share a common theme that a single strategy or a certain category of similar strategies is not uniformly adaptive or maladaptive. As noted earlier, inconsistent findings were reported across studies that examined the direction of association between specific coping/ER strategies and adolescent substance use (e.g., Eftekhari et al., 2004; Fromme \& Rivet, 1994;Nyamathi et al., 2010; Rafnsson et al., 2006; Wills et al., 2006; Wong et al., 2013). One possible explanation for the mixed results is that these studies only assess individuals' general tendency to use certain 
coping/ER strategies across all stressful situations. However, different situational demands may necessitate different types of regulatory responses and individual may use multiple strategies to regulate their emotions in any given situations (e.g., Aldao \& Nolen-Hoeksema, 2013; Egloff, Schmukle, Burns, \& Schwerdtfeger, 2006). In other words, the efficacy of any coping or ER strategies may be situation-specific, suggesting that better adjustment may have less to do with the use of singular "adaptive" strategies or the lack of "maladaptive" strategies, and more to do with the ability to flexibly select effective strategies from a larger repertoire to match situational demands. In the context of adolescent substance use, it may be that adolescents who can flexibly deploy multiple ER strategies would be less likely to rely on substances to regulate their negative and positive emotions. The present study was designed to test whether ER flexibility plays a role in the severity of illicit substance use in a sample of college-age adolescents. The present study also expanded the empirical investigation to include ER strategies for positive emotions. Furthermore, lack of flexibility in regulating negative emotions was expected to predict substance use in negative situation (i.e., cope with unpleasant emotions, relieve physical discomfort, conflict with others), whereas lack of flexibility in regulating positive emotions was expected to substance use inpositive situations (i.e., enhance pleasant emotions and enjoy pleasant time with friends).

\section{ER Flexibility and Adolescent Substance Use}

The ability to flexibly deploy different ER strategies in distinct emotion-eliciting contexts is captured in the construct of ER flexibility (Bonanno \& Burton, 2013). This construct is conceptually similar to coping flexibility (Cheng, 2001) and psychological flexibility (Kashdan \& Rottenberg, 2010), which emphasize a dynamic perspective on ER that takes into account the variability of regulatory strategies and the match between strategies and situational demands. 
More precisely, Bonnano and Burton (2013) defined ER flexibility as having three components. Context sensitivity refers to the ability to evaluate changing situational demands and select appropriate ER strategies in response to those demands. Repertoire pertains to the ability to draw on a wide range of ER strategies to accommodate the situational demands. Responsiveness to feedback is the ability to use feedback about the efficacy of a selected strategy and to adjust regulatory behaviors accordingly.

Based on Bonanno and Burton (2013), greater ER flexibility was conceptualized in the present study as 1) higher sensitivity to emotion-eliciting cues in context-specific situations, 2) a larger repertoire of ER strategies, and 3) willingness to change strategies based on feedback about the efficacy of the deployed ER strategies. Specifically, context sensitivitywas inferred when participants correctly identify the discrete emotions elicited by the scenarios described in a vignette-based questionnaire. Repertoirewas indexed by the total number of ER strategies endorsed across various hypothetical vignettes that elicit positive or negative emotions. Responsiveness to feedbackwas indicated by participants' self-reported willingness to adjust their ER strategies in a standardized questionnaire. Because the three-component model of ER flexibility proposed by Bonanna and Burton (2013) has not been tested empirically, the first goal of the study was to test the measurement model of ER flexibility.

The underlying assumptions of the self-medication hypothesis (Khantzian, 1997) and stress-coping model of substance use (Wills\& Shiffman, 1985) suggest that individuals may use substances to enhance their positive emotions or to cope when they experience high levels of stress. Based on these assumptions, self-administration of mood-altering illicit substances in humans can be conceptualized as a goal-directed behavior to achieve the emotional goal of regulating currently undesirable emotional states (Köpetz, Lejuez, Wiers, \& Kruglanski, 2013). 
If the adolescents can regulate their emotions effectively through flexible use of various ER strategies, they may not need to resort to substance use as an alternative means to achieve the emotional goals of enhancing positive emotions or reducing negative emotions. In support of this notion, the principle of emotion transfer states that the emotional aftermath of goal attainment can be transferred to the behavior that was engaged in to achieve the goal. The amount of emotion transfer depends on 1) the importance of the goal and 2) the strength of association between the goal-directed behavior and the goal (Fishbach, Shah, \& Kruglanski, 2004). In the context of adolescent substance use, the emotional aftermath of substance use (i.e., enhancement of positive emotions or relief of negative emotions) may be associated with the means (i.e., selfadministration of substances) used to achieve the emotional goals. This goal-means association would be strengthened if individuals almost exclusively use mood-altering substances to fulfill the emotional goals that are deemed important to them. However, when multiple means are available for goal attainment, the emotional aftermath of the goal will spread to all means used to achieve the goal. As a result, there is a lower amount of emotional transfer to each particular means (Köpetz et al., 2013). In other words, adolescents who are adept at selecting appropriate regulatory strategies from a larger ER repertoire may not need to rely on substance use as a means to regulate their emotions.

The importance of ER repertoire is supported by the findings of Lougheed and Hollenstein (2012), indicating that adolescents (age 12 -17) who possessed a larger ER repertoire (i.e., scoring high on a range of ER strategies in standardized questionnaires) were less likely to report symptoms of depression and anxiety. Parallel results were also found in the positive ER literature. In particular, adults who endorsed more variety of savoring strategies reported higher levels of happiness (Quoidbach et al., 2010). Although the idea of ER flexibility has yet to be 
applied to substance use research, a recent survey-based study provided preliminary evidence that a subgroup of high-risk youth who endorsed a wide range of coping and ER strategies reported later onset, lower frequency, and fewer problems associated with illicit substance use, compared to those who endorsed fewer strategies (Wong et al., 2013). It is worth noting that a larger ER repertoire is only one of the three components of ER flexibility (Bonanno \& Burton, 2013). The findings of Wong et al. (2013) did not necessarily speak to adolescents' sensitivity to shifting situational demands and their flexibility to adjust ER strategies to match situational demands based on feedback about the efficacy of the deployed strategies.

The importance of flexibly adjusting ER strategies in accord with changes in emotional goals or situational demands (Mauss \& Tamir, 2014) has been supported in survey-based studies and laboratory observations in which participants' ability to match ER strategies to current situational demands was assessed (Cheng, 2001; Bonanno, Papa, Lalande, Westphal, \& Coifman, 2004). Specifically, college-age adolescents (age 18 -20) who reported varying their use of different coping strategies across stressful situations performed better in stress-inducing cognitive tasks in laboratory settings (Cheng, 2001). Similarly, Bonanno and his colleagues (2004) examined ER flexibility in terms of emotional expression and found that college freshmen (at mean age of 18.05) who could flexibly enhance and suppress emotional expressions in a movie-watching task reported lower levels of stress at follow-up. Taken together, these studies suggest that greater ER flexibility in regulating positive and negative emotions is associated with better well-being and adjustment outcomes.

\section{Individual Differences in Vulnerabilityto Substance Use}

Past research has identified several emotion-relevant factors that influence adolescents' vulnerability to substance use (e.g., Bhushan, Blood, Shrier, 2013; Kaiser, Milich, Lynam, 
\&Charnigo, 2012; Willem, Bijttebier, Claes, \& Uytterhaegen, 2012; Zapolski, Cyders, \& Smith, 2009). The focus of the present study was on adolescents' mood states, temperamental reactivity, and urgency to act rashly in response to intense emotions (i.e., the emotion-based dimensional of impulsivity; Whiteside \& Lynam, 2001). These emotion-relevant factors may moderate the association between ER flexibility and adolescent substance use because intense emotional experiences (stemming from transient mood change or trait-linked temperament) and the tendency to react rashly in response to such experiences may require more ER resources and efforts.

Mood.Previous studies have documented that adolescent and adult users of common illicit substances, such as marijuana, ecstasy, LSD, and cocaine, generally reported increased feelings of elation and pleasure upon drug administration, although some users also reported unpleasant experiences of anxiety and panic (Johanson, Roehrs, Schuh, \& Warbasse, 1999; Metrik et al., 2011; Parrott \& Stuart, 1997). In a laboratory study, Kassel and his colleagues (2007) found that adolescent smokers (age 15 - 18) experienced reductions in negative mood and high-arousal positive mood after smoking a cigarette, suggesting that the nicotine content in a cigarette had some mood-altering effects on smokers. Weinstein and Mermelstein (2013) further suggested adolescent smokers who gradually increased their cigarette use over a 15-month period reported reduction in overall negative mood as smoking frequency increased.

When it comes to positive mood, Bhushan and his colleagues (2013) reported that depressed youth, aged $15-21$, had lower levels of positive mood prior to marijuana use. Lower levels of positive mood were also associated with heavy marijuana use in a normative sample of young-adult women (Lex, Griffin, Mello, \& Mendelson, 1989). In a study with college freshmen, Rankin and Maggs (2006) found that college-age adolescents drank more heavily and frequently 
during the weeks when their positive mood was higher, but planned to drink less the following week. One possible explanation is that after adolescents capitalized on their positive mood through frequent and heavy drinking, their motivation to enhance positive mood through drinking ceased.

Drawing from these studies, it is clear that certain substances have mood-altering effects and adolescents may use substances to regulate their undesirable emotional states by enhancing and maintaining positive mood or by reducing negative mood. It would be valuable to examine whether certain mood states would increase adolescents' tendency to regulate their emotions with substances, especially when they lack ER flexibility.

Temperament. Temperament pertains to enduring traits characterized by propensity to exhibit certain emotional reactions across different situations (Rothbart \& Bates, 1998). As such, different temperament dimensions may impact adolescents' susceptibility to use mood-altering substances (e.g., Measelle et al., 2006; Willem et al., 2012). Two dimensions of adolescent temperament that could be particularly relevant are positive emotionality and negative emotionality, both of which reflect the emotional reactivity of an individual. Positive emotionality refers to the tendency to experience intense positive emotions and to seek pleasure from stimulating and novel activities, whereas negative emotionality is characterized by the propensity to experience negative emotions related to anticipation of distress, exposure to suffering and disappointment, and goal-blocking (Evan \& Rothbart, 2007).

Previous studies have demonstrated that high levels of negative emotionality predicted more frequent use of alcohol concurrently (Colder \& Chassin, 1997) and longitudinally over five years (Shoal, Gudonis, Giancola, \& Tarter, 2008). Willem and colleagues (2012) further suggested that adolescents (aged 13 - 20) with higher levels of negative emotionality reported 
more alcohol-related problems (e.g., black-outs) partly because they used alcohol to cope with their emotional distress. With regard to illicit substance use, Shoal and Giancola (2003) reported that high levels of negative emotionality at the age of 15 to 17 predicted more frequent use of alcohol and illicit drugs at a three-year follow-up. Similarly, Measelle and his colleagues (2006) found that adolescent girls with high levels of negative emotionality at the age of 12 to 14 were at increased risk of an onset of clinical-level substance abuse over 4 subsequent years. Comparatively, little research has examined the link between positive emotionality and adolescent substance use, even though the commonly used substances, such as alcohol and marijuana, are known to have mood-enhancing effects (e.g., Crooke et al., 2013; Metrik et al., 2011). A recent study (Oliva et al., 2012) suggested that adolescent experimenters of tobacco, alcohol, and illicit drugs (defined as life-time use of substances without meeting diagnostic criteria of substance use disorder) scored higher on tendency to experience positive emotions derived from social interaction, compared to abstainers. Similarly, other studies with adolescents and young adults have shown that extraverted individuals who often experienced intense positive emotions were at increased risk of excessive drinking and substance use (Tomcikova, Geckova, van Dijk, \& Reijneveld, 2011; Walther, Morgenstern, \& Hanewinkel, 2012).

Together, these studies suggest that temperamentally reactive individuals may be more prone to using substances to regulate their intense emotional experiences. Although the above studies support the direct link between temperamental reactivity and risk of adolescent substance use, Wills and Dishion (2004) postulated that temperament might also moderate the link between self-control characteristics (e.g., emotional control) and substance use outcomes. In the present study,temperamental reactivity was examined as one of the moderators of the association between ER flexibilityand severity of illicit substance use among college-age adolescents. 
Urgency. Whiteside and Lynam (2001) defined urgency as the emotion-based dimension of the multi-faceted construct of impulsivity. According to Cyders and Smith (2007), there are two forms of urgency. Positive urgency refers to the tendency to act rashly while in a positive mood, whereas negative urgency refers to the tendency to engage in rash action when distressed. Past research has shown that positive urgency predicted heavy drinking for college students who drank to enhance positive mood (Cyders, Smith, Spillane et al., 2007) and higher levels of illicit substance use among college freshmen, controlling for individual differences in the other dimensions of impulsivity, such as sensation seeking and negative urgency (Zapolski et al., 2009). Similarly, negative urgency has been linked to more drinking problems for college students who drank to cope (Adams et al., 2012) and increased risk of substance abuse as evident by self-reported consumption of multiple illicit drugs (Kaiser et al., 2012; Settles et al., 2012). Given that emotion-based urgency is the tendency to act rashly in response to intense emotional states (Cyders\& Smith, 2007; Whiteside \& Lynam, 2001), greater ER flexibility may be especially important to those who are high in urgency so that they have more options to respond to their intense emotional states without resorting to substance use.

\section{The Present Study}

The present study was designed 1) to empirically test Bonanno and Burton (2013)'s model of ER flexibility, 2) to investigate the negative association between ER flexibility and various substance-use outcomes (i.e.,the level of substance use, substance-related problems, and the tendency to use substances in positive and negative situations) in late adolescence, and 3) to examine the moderating effects of other emotion-relevant factors (i.e., typical mood states, temperament reactivity and urgency)on the association between ER flexibility and the substanceuse outcomes. Variables pertaining to positive and negative emotions were tested in separate 
models because past research suggests that positive emotion regulation and negative emotion regulation represent two unique systems of emotion regulation processes (e.g., Bryant, 1989; Heiy \& Cheavens, 2014; Snyder, Heller, Lumian, \& McRae, 2013). Full conceptual models for negatively and positively valenced variables are shown in Figure 1 and Figure 2.

\section{Research Question 1: What are the Components of ER Flexibility?}

Hypothesis 1: Based on the conceptualization of Bonnano and Burton (2013), the latent structure of ER flexibility would consist of context sensitivity, repertoire, and responsiveness to feedback about ER.

\section{Research Question 2: How is ER Flexibility Related to Illicit Substance Use amongAdolescents?}

Hypothesis 2a: Greater ER flexibility to regulate negative emotions (i.e., greater sensitivity to emotion-eliciting cues in context-specific situations, a larger repertoire of ER strategies, and willingness to change strategies based on feedback about the efficacy of ER strategies) would be associated with lower levels of substance use (as indicated by number of illicit substances used and the frequency of usingsubstances), and fewer substance-related problems.

Hypothesis 2b: Greater ER flexibility to regulate negative emotions would be associated with a lower tendency to use substances in negative situations.

Hypothesis 2c: Greater ER flexibility to regulate positive emotions would be associated with lower levels of substance use.

Hypothesis 2d: Greater ER flexibility to regulate positive emotionswould be associated with a lower tendency to use substances in positive situations.

\section{Research Question 3: Is the Association between ER Flexibility and Severity of Adolescent}




\section{Substance Use Moderated by Other Emotion-Relevant Factors?}

Hypothesis 3a: Greater ER flexibility to regulate negative emotions would be associated with lower levels of substance use, fewer substance-related problems, and a lower tendency to use substances in negative situations among participants who report higher levels of daily negative mood.

Hypothesis 3b: Greater ER flexibility to regulate negative emotions would be associated with lower levels of substance use,fewer substance-related problems, and a lower tendency to use substances in negative situations among participants with higher levels of negative emotionality than those with lower levels of negative emotionality.

Hypothesis 3c: Greater ER flexibility to regulate negative emotions would be associated with lower levels of substance use, fewer substance-related problems, and a lower tendency to use substances in negative situations among individuals with higher levels of negative urgency than those with lower levels of negative urgency.

Hypothesis 3d: Greater ER flexibility to regulate positive emotions would be associated with lower levels of substance use and a lower tendency to use substances in positive situations among participants who report lower levels of daily positive mood.

Hypothesis 3e: Greater ER flexibility to regulate positive emotions would be associated with lower levels of substance use and a lower tendency to use substances in positive situations among participants with higher levels of positive emotionality than those with lower level of positive emotionality.

Hypothesis 3f: Greater ER flexibility to regulate positive emotions would be associated with lower levels of substance use and a lower tendency to use substances in positive situations among participants with higher levels of positive urgency than those with lower levels of positive 
urgency.

\section{Method}

\section{Participants}

The sample was638 college students. The sample size was determined based on power analysis for a covariance structure model using RMSEA. According to Preacher and Coffman (2006), a minimum of 368 participants would be sufficient to obtain .80 power for testing covariance structure models with at least 25 degrees of freedom at .05 significance level. Extra participants were recruited to account for missing data or biased responding.

Participants were recruited from a local community center that provides a drug-diversion program and from psychology courses at West Virginia University (WVU). In either case, only students, aged 18 to 20 years, with WVU affiliation were eligible for participation. Because the response rate was low at the community center, the majority of the samples $(n=630)$ were from WVU psychology courses. A total of 146 participants were removed from further analyses because they reported being younger than $18(n=1)$ or older than 20 years old $(n=29)$, omitted all questions in the entire study $(n=7)$,only completed less than $50 \%$ of the questionnaires ( $n=$ 80), provided the same scores for every items on a certain questionnaire (i.e., being a multivariate outliers; $n=29$ ).For the purpose of the study, only those who endorsed using alcohol, marijuana or other illicit substances in the past three month were included in the final sample. Therefore, another 64 non-users of illicit substances (7.69\% of full sample with complete data) were excluded from further analyses. Although non-users of illicit substances (e.g., defined as never using any substances, except tobacco) were allowed to participate, they would skip out of the questions regarding illicit substance use.Prevalences of lifetime use of illicit substances in the full valid sample $(N=492)$ and the final substance-using sample $(N=428)$ 
are shown in Table 1.

The final sample consisted of 428 substance-using adolescents ( $\mathrm{n}=4$ were communityrecruited and $n=424$ were university-recruited). There were 98 males and 330 females. The mean age of participants were $19.00(S D=0.74)$. The majority of the participants self-identified as Caucasian (88.3\%), with 3.7\% African American, 1.6\% Hispanic American, 2.8\% Asian American, 0.2\% Pacific Islander, 3\% reported as mixed races, and 0.2\% identified as “others." About half of the participants $(45.6 \%)$ were college sophomores at the time of the survey. Sixtyone participants $(14.3 \%)$ reported past or current diagnosis of a psychological disorder. About one-sixth(16.9\%) of the final sample reported history of addiction or substance abuse in the immediate family. Another $15.7 \%$ reported family SUD for grandparents and other relatives (e.g., cousin, uncle, aunt, great grandparents), and $2.6 \%$ of participants did not specify the family members. Demographic characteristics of the final sample are shown in Table 2.

\section{Procedure}

Advertisements of the study wereshown in the psychology courses by instructors and students could participate in the study online. University-recruited participants signed up for the study via an online subject recruitment system and completed the study online for course credit.For participants recruited from the local community center, they were told about the study on the last day of their drug-diversion program. Those who expressed interest were contacted through e-mail and were provided with the link to the study website to complete the study at the time of their convenience. Due to the low enrollment rate at the community center, the recruitment e-mails were sent to 30 age-eligible individuals at multiple time points during the Fall 2014 semester. However, only eight of them participated in the study. Both groups of participants were informed that the study was about illicitsubstance and college experiences. The 
university-recruited participants were granted extra credit within one week after their completion of the online survey. Participants recruited from the community center were redirected to a separate link at the end of their survey to make arrangement for picking up their $\$ 10$ subject payment at the local community center.

After indicating their consent, participants were directed to the Survey Monkey website to fill out a battery of questionnaires. They were assured of the confidentiality of their information and the right to withdraw from the study at any time without penalty. Then, they were asked to provide basic demographic information, report on past or current diagnosis of psychological disorders and family history of addiction or substance abuse, and complete additional questionnaires about their emotion-relevant dispositions, ER flexibility, self-reported mood, substance use, and depressive symptoms. At the end of the online study session, each participant was shown a list of referral sources in case anyone needs counseling. Then,the participants were directed to a web page with a note to thank them for their participation and inform them about the general hypothesis of the study.

\section{Materials}

Demographic and Background Information. The demographic questionnaire (See Appendix A) consisted of specific questions about age, date of birth, gender, race, year in college, history of psychological disorders, and family history of addiction or substance abuse disorder (including alcoholism), and subjective SES. Although there were no exclusion criteria based on mental health history and family background, this information is important to consider. Past research suggests that the prevalence of adolescent substance use and the risk of clinicallevel substance abuse disorder are higher among adolescents with psychological disorders and/or family history of addiction and substance abuse disorder (e.g., Battista, Pencer, McGonnell, 
Durdle, \& Stewart, 2013; Chan, Dennis, \& Funk, 2008; Yule, Wilens, Martelon, Simon, \& Biederman, 2013).

ER Flexibility: Context Sensitivity. The typical use of ER strategies was assessed using the Emotion Regulation Profile-revised (ERP-R; Neils, Quoidbach, Hansenne, \& Mikolajczak, 2011), a vignette-based questionnaire measuring individuals' tendency to regulate emotions in 16 different scenarios (see Appendix B). Six vignettes evaluated the regulation of positive emotions and ten vignettes measured coping with emotional distress. Each scenario was followed by eight possible reactions and participants were allowed to select as many reactions as they wanted as long as their responses accurately reflected their typical behaviors in the described situations. Because each scenario in ERP-R was designed to evoke a specific emotion, the context sensitivity component of ER flexibility was indicated by participants' accuracy in identifying the discrete emotions evoked by each scenario. Specifically, the key emotional words (italicized in Appendix B) were left blank in the description of each scenario. The participants were required to fill in the blank with appropriate emotional words/phrases before they were presented with the full version of the questionnaire. Using Shaver, Schwartz, Kirson, and O'Connor (1987)'s hierarchical organization of emotional words as a guideline, participants scored 1 point if they generated words/phrasesthat were consonant with the discrete emotions associated with each scenario.One negative vignette (i.e., scenario 14) was excluded from further analyses because of the ambiguity in the scenario and the participants' open-ended responses indicated some participants viewed it positively and evoking positive emotion. As a result, only 15 scenarios were used in the final analyses. The context sensitivity score for positive scenarios ranged from 0 to 6 , whereas that for negative scenarios ranged from 0 to 9.

The context sensitivity score for each ERP-R scenario was coded by two independent 
coders. To establish inter-coder reliability, one independent coder coded all 15 scenarios for the final sample $(n=428)$, and another coder coded allthese scenarios for $25 \%(n=110)$ of participants randomly selected from the final sample. The two coders were mostly in agreement regarding the context sensitivity scores (percentage of agreement ranged from 76\% - 100\%) However, kappa values ranged considerably from -.03 to 1.00. The kappa values were greater than .50 (indicative of at least moderate agreement; Landis \& Koch, 1977) for nine out of the fifteen scenarios. Onereason for the low kappa values despite relative high agreement is that the computation of kappa takes into account rates of chance. Thus, because there were vignettes when almost every answer was correct (e.g., 98.23\% of accuracy for scenario 2), even a few cases of disagreement would severely penalize and decrease kappa (Viera \& Garrett, 2005).

ER Flexibility: Repertoire. The repertoire component of ER flexibility were also assessed with ERP-R (Neils et al., 2011), indicated by counting how many different types of strategies participants would use to manage their positive and negative emotions across the corresponding scenarios. There were eight different types of ER strategies in each scenario. Regarding positive scenarios, four regulatory strategies were considered adaptive (i.e., behavioral display of positive emotions, mindfully savoring the moment, capitalization, positive mental time travel) and four strategies were considered maladaptive (i.e., inhibition of emotion expression, fault finding, inattention, and external attribution/nostalgia). For the negative scenarios, the four adaptive strategies were situation modification, attention reorientation, positive reappraisal, and emotion expression, whereas the four maladaptive strategies were learned helplessness, substance abuse, rumination, and acting out. The substance abuse strategy wasexcluded from further analyses to reduce shared variance with the substance-use outcomes because that strategy pertained to drinking alcohol or using substances to regulate negative 
emotions. Participants were credited 1 point every time a specific strategy was selected in a scenario. Two repertoire scores were computed to assess ER repertoire for positive (ranged from 0 - 8) and negative emotions (ranged from 0 - 7). Therepertoire scores were averaged across the scenarios of the corresponding valence of emotions. Both positive (Cronbach's $\alpha=.84$ ) and negative scenarios (Cronbach's $\alpha=.77$ ) in ERP-R had good internal consistency in the present study. Following the procedure of Aldao and Nolen-Hoeksema (2013) to assess multiple ER strategies, participants also indicated the extent to which they would use certain strategies in the scenarios on a 4-point scale $(0=$ Not at all, $3=\mathrm{A}$ lot $)$ and reported on their perceived effectiveness of the strategies on a 6-point scale $(0=$ Extremely ineffective, $5=$ Extremely effective).

\section{ER Flexibility: Responsiveness to Feedback about ER. The responsiveness to} feedback component of ER flexibility was assessed with the 5-item evaluative coping subscale from the Coping Flexibility Scale (CFS; Kato, 2012). Five additional items were created to capture ER flexibility to regulate positive emotions (see Appendix C). These items pertained to participants' awareness of the efficacy of their ER strategies and their willingness to change strategies accordingly (e.g., "After coping with stress, I think about how well my ways of coping with stress worked or did not work," "If I feel that I have failed to enhance my positive mood, I change the way of mood enhancement."). The participants rated the extent to which each item applies to them on a 5 -point scale $(0=$ Not applicable, $4=$ Extremely applicable $)$. Due to participants' misinterpretation, two reversed-coded items (i.e., item 1 and 3) from the CFS evaluative coping subscale and the two corresponding items (i.e., item 6 and 8 ) for positive emotion regulation were excluded from further analyses. The Cronbach's alpha coefficients were .65 for the 3 -item evaluative coping subscale and .67 for the 3 -item positive emotion regulation 
subscale in the present study.

Substance Use. Patterns of illicit substance use were assessed with Alcohol, Smoking, and Substance Involvement Screening Test (ASSIST; World Health Organization, 2002). The ASSIST (see Appendix D) consisted of eight questions that provided information regarding use of a wide range of substances, such as stimulants, hallucinogens, and other drugs. Because the present study mainly focused on illicit substance use, tobacco use was excluded from the analyses. Participants responded to yes-or-no question about their lifetime use of different illicit substances. The total number of substances they reported using in their lifetime was aggregated to index number of illicit substance. Participants also reported on their frequency of using different substances in the past three month on a 5-point scale $(0=$ Never, $4=$ Daily or Almost Daily).Frequency of substance use wasindicated by aggregating their frequency scores for all types of substances. For example, if the participants scored 3 for alcohol use (i.e., weekly use) and 4 for marijuana use (i.e., daily or almost daily use), their total score of frequency of substance use would be 7.Participants answered five additional questions in ASSIST about different problems they had experienced as a result of their substance use. Two of the questions on negative consequences and functional impairment related to substance use (question 4 and 5) were assessed on a 5 -point scale ( $0=$ Never, $4=$ Daily or Almost Daily). The other three questions aboutlevels of dependency and injection use (question 6-8) were assessed on a 3point scale $(0=$ No, Never; $2=$ Yes, in the past 3 months). Problems scores were computed for each types of substances by aggregating the participants' responses to the five questions pertaining to their problems with substance use. Substance-related problems were computed byaggregating the participants' problem scores across different substances. For instance, if the participants scored a total of 10 for their marijuana use and a total of 8 for their cocaine use, their 
total score of substance-related problems would be 18 .

Substance-Taking Situations. The 8-item version of Inventory of Drug-Taking Situations (IDTS; Annis \& Martin, 1985) was used to assess participants' tendency of using substances in different situations. This brief IDTS-8 was created by the Center for Addiction and Mental Health $(\mathrm{CAMH})$ as part of an outpatient intervention for treatment-seeking substance users (CAMH, 2009). The brief IDTS-8 assessed tendency of using substances in eight different situations: 1) unpleasant emotions (e.g., anger, boredom, or sadness), 2) physical discomfort (e.g., physical pain), 3) pleasant emotions (e.g., happiness or joy), 4) testing personal control (e.g., proving self-control over substances), 5) urges and temptations(e.g., being reminded of substance use), 6) conflict with others (e.g., not getting alone with someone), 7) social pressures (e.g., giving in to peer pressure), and 8) pleasant times with others (e.g., enjoy a party). Participants indicated how often they use their first three substances of choice in each of the eight different types of situations on a visual analog scale (ranged from $0 \%$ to $100 \%$ ) anchored Never on one end and Almost always on the opposite end. Higher scores indicated higher tendency to use substances in a given situation. Based on past literature (Hartwell et al., 2012), substance use in positive situations (Cronbach's $\alpha=.77$ ) was computed by aggregating scores from situations involving pleasant emotions and pleasant time with others. Substance use in negative situations(Cronbach's $\alpha=.79$ ) was computed by aggregating scores from situations involving unpleasant emotions and physical discomfort, and conflict with others. Both scores were then averaged across participants' top-three chosen substances. Overall, the top-three substances of choice in the sample were alcohol $(n=316)$, marijuana $(n=177)$, and amphetamine $(n=25)$. Most participants listed one or more of these three substances as their top-three substances of choice.A copy of IDTS-8 is shown in Appendix E. 
Typical Mood States. Participants' typical mood states were assessed with 24 items pertaining to different feeling states. The list of items was generated based on past research on substance-induced mood states (e.g., Green, Kanvanagh, \& Young, 2003; Parrott \& Stuart, 1997) and polls from substance users at a local community center to take into account the subjective mood states that might result from self-administration of illicit substances in humans. Using a 5point scale $(0=$ definitely do not feel, $4=$ definitely feel $)$, participants indicated the extent to which they feel each mood states over a typical week. Positively valenced feeling states (e.g., excited, happy) were aggregated to index positive mood, whereas negatively valenced items (e.g., panic, depressed) were aggregated to index negative mood. Both scales had good internal consistency in the present study (Cronbach's $\alpha=.87$ and .85 for positive and negative mood, respectively). See Appendix F for a copy of the mood survey.

Temperament. The Adult Temperament Questionnaire (ATQ; Rothabart, Ahadi, \& Evans, 2000) were used to assess the temperamental reactivity of the participants (see Appendix G). To keep the whole survey at a reasonable length, selectedATQ scales were included, pertaining to the reactivity dimension of positive emotionality and negative emotionality. Example items were "Sometimes, minor events cause me to feel intense happiness" for the positive emotionality scale, and "I often feel sad" for the negative emotionality scale. Participants rated each item on a 7-point Likert scale $(1=$ extremely untrue of you and $7=$ extremely true of you). The positive emotionality score were calculated by averaging participant's rating of 17 items pertaining to their sociability (Cronbach's $\alpha=.46$ ), high intensity pleasure (Cronbach's $\alpha=$ .42 ), and positive affect (Cronbach's $\alpha=.59$ ). The negative emotionality score were calculated by averaging 20 items pertaining to their fear (Cronbach's $\alpha=.52$ ), sadness (Cronbach's $\alpha=$ .54 ), and frustration (Cronbach's $\alpha=.51$ ). Although mostly being used for assessing 
temperament in grown adults, the ATQ has been validated with college sample (Evan \& Rothbart, 2007). Both positive emotionality (Cronbach's $\alpha=.68$ ) and negative emotionality (Cronbach's $\alpha=.71$ ) scales hadacceptable reliability in the present study, compared to some past literature (e.g., Gomez, Kyriakides, \& Devlin, 2014).

Urgency. The UPPS-P Impulsive Behavior Scale (Lynam, Smith, Cyders, Fischer, \& Whiteside, 2007) assessed different facets of impulsivity. Participants indicated the extent to which they agree with each statement from 1 (agree strongly) to 4 (disagree strongly). The present study focused on positive urgency (e.g., "When I am very happy, I can’t seem to stop myself from doing things that can have bad consequences") and negative urgency (e.g., "I often make matters worse because I act without thinking when I am upset"). Both the 14-item positive urgency and the 12-item negative urgency scales had good reliability in the present study (Cronbach's $\alpha=.96$ and .87, respectively). The copy of UPPS-P is shown in Appendix H.

Depressive Symptoms. The 20-item Center for Epidemiologic Studies Depression Scale (CES-D; Radloff, 1977) was used to access participants' past-week depressive symptoms as a potential covariate. Participants indicated how often they felt in a certain way during the past week on a 4 -point scale $(0=$ rarely or none of the time/less than one day; $3=$ most or all of the time/five to seven days). Example items included "I had trouble keeping my mind on what I was doing," and "I felt hopeful about the future" (reverse-coded). The Cronbach's alpha coefficient of CES-D was .92 in the present study. A copy of CES-D is shown in Appendix I.

\section{Results}

After discarding participants who were out of the age range and those who omitted all questions, participants who provided invalid responses (i.e., having more than $50 \%$ of omission rate or patterning their responses; $n=109)$ were compared to the remaining sample $(n=492)$ on 
various demographic characteristics. Results of a two-tailed chi-square test suggested that participants who provided invalid responses significantly differed from the remaining sample in terms of year in college, $\chi^{2}(3, N=601)=17.19, p=.001$. Specifically, those who provided invalid responses were more likely to be freshmen. Those who provided invalid responses did not differ from the retained sample in history of substance use disorder (SUD) in the any family members. However, the rate of SUD in the immediate family (i.e., including parents and siblings) was marginally higher in the retained sample, $\chi^{2}(1, N=601)=4.00, p=.05$. No other socio-demographic differences were found.

For the purpose of the study, another 64 non-users of substances were removed from further analyses. Independent sample t-tests were conducted to examine any individual differences between users and non-users. The results revealed no significant differences by user status on age, subjective social economic status (subjective SES), depressive symptoms, and the other main variables in the present study, except for two emotion-relevant predictors. In particular, illicit substance users $(M=5.53, S D=.76)$ scored significantly higher on their repertoire for regulating negative emotions, compared to non-users $(M=5.27, S D=.90, t(490)=$ $-2.55, p=.01)$. Users $(M=2.36, S D=.66)$ also reported significantly higher levels of negative urgency, compared to non-users $(M=2.16, S D=.73, t(490)=-2.28, p=.02)$. In addition, a twotailed Chi-square test indicated that users reported higher rate of history of SUD in their immediate family, compared to non-users, $\chi^{2}(1, N=492)=4.77, p=.03$. No other significant differences were found.

Variables of interest were then screened for missing data, outliers, and violations of normality. There were minimal missing data $(<2 \%)$ in the final sample after excluding those with extensive amount of missingness. Due to the need for complete case analyses, group mean 
imputation was used to replace missing values on the coping flexibility scales and the corresponding positive emotion regulation scales. Continuous predictors and outcomes were screened for unvariate outliers (indicated by absolute z-score of 3 or higher on a variable; Howell, 1998). Minor outliers (<2\% of the final sample) were found on the predictor variables and substance use outcomes. Further investigation suggested that none of the participants with these outlying scores had problematic scores on other variables. Therefore, these outliers were retained in analyses because they might represent individual differences in variables that were expected to vary widely. Descriptive statistics of the main variables were examined for violation of normality. Consistent with past literature (e.g., Shoal \& Giancola, 2003; Simons et al., 2005), all substance use outcomes were positively skewed and kurtotic, except substance use in positive situations. In addition, participants were generally accurate in identifying the discrete emotions from the corresponding ERP-R scenarios, resulting in negatively skewed context sensitivity scores for both positive and negative emotions. Transformations of these variables did not improve the violation of normality issue. Therefore, the raw scores of these variables were retained for further analyses. Means, standard deviations and ranges of main variables are shown in Table 3.

\section{Preliminary Analyses}

Preliminary analyses were conducted to examine the associations among the outcomes variables (i.e., number of illicit substances, frequency of substance use, substance-related problems, substance use in positive situations, and substance use in negative situations) and various demographic characteristics. Bivariate correlations among these variables are shown in Table 4. The results revealed that participants' self-reported depressive symptoms were positively related to substance-related problems $(r(426)=.14, p=.003)$, and substance use in 
negative situations $(r(426)=.14, p=.01)$. Independent sample t-tests revealed gender differences in number of illicit substance used $(t(426)=2.40, p=.02)$, frequency of use $(t(426)=$ $2.50, p=.01)$, and substance-related problems $(t(426)=3.40, p=.001)$. These results suggested that female participants used fewer substances less frequently and had fewer substance-related problems, compared to male participants. Differences by history of psychological disorders were also found for number of illicit substance used $(t(426)=-4.45, p<.001)$, frequency of use $(t(426)$ $=-2.37, p=.02)$, and substance-related problems $(t(426)=-3.22, p=.001)$. In particular, individuals with current or past diagnosis of psychological disorders reported using more substance more frequently and had more substance-related problems. Lastly, individuals with a family history of substance use disorder in any family members reported using more substances $(t(426)=-2.79, p=.01)$ and had a higher tendency to use substance in positive situations $(t(426)$ $=-2.09 p=.04)$, compared to individuals without a family history of substance use disorder.

Based on the preliminary results, participants' gender and depressive symptom were included as covariates in the proposed analyses. Depressive symptom was chosen over diagnosis of psychological disorders as a covariate. Out of the 61 participants who reported any diagnosis of psychological disorders, 37 of them indicated they were diagnosed with depression or other mood disorders (e.g., bipolar disorder). Others reported diagnoses included various anxiety disorder, attention-deficit hyperactivity disorder, panic disorder, post-traumatic stress disorder, and any combination thereof. In the present study, self-reported depressive symptoms and diagnosis of psychological disorders were correlated $(r(426)=.21, p<.001)$. Importantly, depressive symptom was measured as a continuous variable, which allowed for more variability in the covariate.

The above preliminary analyses were followed by examination of the intercorrelations 
among the main study variables. Correlations among predictors, outcomes, and moderators are reported in Table 5, 6, and 7.

\section{Research Question 1: What are the Components of ER Flexibility?}

Structural equation modeling (SEM) was performed to test the measurement model regarding the conceptualization of ER flexibility proposed by Bonnano and Burton (2013). The SEM analyses were conducted using the AMOS V22.0.0 software. The use of SEM allowed for concurrent examination of all hypothesized associations within the same analysis and inclusion of latent variables. The latent variable of ER flexibility (computed for positive emotions and negative emotions separately) consisted of three indicators (i.e., context sensitivity, repertoire, and responsiveness to feedback about ER). Higher scores in this latent variable were indicative of higher levels of ER flexibility. The measurement model was created (see Figure 3) to assess the latent variables of ER flexibility measured by the manifest variables of context sensitivity, repertoire, and responsiveness to feedback about ER. Beta ( $\beta)$, critical ratio (C.R.) and p-value of each path were reported. Several fit indices were utilized to assess model fit, including omnibus chi square test $(\chi 2 / \mathrm{df} \leq 3)$, comparative fit index(CFI $\geq .95)$, and root-mean-square error of approximation(RMSEA $\leq .05 ; \mathrm{Hu} \&$ Bentler, 1999). The overall model fit for the measurement model indicated a poor fit to the data $(\chi 2(9)=107.86, \chi 2 / \mathrm{df}=11.98, p<.001, \mathrm{CFI}=.84$, RMSEA = .16). The covariance between ER flexibility for positive and negative emotions was significant $(\beta=.61$, C.R. $=7.48, p<.001)$. The indicators of ER flexibility did not load significantly onto the assigned latent variables.

In summary, the full measurement model did not provide support for the hypothesized latent variable structure. Examination of bivariate correlations among the ER flexibility variables suggested that indicators of ER flexibility within each valence of emotions were mostly 
unrelated (see Table 7). Specifically, indicators for flexibility with negative ER were not related ( $r$ ranged from -.04 to .07) and the correlations among the indictors for positive ER ranged from $r=-.003$, to $r=-.10$. Only one association among the indictors for positive ER was statistically significant $(r=-.10$ for the association between context sensitivity and repertoire for positive ER). Therefore, these indicators of ER flexibility were modeled as separated indices within the structural models.

\section{Research Question 2: How is ER Flexibility Related to Illicit Substance Use among}

\section{Adolescents?}

The negative associations between ER flexibility and illicit substance use among adolescents were examined using SEM. The three indices of ER flexibility were modeled as separate variables and level of substance use was modeled as a latent variable with two indices (number of illicit substances and frequency of use). To achieve model identification, the loading for frequency of use was set as a constant in all the following models. Because the substance use outcomes were highly corrected, their residuals were allowed to covary in all models. Based on the preliminary analyses, participants' gender and depressive symptom were included as covariates in the negative ER models, with gender predicting levels of use and substance-related problems, and depressive symptom predicting substance-related problems and tendency to use substances in negative situations. For positive ER model, only gender was modeled as a covariate because depressive symptom was not associated with levels of substance use and tendency to use substances in positive situations. Modification indices were also examined.The predictor variables and the covariates would be allowed to covary to obtain the best model fit, provided that the modifications made theoretically sense and were conceptually sound (MacCallum, Roznowski, \& Necowitz, 1992). 
Hypothesis 2a and b: The first structural model was created to assess how different indices of ER flexibility for regulating negative emotions related to levels of substance use, substance-related problems, and tendency to use substances in negative situations. Two of the fit indices suggested that the initial model fit the data well, $\chi^{2}(18)=51.81, \chi 2 / \mathrm{df}=2.88, p<.001$, $\mathrm{CFI}=.95, \mathrm{RMSEA}=.07$. No modification was needed In contrast to the hypotheses, context sensitivity for negative emotions was not associated with levels of substance use $(\beta=.04$, C.R. $=$ $0.77, p=.44)$, substance-related problems $(\beta=.04$, C.R. $=0.88, p=.38)$, and tendency to use substances in negative situations $(\beta=-.01, \mathrm{C} . \mathrm{R} .=-0.08, p=.92)$. For repertoire for regulating negative emotions, although it was unrelated to levels of substance use $(\beta=.06$, C.R. $=1.23, p=$ $.22)$ and a tendency to use substances in negative situations $(\beta=.05$, C.R. $=.97, p=.33)$, a larger repertoire of negative ER was significantly associated with more substance-related problems $(\beta=$ .10$, C.R. $=2.02, p=.04)$, which was in the opposite expected direction. Responsiveness to feedback about negative emotion regulation were also unrelated to levels of substance use $(\beta=-$ .08 , C.R. $=-1.51, p=.13)$, substance-related problems $(\beta=.01$, C.R. $=0.27, p=.79)$, and a tendency to use substances in negative situations $(\beta=-.01$, C.R. $=-0.23, p=.82)$. The full structural model for negative ER flexibility is shown in Figure 4.

Hypothesis 2c and d: A similar structural model was created to test how different indices of ER flexibility for regulating positive emotions related to levels of substance use and tendency to use substances in positive situations. The model fit of the initial model was good, $\chi^{2}$ $(12)=25.40, \chi 2 / \mathrm{df}=2.12, p=.01, \mathrm{CFI}=.97, \mathrm{RMSEA}=.05$. In contrast to the hypotheses, context sensitivity for positive emotions was not associated with levels of substance use $(\beta=.01$, C.R. $=0.17, p=.86)$ and tendency to use substances in positive situations $(\beta=.04$, C.R. $=0.83$, $p=.41)$. Regarding repertoire for regulating positive emotions, a larger repertoire of positive ER 
strategies was associated with higher levels of substance use $(\beta=.11$, C.R. $=2.11, p=.04)$, which was in the unexpected opposition direction. However, consistent with hypothesis, a larger ER repertoire of positive emotions was significantly associated with a lower tendency to use substances in positive situations $(\beta=-.11$, C.R. $=-2.22, p=.03)$. Responsiveness to feedback about positive emotion regulation were also unrelated to levels of substance use $(\beta=-.06, \mathrm{C} . \mathrm{R} .=$ $-1.10, p=.27)$ and tendency to use substances in positive situations $(\beta=.07$, C.R. $=1.43, p=$ .15). The full structural model for positive ER flexibility is shown in Figure 5.

\section{Research Question 3: Is the Association between ER Flexibility and Severity of Adolescent Substance Use Moderated by Other Emotion-Relevant Factors?}

Only three moderations (out of 54)were significant across both models for negative and positive ER flexibility. Therefore, the findings and discussion of the moderation analyses are presented in Appendix J. Instead, two structural models (for negative and positive emotions, respectively) were created to examine the main effects of the three indices of ER flexibility additively when the three moderators that were known to predict the substance-use outcomes were accounted for. Compared to the moderation models, these new models tested fewer paths and provided information about the main effects of the indices of ER flexibility and the moderators additively. Because temperamental reactivity is characterized by intense experience of certain emotions (Rothbart \& Bates, 1998), negative emotionality and positive emotionality were allowed to covary with mood state of the same valence in both of the models.

Hypothesis 3a, b, and c: The initial model provided a poor fit to the data, $\chi 2(38)=$ $372.27, \chi 2 / \mathrm{df}=9.80, p<.001, \mathrm{CFI}=.69, \mathrm{RMSEA}=.14$. Several modifications were made based on the modification indices and past literature. Specifically, depression symptom was allowed to covary with negative mood, negative emotionality, negative urgency because past literature has 
shown that individuals with higher levels of these emotion-relevant characteristics also reported higher levels of depressive symptoms (e.g., Boschloo et al., 2013;Gonzalez, Reynolds, \& Skewes, 2011: Heiy \& Cheavens, 2014). In addition, the covariance between gender and negative emotionality was added to account for the gender difference in negative emotionality (e.g., Fujita, Diener, \& Sandvik, 1991). According to more lenient cutoffs for CFI (.90 or higher), and RMSEA (.08 or lower; Byrne, 2010), two of the fit indices met the threshold for adequate fit in the modified model (see Figure 6), $\chi^{2}(34)=116.06, \chi 2 / \mathrm{df}=3.41, p<.001, \mathrm{CFI}=.92$, RMSEA $=.075$. In this model, the main effect of negative ER repertoire became non-significant $(\beta=.06$, C.R. $=1.23, p=.22)$. Although negative mood was unrelated to levels of substance use $(\beta=.03$, C.R. $=0.60, p=.55)$ and substance-related problems $(\beta=.04$, C.R. $=0.36, p=.72)$, it was significantly related to higher tendency to use substances in negative situations $(\beta=.19$, C.R. $=3.19, p=.001)$. Furthermore, higher levels of negative emotionality were significantly associated with higher tendency to use substances in negative situations $(\beta=.12$, C.R. $=2.22, p$ $=.03)$, but were unrelated to levels of substance use $(\beta=.02$, C.R. $=.41, p=.68)$ and substancerelated problems $(\beta=.04$, C.R. $=.67, p=.50)$. For negative urgency, higher levels of this variable was significantly associated with higher level of substance use $(\beta=.10$, C.R. $=2.01, p=$ $.04)$ more substance-related problems $(\beta=.21$, C.R. $=4.36, p<.001)$ and higher tendency of using substances in negative situations $(\beta=.15$, C.R. $=3.18, p=.001)$.

Hypothesis 3d, e, and f: The initial model with positively valenced predictors did not provide a good fit to the data, $\chi 2(29)=113.21, \chi 2 / \mathrm{df}=3.90, p<.001, \mathrm{CFI}=.87, \mathrm{RMSEA}=.08$. According to the modification index, responsiveness to feedback about positive ER was allowed to covary with positive mood to improve the model fit. This modification made theoretical sense because Bonnano and Burton (2013) conceptualized responsiveness to feedback as an ability, 
with higher levels on this variables relating to better adjustment (e.g., higher levels of positive mood). The modified model (see Figure 7 ) adequately fit the data, $\chi 2(28)=80.62, \chi 2 / \mathrm{df}=2.88$, $p<.001, \mathrm{CFI}=.92, \mathrm{RMSEA}=.07$. In this model, positive ER repertoire became marginally associated with levels of use $(\beta=.10$, C.R. $=1.94, p=.05)$, but the association between positive ER repertoire and tendency to use substances in positive situations remained significant $(\beta=$ .11 C.R. $=-2.30, p=.02$ ). Furthermore, positive mood was unrelated to levels of substance use $(\beta=.03$, C.R. $=0.45, p=.65)$ and tendency to use substances in positive situations $(\beta=-.07$, C.R. $=-1.33, p=.19)$.On the other hand, higher levels of positive emotionality was significantly associated with higher levels of substance use $(\beta=.14$, C.R. $=2.69, p=.01)$ and a higher tendency of using substances in positive situations $(\beta=.19$, C.R. $=3.84, p=.001)$. Higher levels of positive urgency was also significantly associated with higher levels of substance use $(\beta=.14$, C.R. $=2.91, p=.004)$, but was unrelated to tendency of using substances in positive situations $(\beta$ $=.08, \mathrm{C} . \mathrm{R} .=1.60, p=.11)$.

\section{Exploratory Analyses}

In contrast to the hypotheses, a larger repertoire for regulating negative and positive emotions was generally associated with more severe illicit substance use. As expected, however, a larger repertoire for regulating positive emotions was associated with lower tendency to use substances in positive situations. Thus, exploratory analyses were performed to further investigate the association between ER repertoire and illicit substance use among adolescents. In particular, the participants' repertoires of adaptive and maladaptive strategies were examined separately in relation to their patterns of substance use, controlling for participants' gender and depressive symptom. Separate models were tested for positive and negative emotions.

\section{Adaptive and Maladaptive ER Repertoire for Negative Emotions}


The structural model of adaptive and maladaptive repertoire for regulating negative emotions (see Figure 8) fit the data well, $\chi 2(11)=17.40, \chi 2 / \mathrm{df}=1.58, p=.10, \mathrm{CFI}=.99$, RMSEA $=.04$. The results suggested that participants' repertoire of adaptive regulatory strategies for negative emotions was unrelated to levels of substance use $(\beta=-.04$, C.R. $=-0.76$, $p=.45)$, substance-related problems $(\beta=.03$, C.R. $=0.63, p=.53)$, and tendency to use substances in negative situations $(\beta=-.07, \mathrm{C} . \mathrm{R} .=-1.27, p=.21)$. One the other hand, a larger repertoire of maladaptive regulatory strategies for negative emotions was marginallyrelated to higher levels of substance use $(\beta=.10$, C.R. $=1.90, p=.058)$. Furthermore, a larger repertoire of maladaptive strategies for negative ER was unrelated to substance-related problems $(\beta=.08$, C.R. $=1.52, p=.13$ ), but was significantly associated with higher tendency to use substances in negative situations $(\beta=.11, \mathrm{C} . \mathrm{R} .=2.00, p=.046)$.

\section{Adaptive and Maladaptive ER Repertoire for Positive Emotions}

For adaptive and maladaptive repertoire of positive emotion regulation (see Figure 9), two of the fit indices suggested good model fit, $\chi^{2}(7)=18.21, \chi 2 / \mathrm{df}=2.60, p=.01, \mathrm{CFI}=.98$, $\mathrm{RMSEA}=.06$. A larger repertoire of adaptive regulatory strategies for positive emotions was marginally associated with higher levels of substance use $(\beta=.10$, C.R. $=1.90, p=.057)$, and higher tendency to use substances in positive situations $(\beta=.13$, C.R. $=2.81, p=.01)$. Interestingly, a larger repertoire of maladaptive regulatory strategies for positive emotions was significantly associated lower tendency to use substance in positive situations $(\beta=-.16$, C.R. $=$ 3.46, $p<.001)$, but was unrelated to levels of substance use $(\beta=.08$, C.R. $=1.51, p=.13)$. Other

\section{Indices of ER Flexibility}

Based on the procedure of Aldao and Nolen-Hoeksema $(2012,2013)$, two additional indices of ER flexibility were created: 1) variability of using different strategies across situations, 
and 2) averaged effectiveness of ER strategies in one's repertoire. The former index was computed by calculating the standard deviation of the extent to which the participants' use different regulatory strategies across the ERP-R vignettes. The latter was created by averaging their self-reported effectiveness of the strategies they would use in each vignette. Structural models were created with both indices as the predictors of the substance use outcomes, controlling for participants' gender and depressive symptoms. Negatively and positively valenced variables were run in separate models.

New Model for Negative ER Flexibility

Two of the fit indices suggested that the model with new indices of negative ER flexibility (see Figure 10) provided good fit to the data, $\chi^{2}(10)=25.06, \chi^{2} / \mathrm{df}=2.50, p=.01$, $\mathrm{CFI}=.98, \mathrm{RMSEA}=.06$. The results revealed that variability in the extent of using negative ER strategies was not significantly associated with levels of substance use $(\beta=-.09$, C.R. $=-1.58, p$ $=.11)$, substance-related problems $(\beta=-.01$, C.R. $=-0.19, p=.85)$, and tendency to use substances in negative situations $(\beta=-.04$, C.R. $=-0.76, p=.45)$. On the other hand, there was a non-significant trend that higher levels of effectiveness of negative emotion regulation was associated with lower tendency to use substances in negative situations $(\beta=-.09$, C.R. $=-1.78, p$ $=.075)$, but was unrelated to levels of substance use $(\beta=.02, \mathrm{C} . \mathrm{R} .=0.35, p=.72)$, or substancerelated problems $(\beta=-.03$, C.R. $=-0.56 p=.58)$. Overall, these results indicated that the effectiveness of negative ER strategies might influence individuals' tendency to use substances in negative situations. Variability of using negative ER strategies across scenarios was not associated with illicit substance use in the current sample.

New Model for Positive ER Flexibility 
For the model with new indices of positive ER flexibility (see Figure 11), two of the fit indices suggested adequate fit to the data, $\chi 2(6)=20.07, \chi 2 / \mathrm{df}=3.35, p=.003, \mathrm{CFI}=.98$, RMSEA $=.07$ according to more lenient cutoffs for CFI (.90 or higher), and RMSEA (.08 or lower; Byrne, 2010). The results indicated that more variability in the extent of using positive ER strategies was associated with higher tendency to use substances in positive situations $(\beta=.16$, C.R. $=2.97, p=.003)$, but was unrelated to levels of substance use $(\beta=-.09$, C.R. $=-1.46, p$ $=.14$ ). On the other hand, effectiveness of positive emotion regulation was unrelated to levels of substance use $(\beta=.05$, C.R. $=0.85, p=.39)$ and tendency to use substances in positive situations $(\beta=-.01$, C.R. $=-0.09, p=.93)$. In contrast to the new model for negative ER flexibility, the model for positive ER flexibility indicated that variability in the extent of using positive ER strategies was associated with tendency to use substances in positive situations, but in the opposite direction that was predicted. The effectiveness of the positive ER strategies, on the other hand, was unrelated to illicit substance use.

\section{Discussion}

The goals of the present study were three-fold: to test the three-component measurement model of ER flexibility proposed by Bonanno and Burton (2013), to test whether ER flexibility is negatively associated with illicit substance use, and to identify other emotion-relevant variables that moderate these associations in a sample of 18-20-year-old college-age adolescents. Previous studies tended to report mixed results regarding whether a specific ER strategy or a group of similar strategies would be uniformly related to more severe substance use among adolescents (e.g., Boujut et al., 2012; Dashora et al., 2011; Hamdan-Mansour at al., 2007; Nyamathi et al., 2010). The present study contributed to the current literature by applying the perspective of ER flexibility to research on adolescent substance use. Although the overall results provided some 
support that aspects of ER flexibility related to levels of illicit substance use, substance-related problems and substance use in emotion-laden situations, some of the associations were in the unexpected directions. Also, there was evidence that the link between ER flexibility and illicit substance use might be more pronounced among adolescents with certain emotion-relevant characteristics (discussed in Appendix J). Overall, this study enhances current understanding of ER flexibility and illicit substance use among college-age adolescents.

\section{Testing of the Measurement Model}

Contrary to our hypothesis, the overall measurement model provided a poor fit to the data. In addition, the three proposed indices of ER flexibility did not significantly load onto their assigned latent variables, suggesting that the assessments of context sensitivity, repertoire, and responsiveness to feedback about ER in the present study did not capture the underlying latent structure of ER flexibility. However, these results do not necessarily refute Bonanno and Burton (2013)'s model of ER flexibility. As Bonanno and Burton (2013) pointed out in the discussion of their conceptual model, there may be intra-individual variability in ones' ability to recognize situational demands, to use a diverse ER repertoire, and to respond to feedback about regulatory efficacy and make adjustments accordingly. For example, it is plausible that some individuals may be good at evaluating emotion-laden situations, but do not have a diverse repertoire of strategies to regulate their emotions and to address the changes in situational demands. Given that there may be intra-individual variability across the three components of ER flexibility, it is plausible that the components may not be correlated. In addition, Bonnano and Burton (2013) also conceptualized the three components as unfolding sequentially during the course of emotion regulation. This assumption about the temporal relation among the components may not be fullycaptured by the cross-sectional design of the present study. In particular, responsiveness to 
feedback was assessed with a separate questionnaire as the other two components. The questionnaire on responsiveness to feedback only assessed general, but not context-specific, tendency to change strategies after certain regulatory attempt fails. On the other hand, context sensitivity and repertoire were both assessed with vignette-based questionnaire that pertained to ER in specific contexts. Real-time assessment of ER in response to emotion-eliciting situations in a laboratory may better capture the temporal relations among context sensitivity, repertoire, and responsiveness to feedback (e.g., Aldao \& Nolen-Hoeksema, 2013; Bonanno et al., 2004).

\section{Context Sensitivity and Illicit Substance Use}

Because the latent structure of ER flexibility was not supported by the data, context sensitivity, repertoire and responsiveness to feedback were modeled as separate indices in the main analyses. In contrast to the expectations, higher levels of context sensitivity for both negative and positive emotions were unrelated to levels of illicit substance use (as indicated by frequency-quantity measure), substance-related problems and substance use in emotion-laden situations, after controlling for the participants' gender and depressive symptoms. One possible explanation is that the ceiling effects in the context sensitivity variables might have reduced the variability, limiting the detection of the main effects. Past research has shown that healthy young adults are generally adept at perceiving the contextual cues about the emotional meaning of an emotion-eliciting situation (e.g., Cheng, Chiu, Hong, \& Cheung, 2001; Cheng, Hui, \& Chiu, 2000; Rottenberg, Gross, \& Gotlib, 2005). For example, Cheng and her colleagues defined sensitivity to contextual cues in stressful situations and situation-appropriate matching of coping strategies as discriminative facility. Using a vignette-based questionnaire, they found that people generally scored high on discriminative facility as evident by the negative skewness in the variable (Cheng et al., 2001; Cheng et al., 2000). Rottenberg and his associates (2005) also found 
that healthy individuals and those recovered from depression reported higher levels of the intended emotions after watching or imagining emotional movie scenes, suggesting that they were highly sensitive to the emotional cues portrayed in the scenes. It is not surprising that the participants' in the present study would be highly accurate in perceiving the emotional cues from each scenario, resulting in the ceiling effects in the context sensitivity variables $(M=5.01, S D=$ 0.94 , range $=1-6$ for positive scenarios, $M=6.5, S D=1.33$, range $=1-9$ for negative scenarios).

An alternative explanation for the null findings on context sensitivity may be that one's sensitivity to contextual cues in emotional situations is a prerequisite for emotion regulation, but not in itself a regulatory response. As Bonnano and Burton (2013) pointed out, context sensitivity represents the initial step that set the stage for the deployment of any emotion regulatory strategies. Given that most theoretical perspectives on emotion and substance use emphasize the actual attempts to regulate emotions (de Wit \& Phan, 2010; Khantzian, 1997; Wills\& Shiffman, 1985), context sensitivity, as a prerequisite for emotion regulation, may not directly predict any substance use outcomes. Another explanation could be that sensitivity to contextual cues is more important in facilitating social interaction in interpersonal settings. Thus, higher levels of context sensitivity may be more relevant to interpersonal outcomes (e.g., perceived quality of social interactions; Cheng et al., 2001), than to personal outcomes, such as making autonomous decision about substance use.

\section{ER Repertoire and Illicit Substance Use}

Regarding participants' repertoire of ER strategies (i.e., average number of strategies endorsed across scenarios), the results indicated that a larger ER repertoire for negative emotions was associated with more substance-related problems, which was in the opposite direction as 
expected. These results were not consistent with Wong et al. (2013) who found that high-risk youth with a wide range of ER strategies for negative emotions reported fewer problems with illicit substance use and misuse of prescription drugs, compared to those who had a limited ER repertoire. Such discrepancy in findings may be attributed to the methodological differences between Wong et al. (2013) and the present study. For example, six out of the nine coping and ER strategies in Wong et al. (2013) were generally considered as adaptive, whereas there were equal number of adaptive and maladaptive strategies (four for each class) in the present study. It was possible that the participants in Wong et al. (2013) reported using more adaptive strategies, which were presumably protective against substance use. The exploratory analyses in the present study, by contrast, revealed that participants' repertoire of maladaptive strategies (as opposed to adaptive strategies) for negative emotions accounted for the positive association between ER repertoire for negative emotions and the substance use outcomes (discussed in later section). It is also worth noting that Wong et al. (2013) measured coping and ER with the Brief COPE (Carver, 1997) and Emotion Regulation Questionnaire (Gross \& John, 2003), both of which assessed general tendency to cope with stress and regulate emotions without specifying the situational contexts. In other words, these assessments at best assessed what the individuals have been doing whenever they encounter emotional situations. According to the principle of emotion transfer (Fishbach et al., 2004), endorsing more ER strategies may be protective against substance use in a sense that the individuals would have more alternatives to meet their emotional goals to regulate emotions besides using substances. On the other hand, the revised Emotion Regulation Profile (Neils et al., 2011) in the present study assessed, on average, how many ER strategies the individuals would deploy across different emotion-eliciting situations. Higher value on the repertoire variables might mean that the individuals have to draw on as many strategies as they 
can to regulate their emotions in all kinds of situations, suggesting that they might not tactically choose the situational-appropriate strategies to regulate their emotions across different contexts. Indeed, Aldao and Nolen-Hoeksema (2013) and Bonanno and Burton (2013) both raised the concern that deployment of multiple strategies in some emotional contexts may be indicative of erratic use of ER strategies. In other words, using a lot of ER strategies for negative emotions across all kinds of situations may be indicative of haphazard use of ER, suggesting that the individuals might have difficulties regulating their negative emotions effectively. In the present study, a larger ER repertoire for negative emotions was associated with more severe substancerelated problems, but not quantity and frequency of useand tendency to use substances in negative situations. It may be that difficulties with negative emotion regulation may contribute to the occurrence of more substance-related problems. Such an interpretation is consistent with previous studies that linked difficulties with regulating negative emotions to alcohol and substance abuse among adolescents and substance dependency among treatment-seeking adults (e.g., Fox, Axelrod, Paliwal, Sleeper, \& Sinha, 2007; Fox, Hong, \& Sinha, 2008; Weinberg \& Klonsky, 2009).

With regard to repertoire of regulating positive emotions, a larger repertoire was associated with lower tendency to use substances in positive situations as predicted, but was unexpectedly related to higher levels of substance use. Past research on positive emotion regulation tended to suggest that more diverse ways to regulate positive emotions should be associated with more positive outcomes, such as higher levels of subjective well-being (Livingstone \& Srivastava, 2012; Quoidbach et al., 2010). In the context of substance use, however, those who have a larger ER repertoire for positive emotion may also strive for the experiences of positive emotions even if it means using illicit substances to feel the positive 
emotional states. For individuals with a larger positive repertoire, substance use could be one of the ways through which they enhance their positive emotions. However, they may not necessarily use substances when they already feel good.Indeed, past research has shown that adolescents had less intention to use alcohol when they already experience relatively higher positive emotions (Rankin \& Magg, 2006).

Together, these patterns of results on ER repertoire and substance use suggest that the regulation of positive and negative emotions do not relate to substance use in the same way. While positive emotion regulation may be more important in determining how many substances and how frequent ones use, and whether ones tend to use substances in positive situations, negative emotion regulation may be more relevant to having more problematic patterns of use (e.g., Cheetham et al., 2010; Kassel \& Veilleux, 2010). Future research should consider positive and negative emotion regulation separately in relation to adolescent substance use.

\section{Responsiveness to Feedback and Illicit Substance Use}

The last component of ER flexibility, namely responsiveness to feedbackabout ER, was not associated with any substance-use outcomes after controlling for the two covariates in the present study. One reason for the null findings may be that the reliability of the measurement of responsiveness to feedback was relatively low $(\alpha=.65$ for the evaluative coping subscale and $\alpha$ $=.67$ for the corresponding subscale created for positive emotion regulation). Furthermore, two reversed-coded items needed to be excluded from both subscales due to the participants' misinterpretation of the items, resulting in 3 items per subscales. The relatively low reliability of the subscales and the small number of items may reduce the statistical power in detecting the main effects of responsiveness to feedback. An alternative explanation is that responsiveness to feedback only comes into play after the original regulatory attempt has been made (Bonanno 
\&Burton, 2013). Given that the emotion-related theoretical perspectives on substance use mainly focus on the actual attempt to regulate emotions (de Wit \& Phan, 2010; Khantzian, 1997; Wills\& Shiffman, 1985), responsiveness to feedback (as the response to the original attempt) may not directly related to substance use among adolescents.

\section{Other Emotion-relevant Characteristics and Illicit Substance Use}

When the indices of ER flexibility were examined additively with typical mood states, temperament, and urgency, some of the main effects of ER repertoire became non-significant or marginally significant. In the model with negatively valenced variables, repertoire of negative ER strategies was no longer associated with substance-related problems, suggesting that the main effect of negative ER repertoire may be overridden by the other emotion-relevant variables of the same valence.

With regard to the main effects of negative mood, individuals who reported higher levels of negative mood over the course of a typical week also indicated that they were more likely to use substances in negative situations. Consistent with past literature that people may use substances to regulate undesirable mood states (Kassel et al., 2007; Weinstein \& Mermelstein, 2013), the results suggest that transient negative mood seems to influence individuals' tendency to use substances in negative situations. However, whether higher levels of negative mood precede any incidences of substance use could not be determined in this cross-sectional study.

The results for negative emotionality were similar to those with negative mood. It was found that individuals with higher levels of negative emotionality were more likely to use substances in negative situations. These results suggest that individuals with higher levels of negative emotionality may be more likely to use substances as a coping mechanism (Willem et al. 2012). Thus, they may be at risk for developing a habitual tendency to use substances in the 
face of emotional distress or physical discomfort. In contrast to past literature (e.g., Measelle et al., 2006; Shoal \& Giancola, 2003) however, negative emotionality was not associated with levels of substance use and substance-related problems in the present study. One possible explanation may be that the effect of negative emotionality on levels of use and problems related illicit substance use may be mediated by other variables, such as motives for use (Willem et al., 2012; Wills, Sandy, Shinar, \& Yaeger, 1999). It is also possible that individuals with high levels of negative emotionality may be less effective in regulating their intense emotions, which in turn, put them at risk for illicit substance use (Wills, DuHamel, \& Vaccaro, 1995). Given the crosssectional nature of the present study, these mediating associations were not tested because the temporal precedence from the predictors to the mediators to the outcomes could not be determined.

In line with past literature (Adams et al., 2012; Kaiser et al., 2012; Settles et al., 2012), negative urgency was a strong predictor of higher levels of substance use, more substance-related problems, and higher tendency to use substances in negative situations. These results suggest that individuals who tend to act rashly in response to emotional distress may be more prone to seek quick relief to their distress. Thus, they may tend to use substances to cope in negative situations, and may experience more problems with their frequent use of illicit substances.

Together, the overall results of the negatively valenced model indicated that the moderators (especially negative urgency) might be stronger predictors of illicit substance use in the current sample. By comparison, the results of the positively valenced model revealed that the main effects of positive ER repertoire remained relatively robust in the additive model when positive mood, positive emotionality, and positive urgency were accounted for. Specifically, a larger repertoire for positive ER was marginally associated with higher levels of substance use 
and significantly associated with lower tendency to use substances in positive situations, over and above the effects of the positivelyvalenced moderators. Furthermore, only two out of the three moderators were significantly associated with the substance-use outcomes in the additive model of positive ER flexibility and the three positively valenced moderators.

In contrast to previous studies that linkeddifferent levels of positive mood to frequency of illicit substance (Bhushan et al., 2013; Lex et al., 1989; Rankin \& Maggs, 2006), no significant associations were found between positive mood and any substance use outcomes in the present study. One plausible explanation is that the outcomes were aggregated across substances. Given that positive mood may be differentially associated with the use of different substances, the scale aggregated across substances may cancel out opposing mood effects. Another possibility is that the researchers in previous studies (e.g., Bhushan et al., 2013; Lex et al., 1989; Rankin \& Magg, 2006) utilized daily diary to assess momentary mood states prior to incidences of substance use. Given the cross-sectional nature of the present study, the precise temporal associations between positive mood and substance use could not be captured.

For positive emotionality, individuals who were high on this trait reported higher levels of substance use and higher tendency to use substances in positive situations (i.e., when feeling pleasant emotions and having pleasant time with friends), which was consistent with the findings from previous studies (Oliva et al., 2012; Tomcikova et al., 2011; Walther et al., 2012). Enhancement and social motives have been identified as the common reasons for substance use among college students (Corbin, Iwamoto, \& Fromme, 2011; Jones, Chryssanthakis, \& Groom, 2014; Jones, Spradlin, Robinson, \& Tragesser, 2014; van Damme et al., 2013). Given that individuals with higher levels of positive emotionality also tend to be more extraverted (e.g., Evans \& Rothbart, 2007; Rothbart, Ahadi, \& Evans, 2000), it is not surprising that those who are 
more prone to intense experiences of positive emotions would be more likely to experiment with mood-altering substances to enhance their positive emotions, especially when they are in a social setting with friends.

With positive urgency, the findings in the present study were consistent with previous studies in that higher levels of positive urgency was related to higher levels of illicit substance use among college students (Cyders, Smith, Spillane et al., 2007; Zapolski et al., 2009). In a college environment where illicit substance use is relatively prevalent, individuals who tend to act impulsively when they experience intense positive emotions may take the opportunity to experiment with illicit substances that help them to enhance their positive emotions and their enjoyment of their social life.

Overall, the results from the additive models of ER flexibility and other emotion-relevant characteristics suggest that positive emotion regulation may be an important correlate of illicit substance use among college-age adolescents, over and above the effect of other positively valenced emotional characteristics. On the other hand, negative emotion regulation may be less predictive of illicit substance use in a college sample when other negatively valenced emotional characteristics were accounted for.

\section{Discussion of the Exploratory Findings}

Because ER repertoire was associated with the substance use outcomes in the opposite directions as expected, exploratory analyses were performed to determine which aspects of ER repertoire would be the most relevant to illicit substance use among college-age adolescents. In particular, the participants' repertoires for adaptive and maladaptive ER strategies were examined separately in relation to their substance use. Also, the participants' variability of using different strategies across situations and the overall effectiveness of the ER strategies in their 
repertoire were examined.

When the ER repertoire variables were broken down based on the adaptiveness of the strategies (Neils et al., 2011), a larger repertoire for adaptive ER strategies for negative emotionswas unrelated to any substance use outcomes in the present study. On the other hand, there was evidence that having a larger repertoire for maladaptive ER strategies for negative emotions (e.g., rumination) was associated with higher tendency to use substances in negative situations. Past research has shown that over-reliance on maladaptive ER strategies, such as avoidance coping and rumination, may be indicative of difficulties with emotion regulation(Hamdan-Mansour et al., 2007; Rafnsson et al., 2006; Skitch \& Abela, 2008; Willem, Bijttebier, Claes, \& Raes, 2011; Willem, Bijttebier, Claes, Vanhalst, \& Raes, 2014), which is a risk factor of substance use(Fox et al., 2007; Fox et al., 2008; Weinberg \& Klonsky, 2009). It is reasonable if the individuals mostly relied on maladaptive strategies to regulate their negative emotions, they would be more prone to using substances to cope even when they have a relatively larger ER repertoire. On the other hand, having fewer adaptive ER strategies in the repertoire may not necessarily mean that the person has difficulties regulating their emotions (Aldao, Jazaieri, Goldin, \& Gross, 2014; Aldao, Nolen-Hoeksema, \& Schweizer, 2010). Such notion may explain why repertoire of adaptive ER strategies for negative emotions was unrelated to any substance use outcomes. One implication of the findings is that intervention for adolescent substance use may focus on reducing the use of maladaptive strategies for regulating negative emotions before helping adolescents to build up their repertoire of adaptive strategies.

The corresponding examination of an ER repertoire for positive emotions resulted in paradoxical findings. In particular, having a larger repertoire of adaptive ER strategies for positive emotions was related to higher levels of substance use and higher tendency of using 
substances in positive situations. By contrast, a larger repertoire of maladaptive ER strategies for positive emotions was associated with lower tendency of substance use in positive situations, but not with levels of substance use. These paradoxical findings may be attributed to how adaptive and maladaptive strategies for positive emotions were defined in ERP-R (Neils et al., 2011). In the questionnaire, adaptive strategies for regulating positive emotions (e.g., capitalization, behavioral display of positive emotions) consisted of savoring strategies that up-regulate ones' positive emotions, whereas maladaptive strategies (e.g., fault-finding, inhibition of emotional expressions) were made up of dampening strategies that reduce the emotional impacts of the positive experiences. It might be that those who used more savoring strategies were also more likely to seek out positive experiences through antecedent-focused ER (i.e., proactive emotion regulation that occurs before the emotion is generated; Gross, 1998), even if it meant using illicit substances to enhance their positive emotions. On the other hand, those who used more dampening strategies to downplay the importance of their positive experiences might be less inclined to enhance their positive emotions, and thus, were less likely to use substances in positive situations that involved pleasant emotions or pleasant time with friends.

In addition to the size of adaptive and maladaptive ER repertoire, the variability of using different strategies across situations and the overall effectiveness of the strategies may also matter. For negative emotion regulation, higher variability of using diverse ER strategies across situations was not associated the substance use outcomes. According to Bonnano and Burton (2013), high variability in the use of diverse ER strategies is indicative of ER flexibility because the individuals are able to vary their extent of using different ER strategies based on the situational demand. With more comprehensive measure of this variability, future researchers may be able to detect its main effect on substance use. With regard to overall effectiveness of ER 
strategies for negative emotions, there was a non-significant trend that higher levels on this variable were related to lower tendency of using substances in negative situations. Given that difficulties with negative ER is a risk factor of substance use (Fox et al., 2007; Fox et al., 2008; Weinberg \& Klonsky, 2009), being able to effectively regulate negative emotions may prevent substance use in the time of distress.

With regard to positive emotion regulation, the variability of using diverse ER strategies was associated with higher tendency to use substances in positive situations, whereas the overall effectiveness of the strategies were unrelated to any substance use outcomes. It is plausible that those who used more diverse ways to regulate their positive emotions were also more likely to seek out positive emotional experiences, and thus might use mood-altering substances to enhance pleasant emotions and facilitate enjoyment of pleasant time with friends.

\section{Limitations and Future Directions}

Several limitations of the present study are worth discussing. First, the three proposed components of ER flexibility were all assessed with self-reported questionnaires, which may be subject to reporter bias. In addition, the cross-sectional design of the study could not precisely capture the sequential relations of the three components of ER flexibility. A multi-method study that combines self-reported questionnaires with live observation of behavioral responses and physiological measures of emotional reactions to emotion-eliciting tasks may be better suited for assessing the sequential components of ER flexibility. In addition, the ceiling effects of the context sensitivity variables might have limited the variability in the predictor and reduced the chance of detecting a main effect. More comprehensive coding of the variables may help increase the variability in these variables. Furthermore, emotion-specific ER was not assessed in the present study because the emphasis was on one's flexibility in regulating emotions across 
different emotional situations. Past research has suggested that the use and the effectiveness of ER strategies may vary by types of emotions within the same valance due to the functionalistic differences between different emotions (e.g., Zimmermann \& Iwanski, 2014). Emotion-specific assessment of ER flexibility may offer additional insight on ER flexibility and illicit substance use in future research.

Another critical limitation pertains to the computation of the substance-use outcomes, which were aggregated across different classes of substances due to low prevalence of the use of certain substances. It is possible that negative and positive ER may be differentially associated with the use of different types of substances (e.g., negative ER predicting sedative use, whereas positive ER predicting stimulant use). However, to retain a large sample, analyses were combined across substances within and across participants. With a more diverse substance-using sample, future researchers may be able to examine the associations between ER flexibility and illicit substance use by the types of substances. It is also important to note that a considerable number of participants ( $41.8 \%$ for negative situations and $28.7 \%$ for positive situations) reported that they never used substance in the given negative and positive situations. It could be that there are other situations in which people use substances (e.g., out of curiosity) that were not captured in the brief 8-item IDTS-8 (CAMH, 2009). An additional consideration is that college-age adolescents may use substances for non-emotional reasons (e.g., feeling the urge to use when substances are available, using substance to conform to peer pressure, being curious about the effects of substances; Coopers, 1994; Garnier-Dykstra et al., 2012). In a college environment where prevalence of illicit substance use is relatively high, the availability of substances and peer norms regarding experimentation with illicit substances may be more important correlates of illicit substance use in the current sample (e.g., Javier,Belgrave,Hill, \& Richardson, 2013; Liang, 
Lenton, Allsop, \& Chikritzhs; McAlaney et al., 2012). On the other hand, the ability to flexibly regulating emotions may be more relevant to severe form of substance dependence among older individuals who require treatment as difficulties with emotion regulation (e.g., having a limited ER repertoire) were common among treatment-seeking adults (Axelrod, Perepletchikova, Holtzman, \& Sinha, 2011; Buckholdt et al., 2015; Gratz \& Tull, 2010).

With regard to the associations between ER flexibility and illicit substance use, the temporal associations among the study variables could not be determined due to the crosssectional nature of the study. It is unclear whether ineffective regulation of emotions lead to more severe substance use or constant use of substances alters the ways in which individuals regulate their emotions. Also, the present study could only provide evidence for which factors concur with substance use and related problems. The question of how substance use develops at the first place could not be addressed in this study. Future researchers may conduct a longitudinal study to follow participants over time and assess the changes in ER flexibility in relation the development of illicit substance use.

Several limitations pertained to the analytic approach. First, post-hoc modifications needed to be made to improve model fit in some of the tested models to account forthe high correlation among the predictors and covariates. Although the modifications were theoretically and conceptually sound, making post-hoc modifications changed the nature of analyses from confirmatory to exploratory. Second, because the indices of ER flexibility were modeled as separate variables, a total of 54 moderating effects were tested. The moderation findings reported in Appendix $\mathbf{J}$ may be based on capitalization on chance.Third, the reliability of some measures (e.g., responsiveness to feedback and temperament) were relatively low, limiting the power to detect some hypothesized effects in the moderation models. 
A few final notes about the study limitations are worth mentioning. First of all, the study spanned over a four-month period across two semesters. Participants' self-reported frequency of substance use might have differed depending on the timing of their participation. For example, they might report more frequent use if they filled out the survey right after a school break than if they filled out the survey before the final exam week. Second, the order of questionnaires was standardized across all participants. There could be an ordering effect such that the participants' responses on a questionnaire might have affected their interpretation of or responses to the subsequent questionnaires.Third, there were no validity questions in the survey to check whether the participants took the survey seriously. Instead, the decision to exclude invalid data was based on inspection of participants' open-ended responses (e.g., typing in nonsense syllables or irrelevant information) and examination of multivariate outliers to detect patterning in responses. Lastly, although the prevalence of illicit substance use in the current sample was relatively high, the majority of the participants were Caucasian American and most of them self-identified as mentally healthy. Therefore, the results from the present study may not generalize to nonCaucasian population or the clinical population.

In sum, the present study contributes to the current understanding on ER flexibility and illicit substance use among college-age adolescents, althoughsome of the associations were not as expected. This study has several implications for research on emotion regulation as well as adolescent substance use. For example, there may be intra-individual differences in the manifestation of three components of ER flexibility. Latent class analyses may be used to identity subgroups of individuals with different profiles of ER flexibility. The current study also provides evidence that positive and negative emotion regulation might be differentially related to levels of substance use, substance-related problems, and tendency to use substance in emotion- 
laden situations. Whereas positive emotion regulation tends to affect levels of use and tendency to use substances in positive situations, negative emotion regulation may be more relevant to accumulated problems with substance use. More longitudinal studies are needed to test whether positive emotion regulation is more related to the initiation of use and experimentation with illicit substances and negative emotion regulation is more predictive of problematic abuse of substances and the tendency to use substances to cope. 


\section{References}

Adams, Z. W., Kaiser, A. J., Lynam, D. R., Charnigo, R. J., \& Milich, R. (2012). Drinking motives as mediators of the impulsivity-substance use relation: Pathways for negative urgency, lack of premeditation, and sensation seeking. Addictive Behaviors, 37(7), 848855.

Aldao, A., Jazaieri, H., Goldin, P. R., \& Gross, J. J. (2014). Adaptive and maladaptive emotion regulation strategies: Interactive effects during CBT for social anxiety disorder. Journal of Anxiety Disorders, 28(4), 382-389. doi:10.1016/j.janxdis.2014.03.005

Aldao, A., \& Nolen-Hoeksema, S. (2012). The influence of context on the implementation of adaptive emotion regulation strategies. Behaviour Research and Therapy, 50(7-8), 493501. doi:10.1016/j.brat.2012.04.004

Aldao, A., \& Nolen-Hoeksema, S. (2013). One versus many: capturing the use of multiple emotion regulation strategies in response to an emotion-eliciting stimulus. Cognition \& emotion, 27(4), 753-60.

Aldao, A., Nolen-Hoeksema, S., \& Schweizer, S. (2010). Emotion-regulation strategies across psychopathology: A meta-analytic review. Clinical Psychology Review, 30(2), 217-237. doi:10.1016/j.cpr.2009.11.004

Allen, J., \& Holder, M. D. (2014). Marijuana use and well-being in university students. Journal Of Happiness Studies, 15(2), 301-321. doi:10.1007/s10902-013-9423-1

Annis, H. M., \& Martin, G. (1985). Inventory of Drug-Taking Situations. Toronto: Addiction Research Foundation of Ontario. 
Axelrod, S. R., Perepletchikova, F., Holtzman, K., \& Sinha, R. (2011). Emotion regulation and substance use frequency in women with substance dependence and borderline personality disorder receiving dialectical behavior therapy. The American Journal of Drug and Alcohol Abuse, 37(1), 37-42. doi:10.3109/00952990.2010.535582

Battista, S. R., Pencer, A., McGonnell, M., Durdle, H., \& Stewart, S. H. (2013). Relations of personality to substance use problems and mental health disorder symptoms in two clinical samples of adolescents. International Journal of Mental Health and Addiction, $11(1), 1-12$.

Bhushan, D., Blood, E. A., \& Shrier, L. A. (2013). Momentary affective states predicting substance use events in depressed youth. Mental Health and Substance Use, 6(3), 203218.

Bonanno, G. A., \& Burton, C. L. (2013). Regulatory Flexibility: An Individual Differences Perspective on Coping and Emotion Regulation. Perspectives on Psychological Science, 8(6), 591-612.

Bonanno, G. A., Papa, A., Lalande, K., Westphal, M., \& Coifman, K. (2004). The Importance of Being Flexible: The ability to both enhance and suppress emotional expression predicts long-term adjustment, Psychological Science, 15(7), 482-487.

Boschloo, L., Vogelzangs, N., van den Brink, W., Smit, J. H., Beekman, A. F., \& Penninx, B. H. (2013). The role of negative emotionality and impulsivity in depressive/anxiety disorders and alcohol dependence. Psychological Medicine, 43(6), 1241-1253.

Boujut, E., Bruchon-Schweitzer, M., \& Dombrowski, S. (2012). Coping among students: Development and validation of an exploratory measure. Psychology, 3(8), 562-568. doi:10.4236/psych.2012.38084 
Britton, P. C. (2004). The relation of coping strategies to alcohol consumption and alcohol-related consequences in a college sample. Addiction Research \& Theory, 12(2), 103-114.

Bryant, F. B. (1989). A four-factor model of perceived control: Avoiding, coping, obtaining, and savoring. Journal of Personality, 57, 773-797.

Bryant, F. B. (2003). Savoring Beliefs Inventory (SBI): A scale for measuring beliefs about savoring. Journal of Mental Health, 12, 175-196.

Buckholdt, K. E., Parra, G. R., Anestis, M. D., Lavender, J. M., Jobe-Shields, L. E., Tull, M. T., \& Gratz, K. L. (2015). Emotion regulation difficulties and maladaptive behaviors: Examination of deliberate self-harm, disordered eating, and substance misuse in two samples. Cognitive Therapy and Research, 39(2), 140-152.

Buckner, J. D. (2013). College cannabis use: The unique roles of social norms, motives, and expectancies. Journal of Studies on Alcohol and Drugs, 74(5), 720-726.

Byrne, B. M. (2010). Structural Equation Modeling with AMOS, $2^{\text {nd }}$ Ed. New York: Routledge.

Carver, C. S. (1997). You want to measure coping but your protocol's too long: Consider the Brief COPE. International Journal of Behavioral Medicine, 4, 92-100.

Carver, C. S., Scheier, M. F., \& Weintraub, J. K. (1989). Assessing coping strategies: A theoretically based approach. Journal of Personality and Social Psychology, 56(2), 267283.

Center for Addiction and Mental Health (2009). Inventory of Drug-Taking Situations - 8 . Retrieved from http://knowledgex.camh.net/amhspecialists/specialized_treatment/relapse _prevention/srp/Documents/srp_problem_situations.pdf. 
Chan, Y., Dennis, M. L., \& Funk, R. R. (2008). Prevalence and comorbidity of major internalizing and externalizing problems among adolescents and adults presenting to substance abuse treatment. Journal of Substance Abuse Treatment, 34(1), 14-24.

Cheetham, A., Allen, N. B., Yücel, M., \& Lubman, D. I. (2010). The role of affective dysregulation in drug addiction. Clinical Psychology Review, 30(6), 621-634. doi:10.1016/j.cpr.2010.04.005

Cheng, C. (2001). Assessing coping flexibility in real-life and laboratory settings: A multimethod approach. Journal of Personality and Social Psychology, 80(5), 814833.

Cheng, C., Chiu, C., Hong, Y., \& Cheung, J. S. (2001). Discriminative facility and its role in the perceived quality of interactional experiences. Journal of Personality, 69(5), 765-786. doi:10.1111/1467-6494.695163

Cheng, C., Hui, W., \& Lam, S. (2000). Perceptual style and behavioral pattern of individuals with functional gastrointestinal disorders. Health Psychology, 19(2), 146-154. doi:10.1037/0278-6133.19.2.146

Colder, C. R., \& Chassin, L. (1997). Affectivity and impulsivity: Temperament risk for adolescent alcohol involvement. Psychology of Addictive Behaviors, 11(2), 83-97.

Cooper, M. L. (1994) Motivations for alcohol use among adolescents: development and validation of a four-factor model. Psychological Assessment, 6, 117-128.

Cooper, M. L., Frone, M. R., Russell, M., \& Mudar, P. (1995). Drinking to regulate positive and negative emotions: a motivational model of alcohol use. Journal of Personality and Social Psychology, 69(5), 990-1005. 
Corbin, W. R., Iwamoto, D. K., \& Fromme, K. (2011). Broad social motives, alcohol use, and related problems: Mechanisms of risk from high school through college. Addictive Behaviors, 36(3), 222-230. doi:10.1016/j.addbeh.2010.11.004

Crooke, A., Reid, S., Forbes, A., et al. (2013). Temporal mood changes associated with different levels of adolescent drinking: Using mobile phones and experience sampling methods to explore motivations for adolescent alcohol use. Drug and Alcohol Review [serial online]. May 2013; 32(3):262-268.

Cyders, M. A., \& Smith, G. T. (2007). Mood-based rash action and its components: Positive and negative urgency and their relations with other impulsivity-like constructs. Personality and Individual Differences, 43,839-850.

Cyders, M. A., Smith, G. T., Spillane, N. S., Fischer, S., Annus, A. M., \& Peterson, C. (2007). Integration of impulsivity and positive mood to predict risky behavior: Development and validation of a measure of positive urgency. Psychological Assessment, 19(1), 107-118.

Dashora, P., Erdem, G., \& Slesnick, N. (2011). Better to bend than to break: Coping strategies utilized by substance-abusing homeless youth. Journal of Health Psychology, 16(1), 158168.

de Wit, H., \& Phan, L. (2010). Positive reinforcement theories of drug use. In Kassel, J. D. (Eds.). Substance Abuse and Emotion. (pp.43 - 60). Washington DC: American Psychological Association.

Diefendorff, J. M., \& Greguras, G. J. (2009). Contextualizing emotional display rules: Examining the roles of targets and discrete emotions in shaping display rule perceptions. Journal of Management, 35(4), 880-898. 
Eftekhari, A., Turner, A. P., \& Larimer, M. E. (2004). Anger expression, coping, and substance use in adolescent offenders. Addictive Behaviors, 29(5), 1001-1008.

Egloff, B., Schmukle, S. C., Burns, L. R., \& Schwerdtfeger, A. (2006). Spontaneous emotion regulation during evaluated speaking tasks: associations with negative affect, anxiety expression, memory, and physiological responding. Emotion, 6(3), 356-66.

Evans, D. E., \& Rothbart, M. K. (2007). Development of a model for adult temperament. Journal of Research in Personality, 41, 868-888.

Feldman, G. C., Joormann, J., \& Johnson, S. L. (2008). Responses to positive affect: A self report measure of rumination and dampening. Cognitive Therapy \& Research, 32, 507525.

Fishbach, A., Shah, J. Y., \& Kruglanski, A. W. (2004). Emotional transfer in goal systems. Journal of Experimental Social Psychology, 40, 723 - 738.

Fox, H., Axelrod, S., Paliwal, P., Sleeper, J., \& Sinha, R. (2007). Difficulties in emotion regulation and impulse control during cocaine abstinence. Drug and Alcohol Dependence, 89(2-3), 298-301. doi:10.1016/j.drugalcdep.2006.12.026

Fox, H. C., Hong, K. A., \& Sinha, R. (2008). Difficulties in emotion regulation and impulse control in recently abstinent alcoholics compared with social drinkers. Addictive Behaviors, 33(2), 388-394. doi:10.1016/j.addbeh.2007.10.002

Fredrickson, B. L. (1998). What good are positive emotions?Review of General Psychology, 2, 300-319.

Fromme, K., \& Rivet, K. (1994). Young adults' coping style as a predictor of their alcohol use and response to daily events. Journal of Youth and Adolescence, 23(1), 85-97. 
Fujita, F., Diener, E., \& Sandvik, E. (1991). Gender differences in negative affect and wellbeing: The case for emotional intensity. Journal of Personality and Social Psychology, 61(3), 427-434. doi:10.1037/0022-3514.61.3.427

Garnier-Dykstra, L. M., Caldeira, K. M., Vincent, K. B., O'Grady, K. E., \& Arria, A. (2012). Nonmedical use of prescription stimulants during college: Fourexposure opportunity, use, motives, and sources. Journal of American College Health, 60(3), 226-234. doi:10.108year trends in 0/07448481.2011.589876

Gentzler, A. L., Kerns, K. A., \& Keener, E. (2010). Emotional reactions and regulatory responses to negative and positive events: Associations with attachment and gender. Motivation and Emotion, 34, 78-92.

Gentzler, A. L., Morey, J. N., Palmer, C. A.,\& Yi, C. Y. (2013). Children’s responses to positive events: Associations with positive affect and adjustment. Journal of Early Adolescence, $33,662-681$.

Gomez, R., Kyriakides, C., \& Devlin, E. (2014). Attention-Deficit/Hyperactivity Disorder symptoms in an adult sample: Associations with Rothbart's temperament dimensions. Personality and Individual Differences, 60, 73-78.

Gonzalez, V. M., Reynolds, B., \& Skewes, M. C. (2011). Role of impulsivity in the relationship between depression and alcohol problems among emerging adult college drinkers. Experimental and Clinical Psychopharmacology, 19(4), 303-313. doi:10.1037/a0022720

Gratz, K. L., \& Tull, M. T. (2010). The relationship between emotion dysregulation and deliberate self-harm among inpatients with substance use disorders. Cognitive Therapy And Research, 34(6), 544-553. doi:10.1007/s10608-009-9268-4 
Green, B., Kavanagh, D., \& Young, R. (2003). Being stoned: A review of self-reported cannabis effects. Drug and Alcohol Review, 22(4), 453-460.

Gross, J. J. (1998). The emerging field of emotion regulation: An integrative review. Review of General Psychology, 2, 271-299.

Gross, J.J., \& John, O.P. (2003). Individual differences in two emotion regulation processes: Implications for affect, relationships, and well-being. Journal of Personality and Social Psychology, 85, 348-362.

Gross, J. J., \& Thompson, R. A. (2007). Emotion regulation: conceptual foundations. In J. J. Gross (Ed.), Handbook of Emotion Regulation (pp. 3-24). New York, NY, US: Guilford Press.

Haase, C. M., \& Silbereisen, R. K. (2011). Effects of positive affect on risk perceptions in adolescence and young adulthood. Journal of Adolescence, 34(1), 29-37.

Hamdan-Mansour, A. M., Puskar, K., \& Sereika, S. M. (2007). Perceived social support, coping strategies and alcohol use among rural adolescents/USA sample. International Journal of Mental Health and Addiction, 5(1), 53-64.

Hawkins, J., Catalano, R. F., \& Miller, J. Y. (1992). Risk and protective factors for alcohol and other drug problems in adolescence and early adulthood: Implications for substance abuse prevention. Psychological Bulletin, 112(1), 64-105.

Heiy, J. E., \& Cheavens, J. S. (2014). Back to basics: A naturalistic assessment of the experience and regulation of emotion. Emotion, 14(5), 878-891. doi:10.1037/a0037231

Howell, D. C. (1998). Statistical methods in human sciences. New York: Wadsworth 
Hu, L. T., \& Bentler, P. M. (1999). Cutoff criteria for fit indexes in covariance structure analysis: Conventional criteria versus new alternatives. Structural Equation Modeling: A Multidisciplinary Journal, 6(1), 1-55.

Javier, S. J., Belgrave, F. Z., Hill, K. V., \& Richardson, J. T. (2013). Ethnic and gender differences in normative perceptions of substance use and actual use among college students. Journal of Ethnicity in Substance Abuse, 12(3), 228-241. doi:10.1080/15332640.2013.798847

Johanson, C., Roehrs, T., Schuh, K., \& Warbasse, L. (1999). The effects of cocaine on mood and sleep in cocaine-dependent males. Experimental and Clinical Psychopharmacology, 7(4), 338-346.

Jones, K. A., Chryssanthakis, A., \& Groom, M. J. (2014). Impulsivity and drinking motives predict problem behaviours relating to alcohol use in University students. Addictive Behaviors, 39(1), 289-296. doi:10.1016/j.addbeh.2013.10.024

Jones, R. E., Spradlin, A., Robinson, R. J., \& Tragesser, S. L. (2014). Development and validation of the Opioid Prescription Medication Motives Questionnaire: A four-factor model of reasons for use. Psychology of Addictive Behaviors, 28(4), 1290-1296. doi: $10.1037 / \mathrm{a} 0037783$

Kaiser, A. J., Milich, R., Lynam, D. R., \& Charnigo, R. J. (2012). Negative Urgency, Distress Tolerance, and substance abuse among college students. Addictive Behaviors, 37(10), 1075-1083.

Kashdan, T. B., \& Rottenberg, J. (2010). Psychological flexibility as a fundamental aspect of health. Clinical Psychology Review, 30, 865-878. 
Kassel, J. D., Evatt, D. P., Greenstein, J. E., Wardle, M. C., Yates, M. C., \& Veilleux, J. C. (2007). The acute effects of nicotine on positive and negative affect in adolescent smokers. Journal of Abnormal Psychology, 116(3), 543-553.

Kassel, J. D. \& Veilleux, J. C. (2010). Introduction: The Complex interplay between substance abuse and emotion. In Kassel, J. D. (Eds.). Substance Abuse and Emotion. (pp.3 - 12). Washington DC: American Psychological Association.

Kato, T. (2012). Development of the Coping Flexibility Scale: evidence for the coping flexibility hypothesis. Journal of counseling psychology, 59(2), 262-73.

Khantzian, E. J. (1997). The self-medication hypothesis of substance use disorders: A reconsideration and recent applications. Harvard Review of Psychiatry, 4(5), 231-244.

Köpetz, C. E., Lejuez, C. W., Wiers, R. W., \& Kruglanski, A. W. (2013). Motivation and SelfRegulation in Addiction A Call for Convergence. Perspectives on Psychological Science, 8(1), 3-24.

Landis, J. R., Koch, G. G. (1977). The measurement of observer agreement for categorical data. Biometrics 33:159-174.

Langston, C. A. (1994). Capitalizing on and coping with daily-life events: Expressive responses to positive events. Journal of Personality and Social Psychology, 67(6), 1112-1125.

Lazarus, R. S., \& Folkman, S. (1984). Stress, appraisal, and coping. New York: Springer.

Lee, C. M., Neighbors, C., \& Woods, B. A. (2007). Marijuana motives: Young adults' reasons for using marijuana. Addictive Behaviors, 32(7), 1384-1394.

Lex, B.W., Griffin, M. L., Mello, N. K., \& Mendelson, J. H. (1989). Alcohol, marijuana, and mood states in young women. International Journal of the Addictions, 24(5), 405-424. 
Liang, W., Lenton, S., Allsop, S., \& Chikritzhs, T. (2011). Does availability of illicit drugs mediate the association between mental illness and substance use?.Substance Use and Misuse, 46(10), 1304-1308. doi:10.3109/10826084.2011.574769

Livingstone, K.M., \& Srivastava, S. (2012). Up-regulating positive emotions in everyday life: Strategies, individual differences, and associations with positive affect and well-being. Journal of Research in Personality, 46, 504-516.

Lougheed, J. P., \& Hollenstein, T. (2012). A limited repertoire of emotion regulation strategies is associated with internalizing problems in adolescence. Social Development, 21(4), 704721.

Lucas, R. E., \& Baird, B. M. (2004). Extraversion and Emotional Reactivity. Journal of Personality and Social Psychology, 86(3), 473-485. doi:10.1037/0022-3514.86.3.473

Lynam, D. R., Smith, G. T.,Whiteside, S. P., \& Cyders, M. A. (2006). The UPPS-P: Assessing five personality pathways to impulsive behavior (tech. rep.). West Lafayette, IN: Purdue University.

McAlaney, J., Boot, C. R., Dahlin, M., Lintonen, T., Stock, C., Rasmussen, S., \& Van Hal, G. (2012). A comparison of substance use behaviours and normative beliefs in North-West European university and college students. International Journal on Disability and Human Development, 11(3), 281-287. doi:10.1515/ijdhd-2012-0032

MacCallum, R.C., Roznowski, M., \& Necowitz, L. B. (1992). Model modifications in covariance structure analysis: The problem of capitalization on chance. Quantitative Methods in Psychology, 111(3), $490-504$. 
Mauss, I. B., \& Tamir, M. (2014). Emotion goals: How their content, structure, and operation shape emotion regulation. In J. J. Gross (Ed.), Handbook of emotion regulation (2nd ed.) (pp. 361-375). New York, NY, US: Guilford Press.

Measelle, J. R., Stice, E., \& Springer, D. W. (2006). A prospective test of the negative affect model of substance abuse: Moderating effects of social support. Psychology of Addictive Behaviors, 20(3), 225-233.

Metrik, J., Kahler, C. W., McGeary, J. E., Monti, P. M., \& Rohsenow, D. J. (2011). Acute effects of marijuana smoking on negative and positive affect. Journal of Cognitive Psychotherapy, 25(1), 31-46.

Neils, D., Quoidbach, J., Hansenne, M., \& Mikolajczak, M. (2011). Measuring individual differences in emotion regulation: The Emotion Regulation Profile-Revised (ERP-R). Psychologica Belgica, 51 (1), 49 - 91.

Nelson, R. A., Boyd, S. J., Ziegelstein, R. C., Herning, R., Cadet, J. L., Henningfield, J. E., \& ... Gorelick, D. A. (2006). Effect of rate of administration on subjective and physiological effects of intravenous cocaine in humans. Drug and Alcohol Dependence, 82(1), 19-24. doi:10.1016/j.drugalcdep.2005.08.004

Nyamathi, A., Hudson, A., Greengold, B., Slagle, A., Marfisee, M., Khalilifard, F., \& Leake, B. (2010). Correlates of substance use severity among homeless youth. Journal of Child and Adolescent Psychiatric Nursing, 23(4), 214-222.

Oliva, E. M., Keyes, M., Iacono, W. G., \& McGue, M. (2012). Adolescent substance use groups: Antecedent and concurrent personality differences in a longitudinal study. Journal of Personality, 80(3), 769-793. 
Parrott, A. C., \& Stuart, M. M. (1997). Ecstacy (MDMA), amphetamine, and LSD: Comparative mood profiles in recreational polydrug users. Human Psychopharmacology: Clinical and Experimental, 12(5), 501-504.

Preacher, K. J., \& Coffman, D. L. (2006, May). Computing power and minimum sample size for RMSEA [Computer software]. Available from http://quantpsy.org/.

Quoidbach, J., Berry, E. V., Hansenne, M., \& Mikolajczak, M. (2010). Positive emotion regulation and well-being: Comparing the impact of eight savoring and dampening strategies. Personality and Individual Differences, 49(5), 368-373.

Radloff, L. S. (1977). The CES-D scale: A self report depression scale for research in the general population. Applied Psychological Measurements, 1, 385-401.

Raes, F., Smets, J., Neils, S., \& Schoofs, H. (2012). Dampening of positive affect prospectively predicts depressive symptoms in a non-clinical sample. Cognition and Emotion, 26(1), 75 $-82$.

Rafnsson, F., Jonsson, F. H., \& Windle, M. (2006). Coping strategies, stressful life events, problem behaviors, and depressed affect. Anxiety, Stress \& Coping: An International Journal, 19(3), 241-257.

Rankin, L. A., \& Maggs, J. L. (2006). First-year college student affect and alcohol use: Paradoxical within- and between-person associations. Journal of Youth and Adolescence, $35(6), 925-937$.

Roberts, K. R., Dimsdale, J., East, P., \& Friedman, L. (1998). Adolescent emotional response to music and its relationship to risk-taking behaviors. Journal of Adolescent Health, 23(1), 49-54. 
Rothbart, M. K., Ahadi, S. A., \& Evans, D. E. (2000). Temperament and personality: Origins and outcomes. Journal of Personality and Social Psychology, 78(1), 122-135. doi:10.1037/0022-3514.78.1.122

Rothbart, M. K., \& Bates, J. E. (1998). Temperament. In W. Damon (Series Ed.) \& N. Eisenberg (Vol. Ed.), Handbook of child psychology: Vol. 3, Social, emotional, and personality development $\left(5^{\text {th }}\right.$ ed., pp. $\left.105-176\right)$. New York: Wiley.

Rottenberg, J., Gross, J. J., \& Gotlib, I. H. (2005). Emotion Context Insensitivity in Major Depressive Disorder. Journal of Abnormal Psychology, 114(4), 627-639. doi:10.1037/0021-843X.114.4.627

Settles, R. E., Fischer, S., Cyders, M. A., Combs, J. L., Gunn, R. L., \& Smith, G. T. (2012). Negative urgency: A personality predictor of externalizing behavior characterized by neuroticism, low conscientiousness, and disagreeableness. Journal of Abnormal Psychology, 121(1), 160-172.

Shaver, P., Schwartz, J., Kirson, D., \& O'Connor, C. (1987). Emotion knowledge: Further exploration of a prototype approach. Journal of Personality and Social Psychology, 52(6), 1061-1086. doi:10.1037/0022-3514.52.6.1061

Shoal, G. D., \& Giancola, P. R. (2003). Negative affectivity and drug use in adolescent boys: Moderating and mediating mechanisms. Journal of Personality and Social Psychology, 84(1), 221-233.

Shoal, G. D., Gudonis, L. C., Giancola, P. R., \& Tarter, R. E. (2008). Negative affectivity and drinking in adolescents: An examination of moderators predicted by affect regulation theory. Journal of Psychopathology and Behavioral Assessment, 30(1), 61-70. 
Simons, J. S., \& Carey, K. B. (2002). Risk and vulnerability for marijuana use problems: The role of affect dysregulation. Psychology of Addictive Behaviors, 16(1), 72-75. doi:10.1037//0893-164X.16.1.72.

Simons, J., Correia, C. J., Carey, K. B., \& Borsari, B. E. (1998). Validating a five-factor marijuana motives measure: Relations with use, problems, and alcohol motives. Journal of Counseling Psychology, 45(3), 265-273.

Simons, J. S., Gaher, R. M., Correia, C. J., Hansen, C. L., \& Christopher, M. S. (2005). An affective-motivational model of marijuana and alcohol problems among college students. Psychology of addictive behaviors : Journal of the Society of Psychologists in Addictive Behaviors, 19(3), 326-34. doi:10.1037/0893-164X.19.3.326

Skinner, E. A., Edge, K., Altman, J. \& Sherwood, H. (2003). Searching for the structure of coping: A review and critique of category systems for classifying ways of coping. Psychological Bulletin, 129 (2), 216 - 269.

Skitch, S. A., \& Abela, J. Z. (2008). Rumination in response to stress as a common vulnerability factor to depression and substance misuse in adolescence. Journal of Abnormal Child Psychology, 36(7), 1029-1045. doi:10.1007/s10802-008-9233-9

Snyder, S. A., Heller, S. M., Lumian, D. S., \& McRae, K. (2013). Regulation of positive and negative emotion: Effects of sociocultural context. Frontiers in Psychology, 4, 1-12.

Staton, M., Leukefeld, C., Logan, T. K., Zimmerman, R., Lynam, D., Milich, R., \& ... Clayton, R. (1999). Risky sex behavior and substance use among young adults. Health \& Social Work, 24(2), 147-154. 
Substance Abuse and Mental Health Services Administration (SAMHSA; 2013). Results from the 2013 National Survey on Drug Use and Health: Summary of National Findings, NSDUH Series H-48, HHS Publication No. (SMA) 14-4863. Rockville, MD: Substance Abuse and Mental Health Services Administration, 2014.

Suerken, C. K., Reboussin, B. A., Sutfin, E. L., Wagoner, K. G., Spangler, J., \& Wolfson, M. (2013). Prevalence of marijuana use at college entry and risk factors for initiation during freshman year. Addictive Behaviors, doi:10.1016/j.addbeh.2013.10.018

Tamir, M. (2009). What do people want to feel and why?: Pleasure and utility in emotion regulation. Current Directions in Psychological Science, 18(2), 101-105.

Tapert, S. F., Granholm, E., Leedy, N. G., \& Brown, S. A. (2002). Substance use and withdrawal: Neuropsychological functioning over 8 years in youth. Journal of the Neuropsychological Society, 8, 873-883.

Tomcikova, Z., Geckova, A., van Dijk, J. P., \& Reijneveld, S. A. (2011). Characteristics of adolescent excessive drinkers compared with consumers and abstainers. Drug and Alcohol Review, 30(2), 157-165.

van Damme, J., Maes, L., Clays, E., Rosiers, J. T., van Hal, G., \& Hublet, A. (2013). Social motives for drinking in students should not be neglected in efforts to decrease problematic drinking. Health Education Research, 28(4), 640-650. doi:10.1093/her/cyt036

Viera, A. J., \& Garrett, J. M. (2005). Understanding interobserver agreement. The Kappa statistic. Family Medicine, 37(5), 360 - 363. 
Voruganti, L. P., \& Awad, A. G. (2005). Brain imaging research on subjective responses to psychotropic drugs. Acta Psychiatrica Scandinavica, 111(s427), 22-28. doi:10.1111/j.1600-0447.2005.00541.x

Walther, B., Morgenstern, M., \& Hanewinkel, R. (2012). Co-occurrence of addictive behaviours: Personality factors related to substance use, gambling and computer gaming. European Addiction Research, 18(4), 167-174.

Wang, M., \& Saudino, K. J. (2011). Emotion regulation and stress. Journal of Adult Development, 18(2), 95-103.

Weinberg, A., \& Klonsky, E. D. (2009). Measurement of emotion dysregulation in adolescents. Psychological Assessment, 21(4), 616-621. doi:10.1037/a0016669

Weinstein, S. M., \& Mermelstein, R. J. (2013). Dynamic associations of negative mood and smoking across the development of smoking in adolescence. Journal of Clinical Child and Adolescent Psychology, 42(5), 629-642.

Whiteside, S. P., \& Lynam, D. R. (2001). The five factor model and impulsivity: Using a structural model of personality to understand impulsivity. Personality and Individual Differences, 30, 669-689.

WHO ASSIST Working Group (2002). The Alcohol, Smoking and Substance Involvement Screening Test (ASSIST): development, reliability and feasibility. Addiction, 97, 11831194.

Willem, L., Bijttebier, P., Claes, L., \& Raes, F. (2011). Rumination subtypes in relation to problematic substance use in adolescence. Personality and Individual Differences, 50(5), 695-699. doi:10.1016/j.paid.2010.12.020 
Willem, L., Bijttebier, P., Claes, L., \& Uytterhaegen, A. (2012). Temperament and problematic alcohol use in adolescence: An examination of drinking motives as mediators. Journal of Psychopathology and Behavioral Assessment, 34(2), 282-292.

Willem, L., Bijttebier, P., Claes, L., Vanhalst, J., \& Raes, F. (2014). The cross-temporal associations between rumination subtypes and substance use in adolescence: Exploring the moderating role of gender. Journal of Psychopathology And Behavioral Assessment, 36(1), 143-154. doi:10.1007/s 10862-013-9373-2

Wills, T. A., DuHamel, K., \& Vaccaro, D. (1995). Activity and mood temperament as predictors of adolescent substance use: test of a self-regulation mediational model. Journal of Personality and Social Psychology,68(5), 901.

Wills, T., \& Dishion, T. J. (2004). Temperament and Adolescent Substance Use: A Transactional Analysis of Emerging Self-Control. Journal of Clinical Child and Adolescent Psychology, 33(1), 69-81.

Wills, T. A., \& Hirky, A. E. (1996). Coping and substance use: A theoretical model and review of the evidence. In M. Zeidner \& N. Endler (Eds.),Handbook of coping: Theory, research, applications(pp. 279-302).New York: Wiley.

Wills, T., Sandy, J. M., Shinar, O., \& Yaeger, A. (1999). Contributions of positive and negative affect to adolescent substance use: Test of a bidimensional model in a longitudinal study. Psychology of Addictive Behaviors, 13(4), 327-338.

Wills, T. A., Sandy, J. M., \& Yaeger, A. M. (2002). Moderators of the relation between substance use level and problems: Test of a self-regulation model in middle adolescence. Journal of Abnormal Psychology, 111(1), 3-21. doi:10.1037//0021843X.111.1.3 
Wills, T. A. \& Shiffman, S. (1985). Coping and substance abuse: A conceptual framework. In S., Shiffman \& T. A., Wills (Ed.). Coping and substance use. (pp. 3-24). Orlando: Academic Press.

Wills, T. A., Walker, C., Mendoza, D., \& Ainette, M. G. (2006). Behavioral and emotional selfcontrol: relations to substance use in samples of middle and high school students. Psychology of addictive behaviors:Journal of the Society of Psychologists in Addictive Behaviors, 20(3), 265-78. doi:10.1037/0893-164X.20.3.265

Wong, C. F., Silva, K., Kecojevic, A., Schrager, S. M., Bloom, J., Iverson, E., \& Lankenau, S. E. (2013). Coping and emotion regulation profiles as predictors of nonmedical prescription drug and illicit drug use among high-risk young adults. Drug and Alcohol Dependence. doi: 10.1016/j.drugalcdep.2013.01.024.

Wood, J. V., Heimpel, S. A., \& Michela, J. L. (2003). Savoring Versus Dampening: Self-Esteem Differences in Regulating Positive Affect. Journal of Personality and Social Psychology, $85(3), 566-580$.

Yule, A. M., Wilens, T. E., Martelon, M. K., Simon, A., \& Biederman, J. (2013). Does exposure to parental substance use disorders increase substance use disorder risk in offspring? A 5-year follow-up study. The American Journal on Addictions, 22(5), 460-465. doi:10.1111/j.1521-0391.2013.12048.x

Zapolski, T. B., Cyders, M. A., \& Smith, G. T. (2009). Positive urgency predicts illegal drug use and risky sexual behavior. Psychology of Addictive Behaviors, 23(2), 348-354. 
Zimmerman, P. \& Iwanski, A. (2014). Emotion regulation from early adolescence to emerging adulthood and middle adulthood: Age differences, gender differences, and emotionspecific developmental variations. International Journal of Behavioral Development, $38(2), 182-194$. 
Table 1

Prevalence of Lifetime Use of Illicit Substances

\begin{tabular}{|c|c|c|c|c|}
\hline \multirow[t]{2}{*}{ Types of Substance } & \multicolumn{2}{|c|}{ Full Valid Sample $(\mathrm{N}=492)$} & \multicolumn{2}{|c|}{ Final Sample $(\mathrm{N}=428)$} \\
\hline & $\mathrm{n}$ & $\%$ & $\mathrm{n}$ & $\%$ \\
\hline \multicolumn{5}{|l|}{ Alcohol } \\
\hline No & 67 & 13.6 & 3 & .7 \\
\hline Yes & 425 & 86.4 & 425 & 99.3 \\
\hline \multicolumn{5}{|l|}{ Cannabis } \\
\hline No & 254 & 51.6 & 190 & 44.4 \\
\hline Yes & 238 & 48.4 & 238 & 55.6 \\
\hline \multicolumn{5}{|l|}{ Cocaine } \\
\hline No & 458 & 93.1 & 394 & 92.1 \\
\hline Yes & 34 & 6.9 & 34 & 7.9 \\
\hline \multicolumn{5}{|l|}{ Stimulants } \\
\hline No & 425 & 86.4 & 361 & 84.3 \\
\hline Yes & 67 & 13.6 & 67 & 15.7 \\
\hline \multicolumn{5}{|l|}{ Inhalants } \\
\hline No & 479 & 97.4 & 415 & 97.0 \\
\hline Yes & 13 & 2.6 & 13 & 3.0 \\
\hline \multicolumn{5}{|l|}{ Sedatives } \\
\hline No & 449 & 91.3 & 385 & 90.0 \\
\hline Yes & 43 & 8.7 & 43 & 10.0 \\
\hline \multicolumn{5}{|l|}{ Hallucinogens } \\
\hline No & 455 & 92.5 & 391 & 91.4 \\
\hline Yes & 37 & 7.5 & 37 & 8.6 \\
\hline \multicolumn{5}{|l|}{ Opioids } \\
\hline No & 478 & 97.2 & 414 & 96.7 \\
\hline Yes & 14 & 2.8 & 14 & 3.3 \\
\hline \multicolumn{5}{|l|}{ Dimethyltryptamine } \\
\hline No & 484 & 98.4 & 420 & 98.1 \\
\hline Yes & 8 & 1.6 & 8 & 1.9 \\
\hline \multicolumn{5}{|l|}{ Other Drugs } \\
\hline No & 480 & 97.6 & 416 & 97.2 \\
\hline Yes & 12 & 2.4 & 12 & 2.8 \\
\hline
\end{tabular}


Table 2

Demographic Characteristics of Participants $(N=428)$

\begin{tabular}{|c|c|c|c|c|}
\hline Variables & $M(S D)$ & Range & $\mathrm{n}$ & $\%$ \\
\hline Age & $19.00(.74)$ & $18.00-20.00$ & - & - \\
\hline Subjective SES & $6.50(1.56)$ & $1.00-10.00$ & - & - \\
\hline \multicolumn{5}{|l|}{ Gender } \\
\hline Male & - & - & 98 & 22.9 \\
\hline Female & - & - & 330 & 77.1 \\
\hline \multicolumn{5}{|l|}{ Race } \\
\hline Caucasian & - & - & 378 & 88.3 \\
\hline African American & - & - & 16 & 3.7 \\
\hline Hispanic American & - & - & 7 & 1.6 \\
\hline Asian American & - & - & 12 & 2.8 \\
\hline Pacific Islander & - & - & 1 & 0.2 \\
\hline Mixed & - & - & 13 & 3.0 \\
\hline Others & - & - & 1 & 0.2 \\
\hline \multicolumn{5}{|l|}{ Year in College } \\
\hline Freshman & - & - & 128 & 29.9 \\
\hline Sophomore & - & - & 195 & 45.6 \\
\hline Junior & - & - & 102 & 23.8 \\
\hline Senior & - & - & 3 & 0.7 \\
\hline \multicolumn{5}{|l|}{ Psychological Disorders } \\
\hline No & - & - & 376 & 85.7 \\
\hline Yes & - & - & 61 & 14.3 \\
\hline \multicolumn{5}{|l|}{ Family SUD } \\
\hline No & - & - & 274 & 64.0 \\
\hline Yes & - & - & 154 & 36.0 \\
\hline Parents & - & - & 58 & 13.6 \\
\hline Siblings & - & - & 14 & 3.3 \\
\hline Grandparents & - & - & 35 & 8.2 \\
\hline Other relatives & - & - & 32 & 7.5 \\
\hline Did not specified & - & - & 11 & 2.6 \\
\hline
\end{tabular}

Note. SES = Social Economic Status; SUD = Substance Use Disorder. 
Table 3

\begin{tabular}{lcc} 
Means, Standard Deviations, and Ranges of Main Study Variables & \\
\hline Variables & $M(S D)$ & Range \\
\hline Substance Use Outcomes & & \\
Number of Substances & $2.08(1.40)$ & $1.00-10.00$ \\
Frequency of Use & $3.50(2.96)$ & $0-15.00$ \\
Substance-related Problems & $1.78(3.28)$ & $0-25.00$ \\
Use in Positive Situations & $38.10(34.05)$ & $0-100.00$ \\
Use in Negative Situations & $12.59(18.44)$ & $0-100.00$ \\
ER Flexibility Predictors & & \\
Context Sensitivity for PA & $5.01(.94)$ & $1.00-6.00$ \\
Context Sensitivity for NA & $6.55(1.33)$ & $1.00-9.00$ \\
Repertoire for PA Regulation & $6.26(1.03)$ & $3.67-8.00$ \\
Repertoire for NA Regulation & $5.53(.76)$ & $2.89-7.00$ \\
Responsiveness to Feedback for PA & $3.03(.80)$ & $1.00-5.00$ \\
Responsiveness to Feedback for NA & $3.05(.80)$ & $1.00-5.00$ \\
Moderators & & \\
Positive Mood & $2.02(.67)$ & $0-3.77$ \\
Negative Mood & $1.46(.70)$ & $0-3.82$ \\
Positive Emotionality & $4.19(.81)$ & $1.06-6.47$ \\
Negative Emotionality & $3.80(.77)$ & $1.00-5.95$ \\
Positive Urgency & $2.10(.82)$ & $1.00-4.00$ \\
Negative Urgency & $2.36(.66)$ & $1.00-4.00$ \\
Other variables & & \\
Depressive Symptoms & $18.28(10.91)$ & $0-52.00$ \\
\hline Note. PA Positive Affect;NA Negative Affect. &
\end{tabular}

Note. $\mathrm{PA}=$ Positive Affect; NA = Negative Affect. 
Table 4

Bivariate Correlations among Demographic Characteristics and Substance Use Outcomes

\begin{tabular}{|c|c|c|c|c|c|c|c|c|c|c|c|c|}
\hline & 1 & 2 & 3 & 4 & 5 & 6 & 7 & 8 & 9 & 10 & 11 & 12 \\
\hline 1. Age & - & & & & & & & & & & & \\
\hline 2. Race (dichotomized) & .04 & - & & & & & & & & & & \\
\hline 3. Gender & $-.14 * *$ & -.08 & - & & & & & & & & & \\
\hline 4. Year in College & $.81 * * *$ & .003 & -.09 & - & & & & & & & & \\
\hline 5. Psychological Disorders & .01 & -.07 & $.11 *$ & .04 & - & & & & & & & \\
\hline 6. Family SUD & -.06 & -.07 & $.10^{*}$ & $-.11 *$ & .07 & - & & & & & & \\
\hline 7. Subjective SES & -.04 & -.06 & .02 & -.02 & .01 & $-.19 * *$ & - & & & & & \\
\hline 8. Depressive Symptoms & -.07 & .05 & -.01 & $-.11 *$ & $.21 * * *$ & .07 & $-.13 * *$ & - & & & & \\
\hline 9. Number of Substances & .09 & -.05 & $-.12 *$ & .06 & $.21 * * *$ & .05 & -.01 & .09 & - & & & \\
\hline 10. Frequency of Use & .04 & -.02 & $-.12 *$ & .04 & $.11^{*}$ & .03 & .04 & .06 & $.77 * * *$ & - & & \\
\hline 11.Substance-related Problems & .08 & .07 & $-.16 * *$ & .05 & $.15^{* *}$ & .01 & -.05 & $.14 * *$ & $.49 * * *$ & $.50 * * *$ & - & \\
\hline 12. Use in Positive Situations & .05 & -.05 & .03 & .08 & .08 & .06 & .04 & -.02 & $27 * * *$ & $.41 * * *$ & $.21 * * *$ & - \\
\hline 13. Use in Negative Situations & -.01 & .01 & -.05 & -.03 & .004 & .07 & -.09 & $.14 * *$ & $.35^{* * * *}$ & $.39 * * *$ & $.34 * * *$ & $.48 * * *$ \\
\hline
\end{tabular}

Note. ${ }^{*} p<.05 ;{ }^{*} p<.01 ; * * * p<.001$; Race: 1 = Caucasian, $2=$ Non-Caucasian; Gender: $1=$ Male, $2=$ Female; SUD = Substance Use

Disorder; SES = Social Economic Status. 
Table 5

Bivariate Correlations among ER Flexibility Predictors and Substance Use Outcomes

\begin{tabular}{|c|c|c|c|c|c|c|c|c|c|c|}
\hline & 1 & 2 & 3 & 4 & 5 & 6 & 7 & 8 & 9 & 10 \\
\hline 1. Context Sensitivity for PA & - & & & & & & & & & \\
\hline 2. Context Sensitivity for NA & $.25 * * *$ & - & & & & & & & & \\
\hline 3. Repertoire for PA Regulation & $-.10 *$ & -.04 & - & & & & & & & \\
\hline 4. Repertoire for NA Regulation & $-.14 * *$ & .02 & $.73 * * *$ & - & & & & & & \\
\hline 5. Responsiveness to Feedback for PA & -.03 & -.03 & -.003 & $.11^{*}$ & - & & & & & \\
\hline 6. Responsiveness to Feedback for NA & -.03 & -.04 & -.05 & .07 & $.66^{* * *}$ & - & & & & \\
\hline 7. Number of Substances & .003 & -.01 & .06 & .03 & -.004 & .002 & - & & & \\
\hline 8. Frequency of Use & -.003 & .05 & $.11 * *$ & .07 & -.07 & -.09 & $.76 * * *$ & - & & \\
\hline 9.Substance-related Problems & .01 & .04 & $.16^{* *}$ & $.11^{*}$ & .01 & .02 & $.49 * * *$ & $.50 * * *$ & - & \\
\hline 10. Use in Positive Situations & .05 & .06 & $-.11 *$ & -.09 & .07 & .07 & $27 * * *$ & $.41 * * *$ & $.21 * * *$ & - \\
\hline 11. Use in Negative Situations & .06 & .004 & .06 & .07 & -.01 & -.02 & $.35 * * *$ & $.39 * * *$ & $.34 * * *$ & $.48 * * *$ \\
\hline
\end{tabular}

Note. ${ }^{*} p<.05 ; *^{*} p<.01 ; * * * p<.001 ; \mathrm{PA}=$ Positive Affect; NA = Negative Affect. 
Table 6

Bivariate Correlations among Moderators and Substance Use Outcomes

\begin{tabular}{|c|c|c|c|c|c|c|c|c|c|c|}
\hline & 1 & 2 & 3 & 4 & 5 & 6 & 7 & 8 & 9 & 10 \\
\hline 1. Positive Mood & - & & & & & & & & & \\
\hline 2. Negative Mood & $-.15^{* *}$ & - & & & & & & & & \\
\hline 3. Positive Emotionality & $.35^{* * *}$ & -.09 & - & & & & & & & \\
\hline 4. Negative Emotionality & $-.17 * *$ & $.42 * * *$ & $.23 * * *$ & - & & & & & & \\
\hline 5. Positive Urgency & -.02 & .09 & $-.20 * * *$ & -.03 & - & & & & & \\
\hline 6. Negative Urgency & $-.14 * *$ & $.21 * * *$ & $-.15 * *$ & $.18^{* * *}$ & $.69 * * *$ & - & & & & \\
\hline 7. Number of Substances & .02 & .08 & .06 & .06 & $.11 *$ & $.13 * *$ & - & & & \\
\hline 8. Frequency of Use & .05 & .07 & $.11 *$ & .04 & $.14 * *$ & $.10 *$ & $.76^{* * * *}$ & - & & \\
\hline 9.Substance-related Problems & .01 & $.12 *$ & .01 & .08 & $.22 * * *$ & $.24 * * *$ & $.49 * * *$ & $.53 * * *$ & - & \\
\hline 10. Use in Positive Situations & .03 & -.02 & $.18 * *$ & $.12 *$ & .02 & .03 & $27 * * *$ & $.41 * * *$ & $.21 * * *$ & - \\
\hline 11. Use in Negative Situations & .05 & $.22 * * *$ & .04 & $.19 * * *$ & .06 & $.19 * *$ & $.35 * * *$ & $.39 * * *$ & $.34 * * *$ & $.48 * * *$ \\
\hline
\end{tabular}

Note. ${ }^{*} p<.05 ; * * p<.01 ; * * * p<.001$. 
Table 7

Bivariate Correlations among ER Flexibility Predictor and Moderators

\begin{tabular}{|c|c|c|c|c|c|c|c|c|c|c|c|}
\hline & 1 & 2 & 3 & 4 & 5 & 6 & 7 & 8 & 9 & 10 & 11 \\
\hline 1. Context Sensitivity for PA & - & & & & & & & & & & \\
\hline 2. Context Sensitivity for NA & $.25 * * *$ & - & & & & & & & & & \\
\hline 3. Repertoire for PA Regulation & $-.10 *$ & -.04 & - & & & & & & & & \\
\hline 4. Repertoire for NA Regulation & $-.14 * *$ & .02 & $.73 * * *$ & - & & & & & & & \\
\hline 5. Responsiveness to Feedback for PA & -.03 & -.03 & -.003 & $.11 *$ & - & & & & & & \\
\hline 6. Responsiveness to Feedback for NA & -.03 & -.04 & -.05 & .07 & $.66 * * *$ & - & & & & & \\
\hline 7. Positive Mood & .002 & $-.11 *$ & $-.12 *$ & .004 & $.27 * * *$ & $.26 * * *$ & - & & & & \\
\hline 8. Negative Mood & .03 & $.14 * *$ & $.37 * * *$ & $.25 * * *$ & $-.10 *$ & $-.10 *$ & $-.15^{* *}$ & - & & & \\
\hline 9. Positive Emotionality & .01 & .002 & $-.12 *$ & .001 & .06 & .07 & $.35 * * *$ & -.09 & - & & \\
\hline 10. Negative Emotionality & .01 & $.10^{*}$ & $.23 * * *$ & $.20 * * *$ & $-.11 *$ & $-.15^{* *}$ & $-.17 * *$ & $.42 * * *$ & $.23 * * *$ & - & \\
\hline 11. Positive Urgency & -.02 & -.08 & $.21 * * *$ & $.19 * * *$ & .02 & .01 & -.02 & .09 & $-.20 * * *$ & -.03 & - \\
\hline 12. Negative Urgency & -.002 & .01 & $.22 * * *$ & $.17 * * *$ & -.06 & -.05 & $-.14 * *$ & $.21 * * *$ & $-.15^{* *}$ & $.18 * * *$ & $.69 * * *$ \\
\hline
\end{tabular}

Note. ${ }^{*} p<.05 ; * * p<.01 ; * * * p<.001 ; \mathrm{PA}=$ Positive Affect; NA = Negative Affect. 


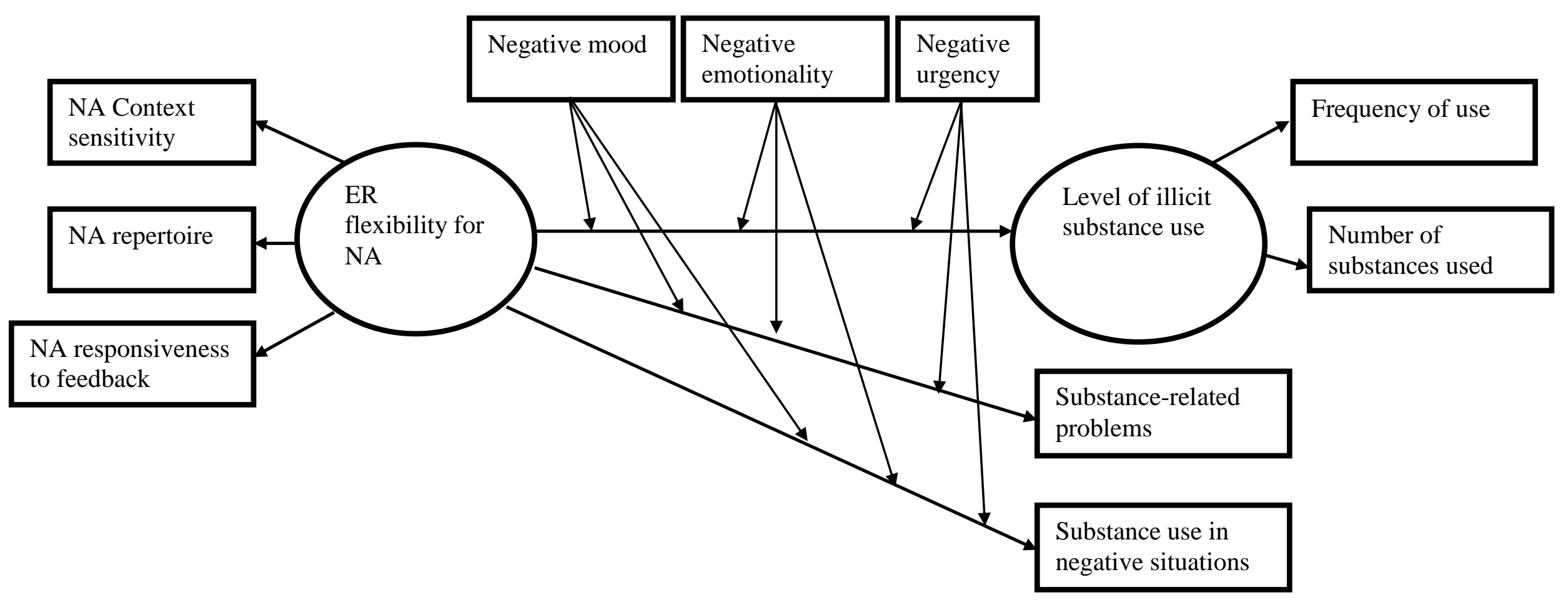

Figure 1. Conceptual model for negatively valenced emotion (NA) variables 


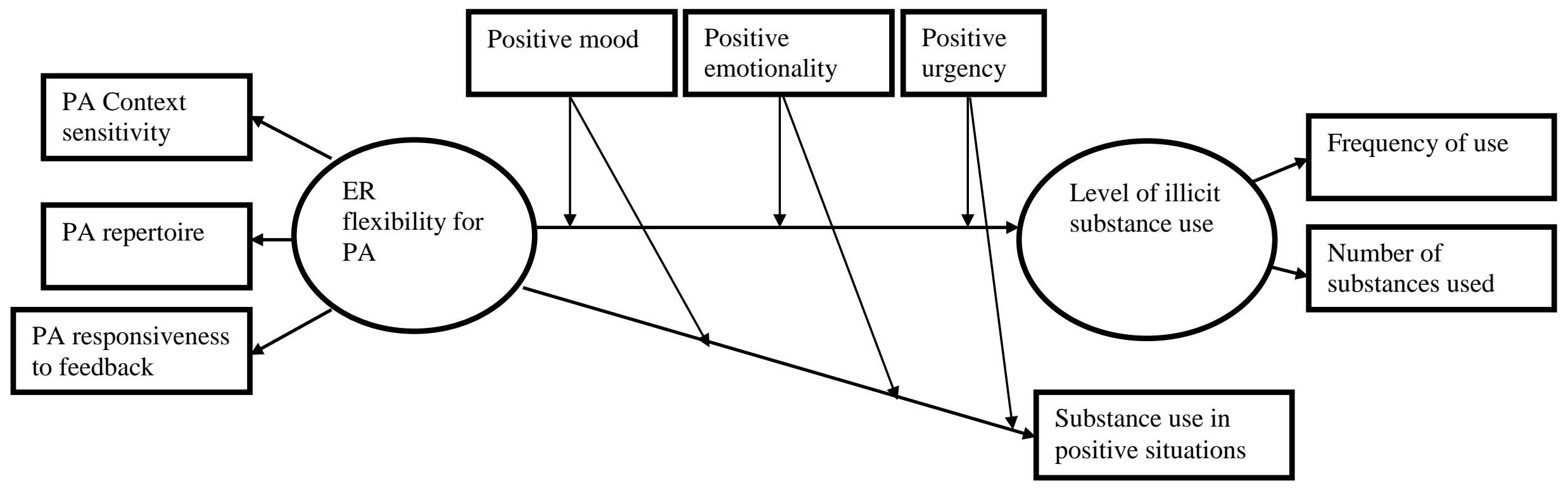

Figure 2. Conceptual model for positively valenced emotion (PA) variables 


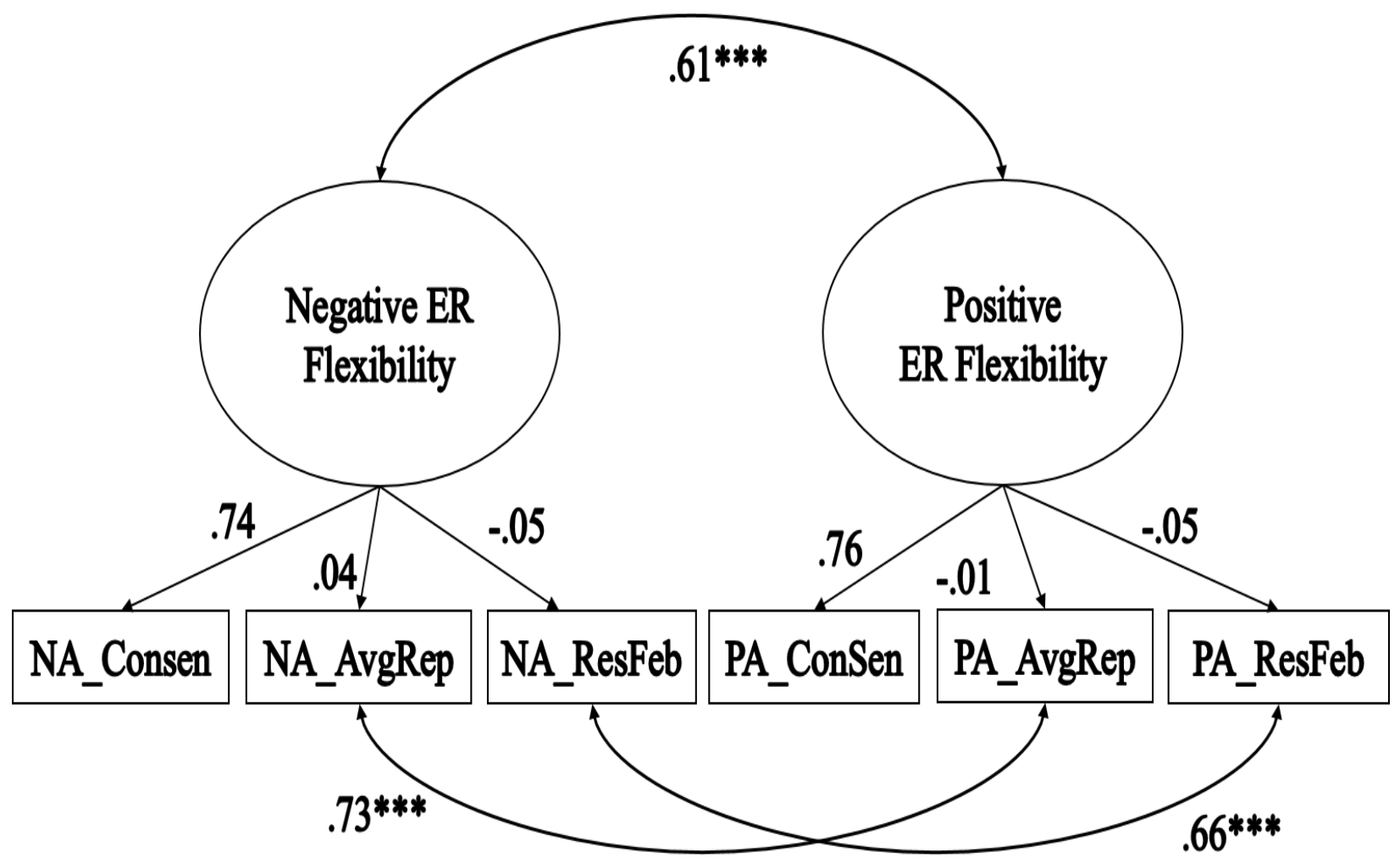

Figure 3. Full Measurement Model 


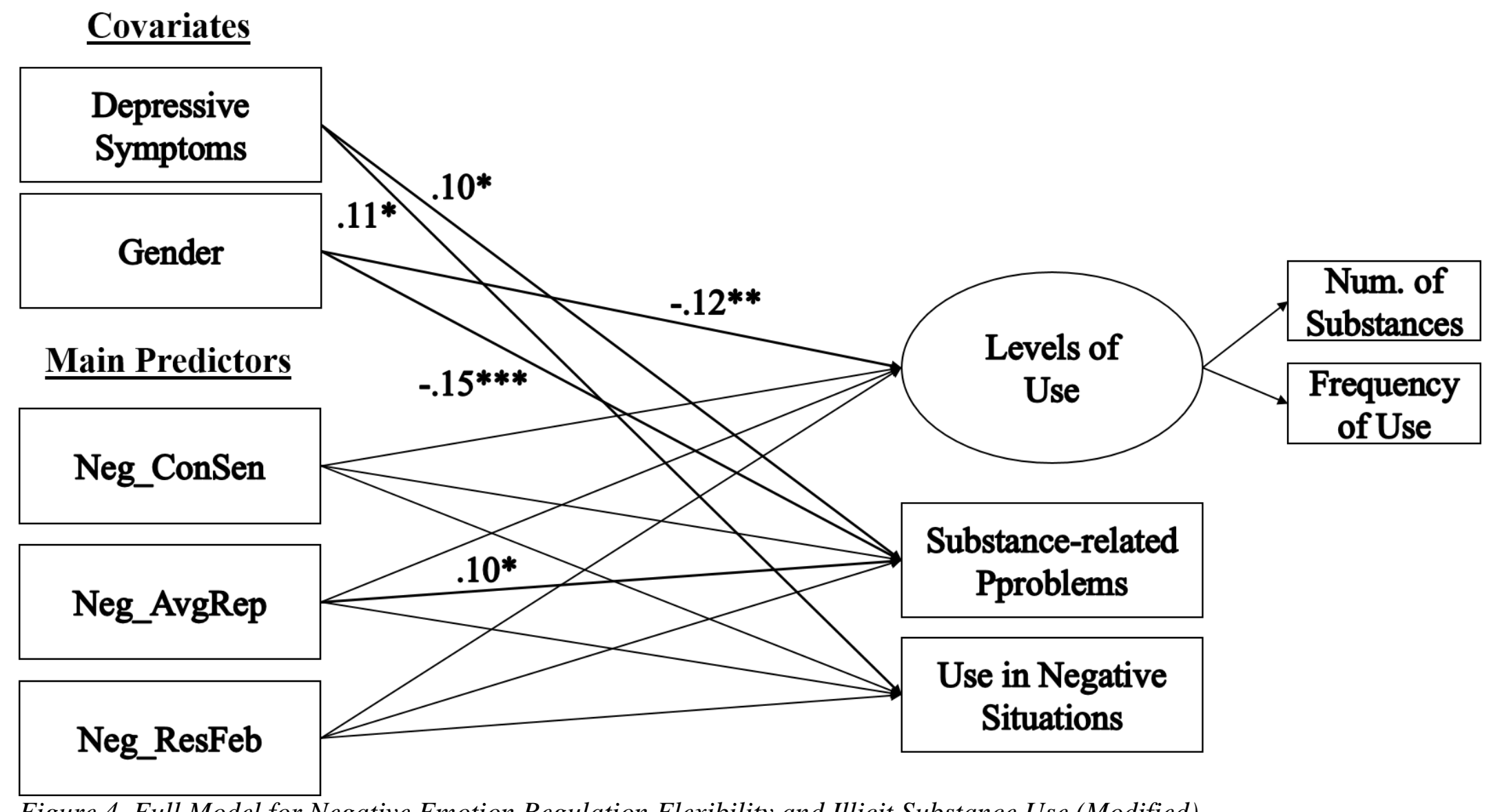

Figure 4. Full Model for Negative Emotion Regulation Flexibility and Illicit Substance Use (Modified) 


\section{$\underline{\text { Covariate }}$}

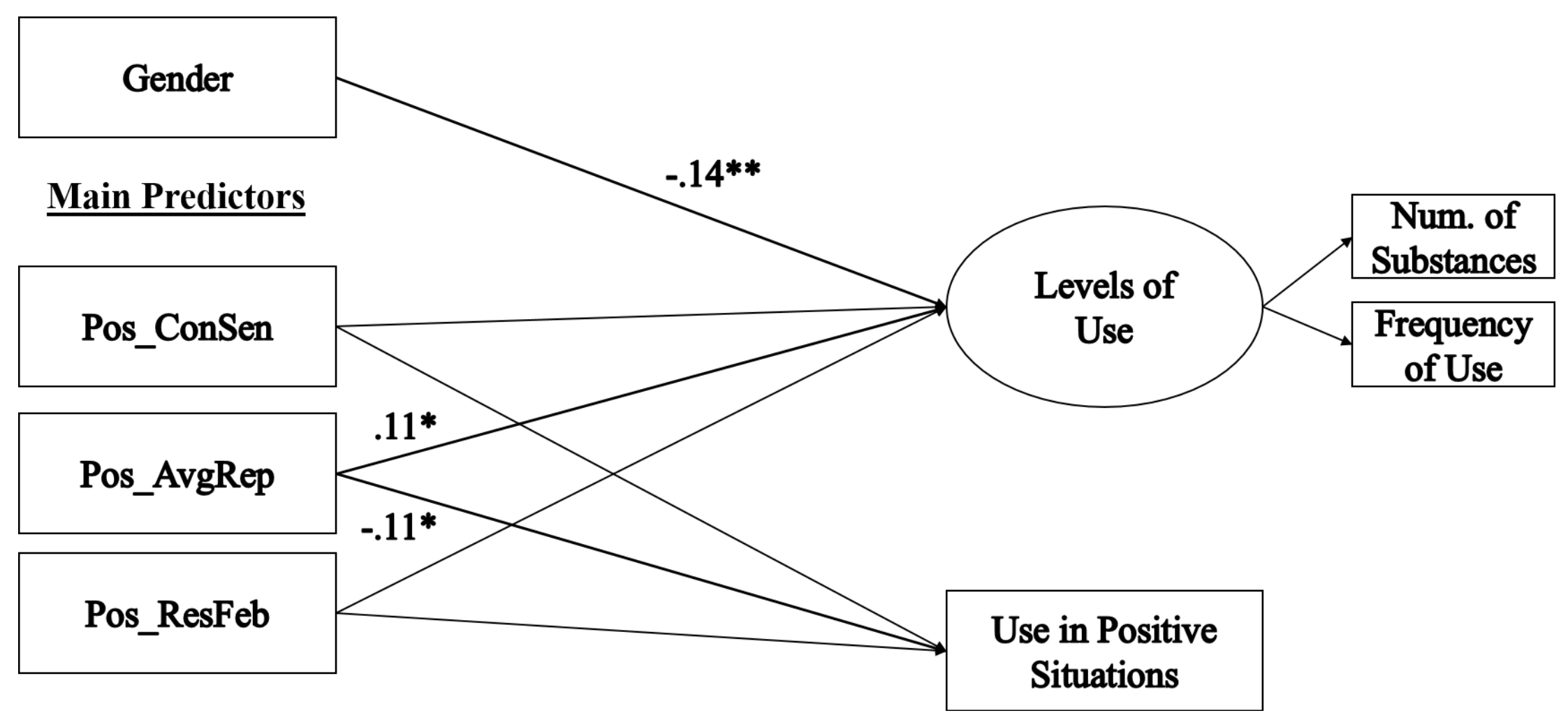

Figure 5. Full Model for Positive Emotion Regulation Flexibility and Illicit Substance Use (Modified) 


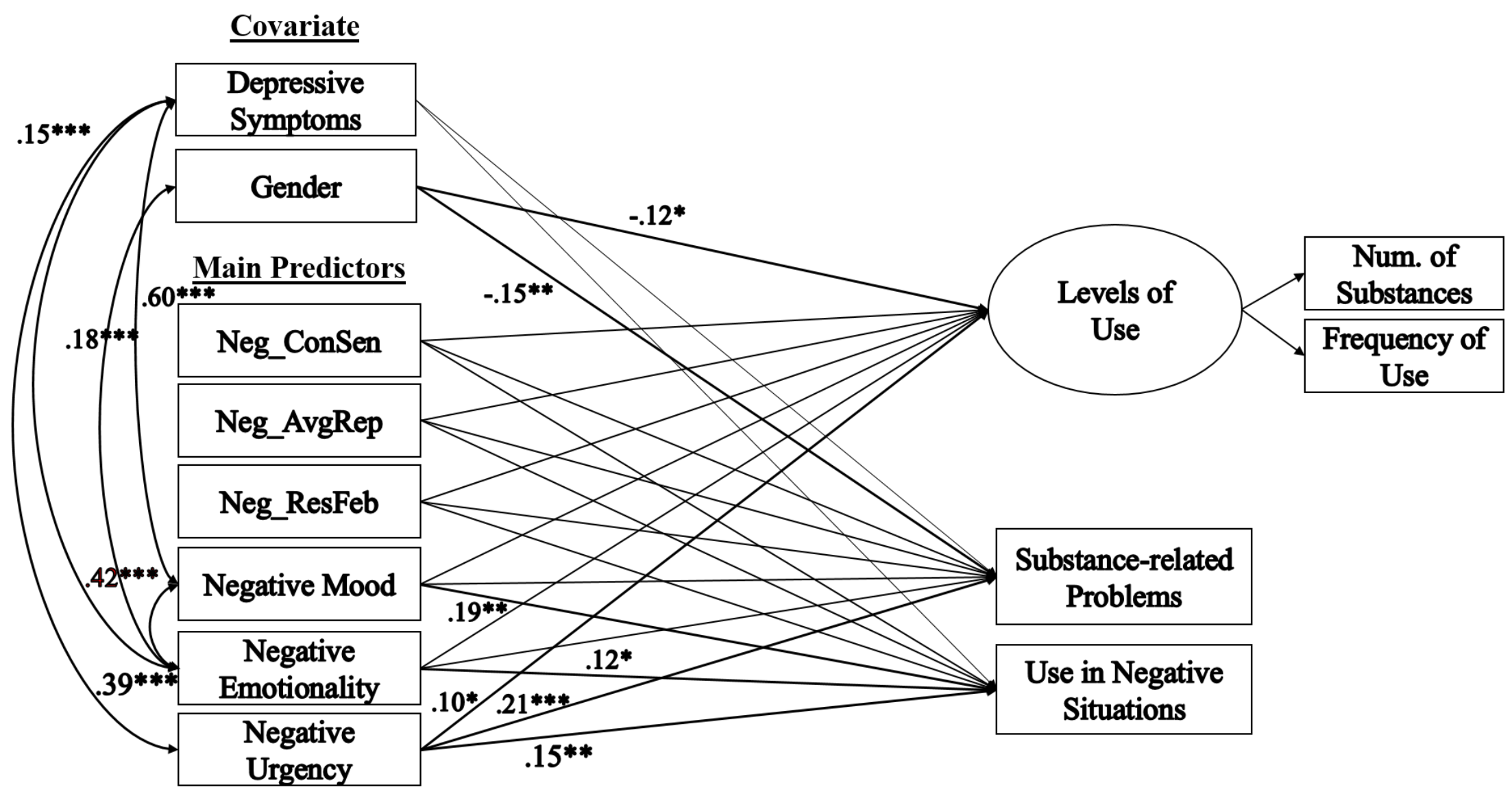

Figure 6. Additive Model for Negative Emotion Regulation Flexibility, the Three Negatively Valenced Moderators, and Illicit Substance Use (Modified) 


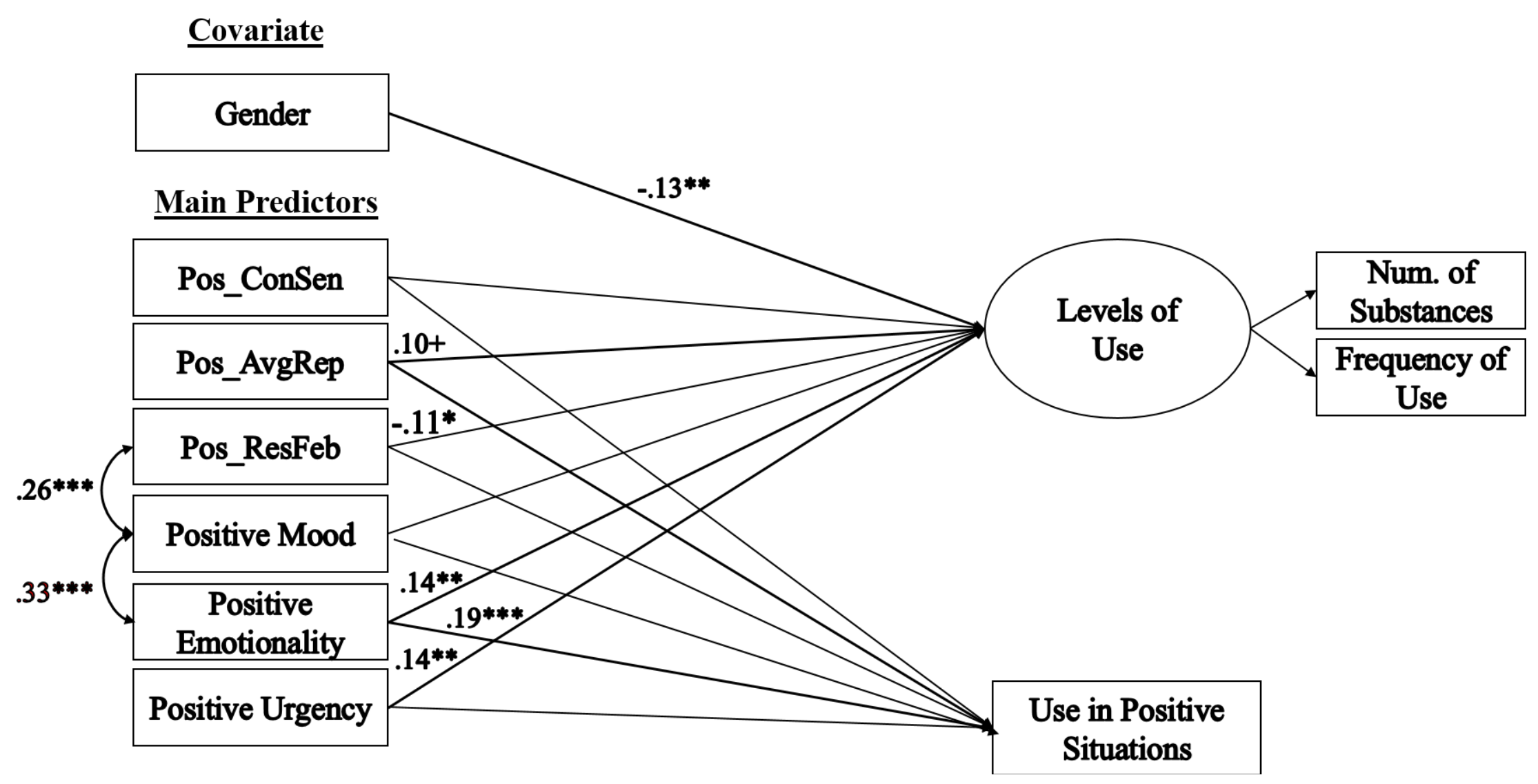

Figure 7. Additive Model for Positive Emotion Regulation Flexibility, the Three Positively Valenced Moderators, and Illicit Substance Use (Modified) 


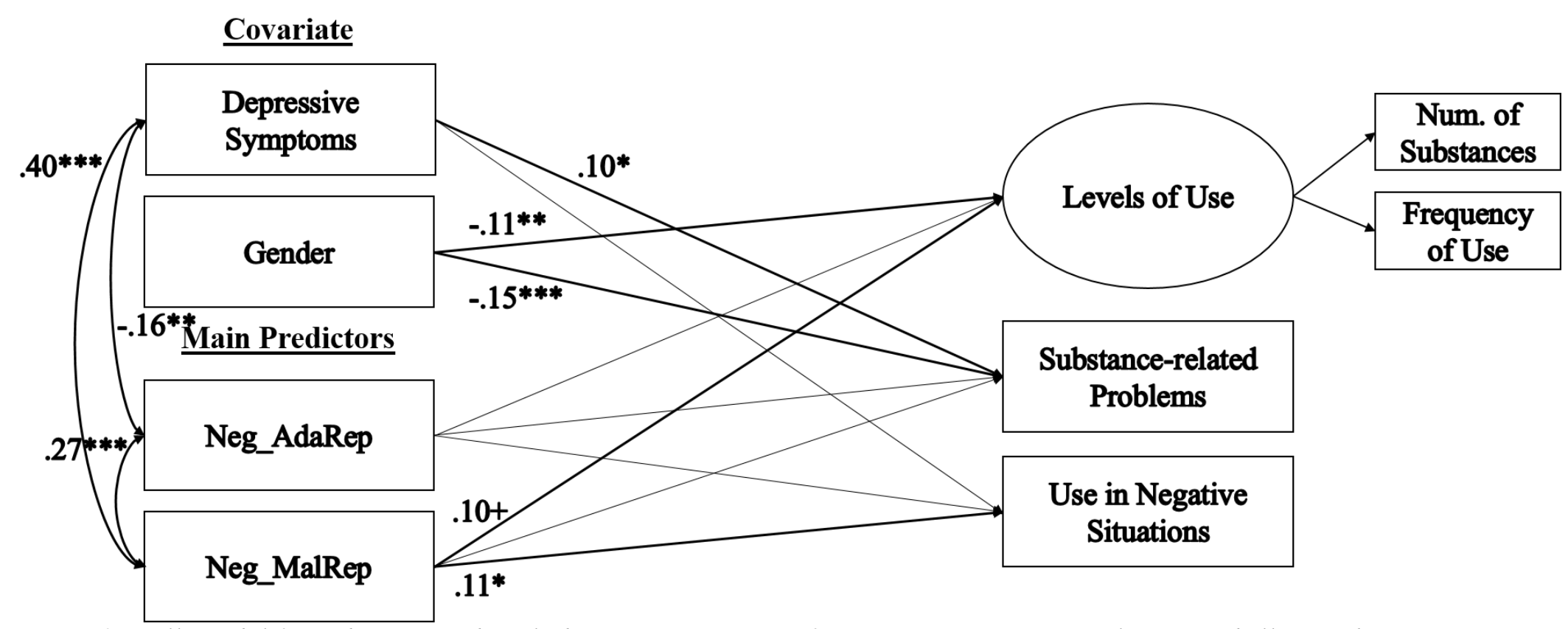

Figure 8. Full Model for Adaptive and Maladaptive Repertoire of Negative Emotion Regulation and Illicit Substance Use 
Covariate

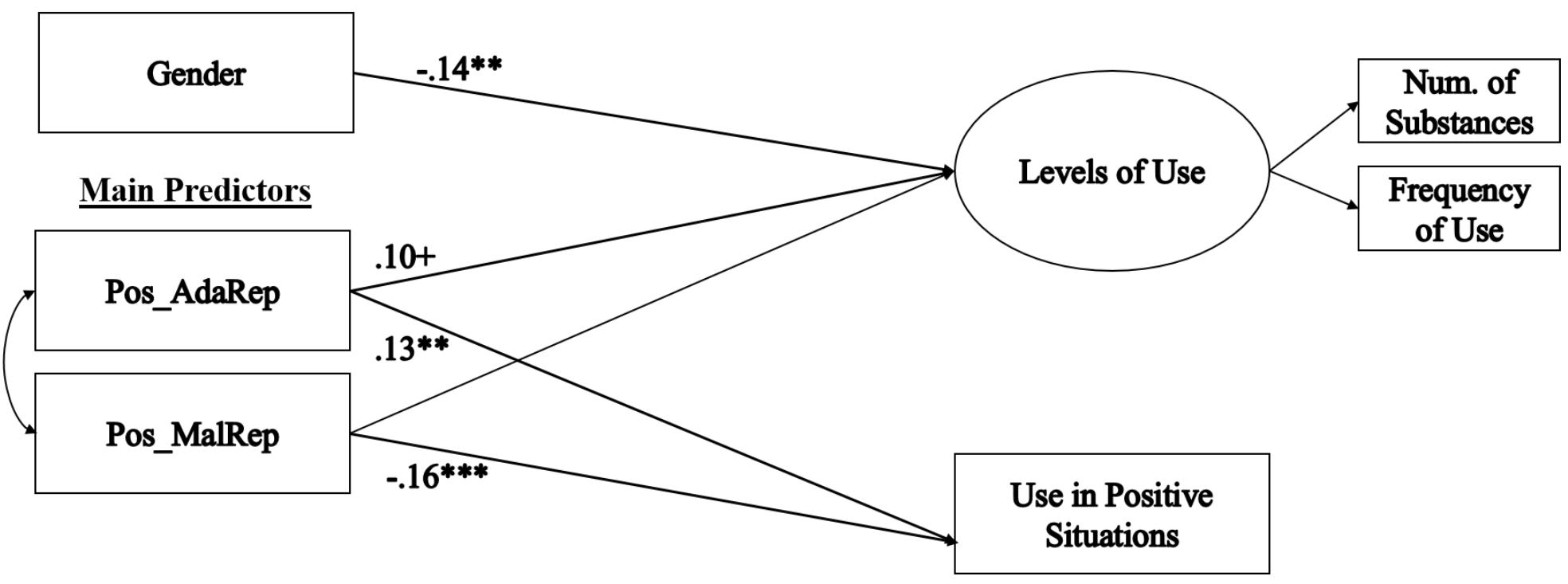

Figure 9. Full Model for Adaptive and Maladaptive Repertoire of Positive Emotion Regulation and Illicit Substance Use 


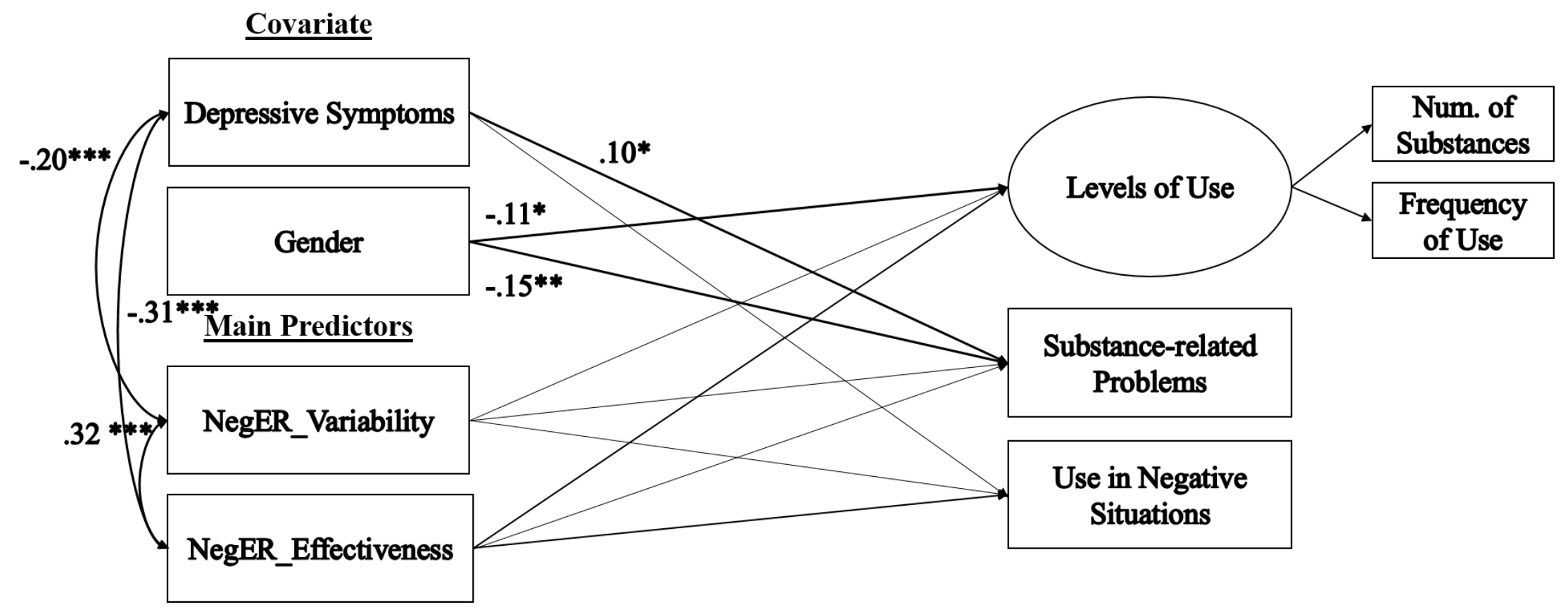

Figure 10. Full Model for New Indices of Negative Emotion Regulation Flexibility and Illicit Substance Use 


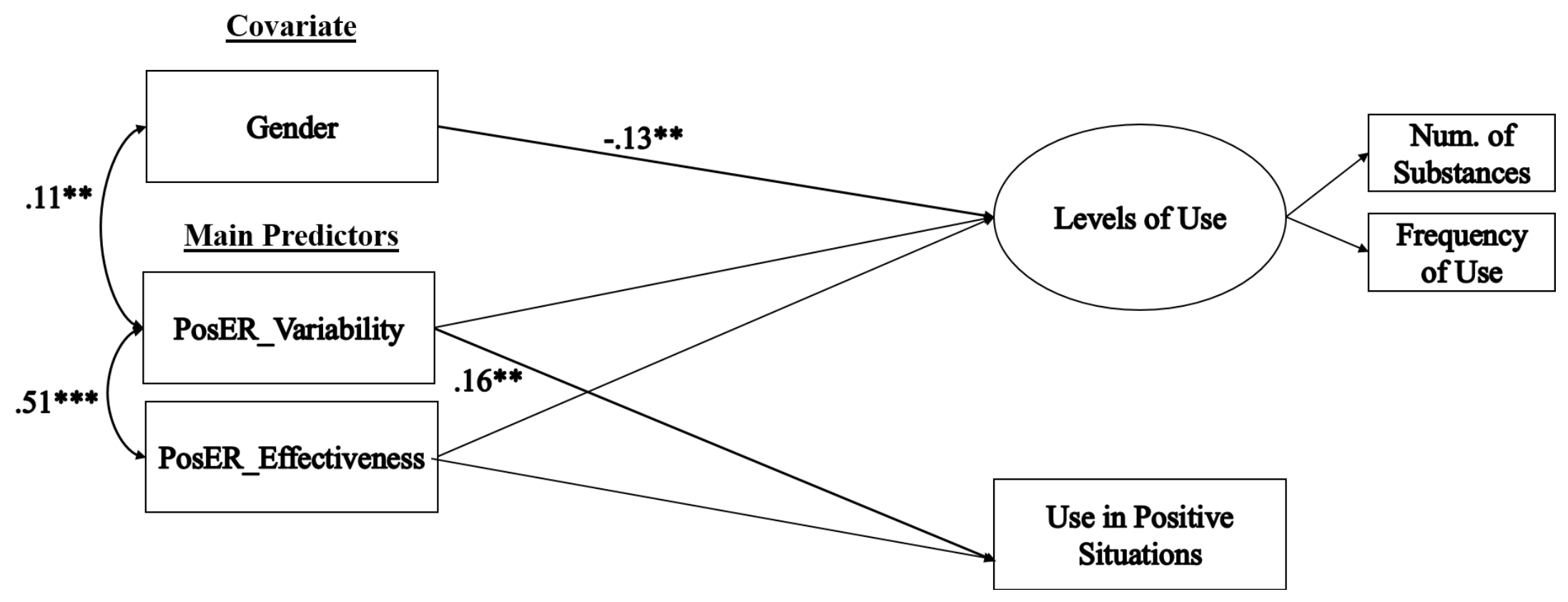

Figure 11. Full Model for New Indices of Positive Emotion Regulation Flexibility and Illicit Substance Use 
Appendix A: Demographic Questionnaire

1. Age:

2. Date of birth (MM/DD/YY):

3. Gender

$\square$ Male

$\square$ Female

4. Race/Ethnicity:

口 Caucasian

$\square$ African America

$\square$ Hispanic

$\square$ Asian

- Pacific Islander

$\square$ Other (Please specify)

5. Year in college (e.g., freshman, sophomore):

6. Have you been diagnosed or are currently diagnosed with any psychological disorder (e.g. Attention-deficit hyperactivity disorder, depression, etc.)?

Y Yes (Please specify)

$\square$ No

7. Do any of your family members have a history of addiction or substance abuse disorder (i.e., showing a strong craving for any substances, a need for increasing amounts of substances to feel the drug effects, physical illness when consumption is stopped, inability to limit consumption despite adverse consequences)?

$\square$ Yes (Please specify the family member)

$\square$ No

8. Imagine that this ladder shows how your society is set up.

- At the top of the ladder are the people who are the best off - they have the most money, the highest amount of schooling, and the jobs that bring the most respect.

- At the bottom are people who are the worst off - they have the least money, little or no education, no jobs or jobs that no one wants or respects.

Now think about your family. Please tell us where you think your family would be on this ladder. Place an ' $X^{\prime}$ on the rung that best represents where your family would be on this ladder.

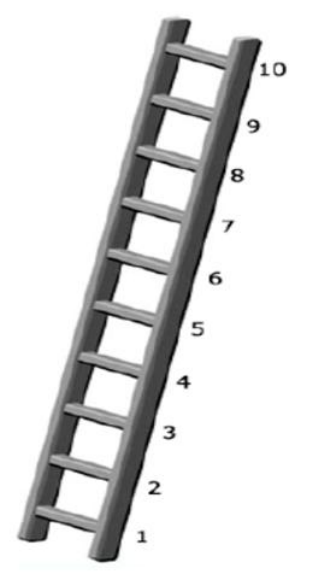


Appendix B: Emotion Regulation Profile - Revised

For each scenario, please indicate the extent to which you engage in each chosen reaction(s) and the effectiveness ofthe reaction(s) usually the following scales:

To what extent would you do this in the situation described above?

$0=$ Not at all

$1=$ A little

$2=$ Somewhat

$3=\mathrm{A}$ lot

How effective is it in managing your emotions in the described situation?

$0=$ Extremely ineffective

$1=$ Ineffective

$2=$ Somewhat ineffective

$3=$ Somewhat effective

$4=$ Effective

$5=$ Extremely effective 


\section{You've been driving around for more than $\mathbf{3 0}$ minutes looking for a parking space. When you finally find a free parking space, the driver of another car overtakes you and takes your place from right under your nose. Obviously that makes you angry!}

From the following options, please mark in the response sheet the reaction(s) that most accurately reflect your reaction(s) to this type of situation.

a) You don't say a word but seethe inside.

b) You say to yourself that it's not that serious after all. You're trying to look for the positive angle, e.g. maybe you'll find a parking space closer to where you have to go.

c) You express your annoyance by repeatedly sounding your horn at the driver.

d) In this kind of situation, there is nothing like having a drink, a joint or any other relaxing substance to help you calm down.

e) You try to forget the incident by turning on your radio or by thinking positive thoughts to clear your mind.

f) You have always had difficulties in asserting yourself and you don't see what you could have done. You feel discouraged.

g) You open your window and politely remark to the driver that their behavior is out of order. If they don't give you the space you'll leave without making a big deal of it. It's not worth the trouble!

h) You decide not to get mad about a parking space and drive into the first paying car park. 


\section{You just finished an important but particularly boring task that you kept postponing (e.g. repainting, spring-cleaning, a good deed, etc.). You feel satisfied and relieved about it. You're pleased with yourself.}

From the following options, please mark in the response sheet the reaction(s) that most accurately reflect your reaction(s) to this type of situation.

a) You don't manage to fully relax. Pretty soon, worries and/or uncompleted tasks fill your mind.

b) You tell or show your friends or relatives what you achieved today.

c) You sigh with relief and you grant yourself a relaxing moment.

d) You're quite satisfied but you can't help noticing the few negative details of your work (e.g. time spent on the task, small imperfections, finishing touches, etc.).

e) You savour the present moment. You contemplate your work and think about what a good job you have done.

f) You think that getting this work done was some kind of miracle. You usually don't manage to finish tasks that bore you and you think that you won't be able to do it again for a while.

g) You think back on the hours spent on the job. Thanks to your patience and perseverance you've reached your goal. Efforts are always rewarded!

h) You don't give yourself the time to rest and you undertake another task right away. 


\section{A close friend has asked you to do them a very big favour. They want you to deliver some documents to a future employer whilst they are abroad.Your friend calls you in a rage upon their return because the employer never received the documents and as a result they weren't hired. You had completely forgotten to do as you had promised! Your friend is terribly upset with you and you feel extremely guilty.}

From the following options, please mark in the response sheet the reaction(s) that most accurately reflect your reaction(s) to this type of situation.

a) You feel the need to talk to your close friends or relatives about what has happened and how guilty you feel.

b) You make lots of excuses and you go out of your way to find your friend another job. In the following weeks you go to extremes to make up for your unforgivable error: lots of invitations to restaurants, various gifts and thoughtfulness, etc.

c) You understand and accept that your friend is angry with you. It was a human error and your friend might have forgotten to do it as well. In any case, in the future, you will be more careful.

d) In order not to let your guilt eat away at you, you embark on a pleasurable activity.

e) You don't stop thinking about it and you blame yourself terribly.

f) You ask your friend how you can make it up to them and offer to help them find a new job.

g) You tell yourself that you're not much of a friend because you're not even able to do this simple favour. You don't know what you could do to make for it and it makes you feel depressed.

h) In order to alleviate your guilt, you relax through the use of various substances (e.g. alcohol, marijuana, medication, etc.). 


\section{The week before you are due to move in with your partner they decide to break up with you and end the relationship. This makes you very sad.}

From the following options, please markin the response sheet the reaction(s) that most accurately reflect your reaction(s) to this type of situation.

a) The break up causes you a great deal of pain and you are broken-hearted. You see yourself as unlucky in love and feel helpless about it!

b) You take time to look after yourself and do things you enjoy doing.

c) You try to feel better through the use of various substances (e.g., food, alcohol, marijuana, medication).

d) You confide in a close friend; you need to speak to someone about how you feel.

e) You try to pull yourself together in order to get back on your feet (e.g. joining a sports club, Internet dating service, parties, etc.). You spend time clarifying your priorities to make sure that the next partner will be "the one".

f) You look at old photos and listen to sad songs.

g) You try to see the positive side of things. This break-up, however difficult, is an opportunity to make a new start and to do the things you did not have the time to do before and, eventually to meet someone better suited to you.

h) Although there is absolutely no chance that your partner will change their mind, you keep trying to get back together with them any way you can. 
5. You have taken part in the latest draw of the national lottery, because there was a major jackpot was at stake. You are at a friend's house and you ask them if you can watch the results of the draw on $\mathrm{TV}$, even though you are not very optimistic about the result. Excitement starts to rise when you notice, with amazement, that 4 out of 6 of your numbers have been drawn! You have won about US\$1500.

From the following options, please mark in the response sheet the reaction(s) that most accurately reflect your reaction(s) to this type of situation

a) You jump for joy; you express your excitement by repeatedly saying how lucky you are.

b) During the next few days, you consider what you are going to do with this money. You think about spending 10 days in a sunny place for your next holiday, going to an expensive restaurant, treating yourself to a day at a spa, etc.

c) You cannot fully enjoy the situation because other things come to your mind (e.g., problems with a relative, atmosphere at work).

d) You share your joy with your friends, you show them the winning ticket, and you call your family to announce the news.

e) You try not to show your emotions; you keep it to yourself because it looks bad to get carried away in front of people. Besides, you don't want your friends to be jealous of you.

f) You feel happy and you celebrate with champagne (for example). It's not every day you win almost a month's salary without doing anything!

g) You think that what you won is ok. However, you can't help thinking that you were so close to winning the major prize! You may also think that this money will not solve your personal problems and that you will be obliged to treat your friends to a nice outing; which would stop you from enjoying all of your win yourself.

h) You think it's too good to be true. Today's luck cannot last forever. You already start to anticipate possible problems in the future. 
6. You have gone with your partner to a party, which they were reluctant to attend. During the evening you notice, from a distance, that your partner is talking to someone of the opposite sex. Each of them seems very interested in what the other is saying: they are looking at each other intensely and laugh together several times. Given that your partner only came to the party reluctantly and that they have now become animated and enthusiastic, you start to feel very jealous!

From the following options, please markin the response sheet the reaction(s) that most accurately reflect your reaction(s) to this type of situation.

a) You watch them out of the corner of your eye. The situation makes you feel uncomfortable but you don't let it show.

b) Instead of getting annoyed/angry, you decide to think about other things and to enjoy the party (e.g., you start talking to people, you go for a dance, etc.).

c) You express your jealousy to your partner without losing your temper. You tell them that you feel uncomfortable when they have quite so much fun with someone else.

d) You're engulfed by a wave of anger and as soon as you get the opportunity, you get angry with your partner.

e) In order to forget what you're seeing and to calm down, you go straight to the bar and spend the rest of the evening drinking.

f) You consider the different options for coping with this problem. You plan the strategy you're going to use to make sure this situation doesn't happen again.

g) You feel sad and abandoned. You think that your partner will eventually find someone more interesting and more desirable than you. What can you do anyway?

h) Despite your jealousy, you consider it important that your partner enjoys themselves and especially when they are not doing anything wrong. By giving your partner some space, they will be in a good mood when you both get home! 
7. You spend a romantic weekend with your partner. The setting is wonderful. Your partner is on great form and you feel particularly happy!

From the following options, please mark in the response sheet the reaction(s) that most accurately reflect your reaction(s) to this type of situation

a) Despite the weekend being very pleasant, you cannot help resenting the few negative details that prevent your break from being perfect.

b) You try to enjoy the moment fully and put everything else out of your mind.

c) The weekend is perfect. It's too good to be true. You dread it all coming crashing down when you get home.

d) You have a great time and are not afraid to express your joy by laughing, joking, hugging your partner, etc.

e) Once on your own after the weekend, you reminisce of the happy time together, and of the things that make your relationship so precious.

f) You are having a good time, but for various reasons (e.g. fear of making a fool of yourself, it's not your style, guilt, etc.) you try not to get too carried away by your emotions, and therefore try to contain your happiness.

g) Over the following few days you share the memory of this good time with your family (or write it up in your diary).

h) The weekend is perfect. However, you struggle to completely forget your personal concerns (e.g. work, family, etc.). 


\section{You have to give a presentation to a large audience. You have done this exercise previously and it did not go very well. You received a great deal of criticism about your presentation. The very idea of making another presentation in public in a few days' time terrifies you.}

From the following options, please markin the response sheet the reaction(s) that most accurately reflect your reaction(s) to this type of situation.

a) You try to distract yourself by embarking on an activity you enjoy. You have done all the preparation for your presentation and you'll see how things go when you come to doing it.

b) You can't stop thinking about it, you focus on what might go wrong and you stress right up until the delivery of the presentation.

c) You confide in the people around you, telling them of your fears and seeking their support and/or advice.

d) You draw up a plan of action so that you have every chance of things being a success. You identify the problem and envisage the various solutions that will enable you to feel surer of yourself (rehearsal, relaxation, information about ways of improving your presentation).

e) You tell yourself that you'll never be able to deliver a good presentation and you feel like a loser.

f) On the days leading up to the presentation, you use some relaxing substances (e.g. alcohol, marijuana, medication, etc.) to help reduce your anxiety.

g) You try to see the positive side of the situation: this is good practice for you and even if things go wrong, it's not the end of the world!

h) Since you have been told about doing the presentation, you have been overwhelmed by stress. It's paralysing you and stopping you from working on your presentation. If it were possible, you would find an "excellent reason" to prevent you from giving the presentation. 


\section{During the last day of your holiday abroad, you go out for a walk with friends. After a few hours walking, you come across a waterfall entirely by chance. The scenery is magnificent and wild: water, greenery in abundance, sunset, sounds, etc. You are completely dazzled by the splendour of the landscape.}

From the following options, please mark in the response sheet the reaction(s) that most accurately reflect your reaction(s) to this type of situation.

a) The scenery is idyllic; although it's a pity that your feet are hurting, that it's a little bit chilly, or that there are mosquitoes. These petty drawbacks prevent you from fully enjoying the circumstances.

b) You express your delight and admiration in your own way (e.g. you express your ecstasy, you shout out loud, you shed a tear, you jump into the waterfall, etc.).

c) The scene is magnificent, but you contain your emotions. You'd rather show selfcontrol in public.

d) During the next few days, you enjoy thinking back on the splendour of the place and/or looking at your photos again.

e) You share your emotion with your companions. Over the next few days, you recommend this place to everyone around you.

f) The fun is spoiled by the thought that it is the last day of your holiday, and that it will be a long time before such a moment happens again.

g) You allow all your senses to be imbued by the place so that you can fully enjoy this moment.

h) The setting is gorgeous, but on the way back home you still think about the evening meal to prepare and/or the prospect of going back to work tomorrow. 
10. You have to present a major project into which you have put a great deal of work. On the morning of D Day, you are told that your presentation has been postponed and that a rival will present their project instead. This piece of news makes you particularly angry.

From the following options, please markin the response sheet the reaction(s) that most accurately reflect your reaction(s) to this type of situation.

a) You go directly to your co-worker's office and express your anger and come straight out again very annoyed.

b) You deliberately launch yourself into an activity that has nothing to do with the situation so that you can cool down. That way you won't do anything rash.

c) You look at the situation as a problem needing a solution. You draw up a plan of action that will enable your work to be recognised and/or to prevent it happening again.

d) You say nothing; you sometimes have problems in asserting yourself in this type of situation. It all makes you feel very weary.

e) You mull things over: why is your co-worker capable of being so opportunistic and spiteful towards you? Without actually taking any action, you imagine ways of taking your revenge on them.

f) You defuse the situation and/or try to learn something from it. Next time it'll be your turn!

g) When you get home, you consume various substances (alcohol, marijuana, medication, etc.) to relieve the stress.

h) You ask your co-worker to explain their actions. You tell them politely but firmly that you are unhappy about it, and then you allow them to tell you their point of view. 
11. As the result of restructuring in your company, you are transferred to a new department $10 \mathrm{~km}$ from where you used to work. This upsets you, because over the course of time, you had built up a really close relationship with your co-workers and some of them had even become good friends.

From the following options, please mark in the response sheet the reaction(s) that most accurately reflect your reaction(s) to this type of situation.

a) Your sadness turns into resentment against your company, and even against your former co-workers because they have been luckier than you. Your bad mood is noticeable.

b) You need time to forget your old job. But you think about it often.

c) You force yourself to look directly on the positive side of things (e.g. new people to meet, new career prospects, etc.).

d) You try to find comfort in drinking, smoking, taking medication, even drugs.

e) You tell the people around you about how sad you are and seek comfort from your friends.

f) You try to find a solution to the problem. If it is impossible to get your old job back, you take positive action (e.g. conversations, invitations to dinner, etc.) to improve and make the most of your new work situation.

g) You immediately try to resume doing things you enjoy, things that give you brief moments of pleasure.

h) Out of all the people in your team, it had to happen to you (again!). You feel unmotivated and can't find the energy to respond. 
12. After months of relentless work, you have at last obtained the diploma or promotion you were dreaming about. It wasn't easy and you have done really well to have got this far - you are very proud of yourself. Relatives and friends have organised a party in your honour.

From the following options, please mark in the response sheet the reaction(s) that most accurately reflect your reaction(s) to this type of situation.

a) During the party you cannot prevent other thoughts from coming into your mind (e.g. dread regarding your new status, personal concerns, etc.).

b) Over the next few days, you frequently think back on your success, the efforts and personal merit you have demonstrated, the pride of certain of your relatives, your prospects for the future, etc.

c) Even though everybody is congratulating you, you don't think that you deserve it. It was probably a stroke of luck and may not happen again.

d) You are proud of yourself and allow yourself to show it (e.g. shouts/tears of joy, gestures of victory, etc.).

e) In spite of the pleasure of having been successful, a part of you can't help thinking that you could have done better.

f) It is your hour of glory and you enjoy it fully. You have worked hard, and you do deserve this praise.

g) You are proud of yourself but for various reasons (e.g. fear of making a fool of yourself, modesty, reserve, etc.) you hold back from expressing your pride and fully celebrating your success.

h) During the next few days you tell everyone around the good news and share your success with your family and friends. 


\section{You happen to meet an old classmate whom you haven't seen for a long time. They invite you to pay them a visit the following week. You find they live in a magnificent apartment, while you are struggling in a tiny place. You feel jealous.}

From the following options, please mark in the response sheet the reaction(s) that most accurately reflect your reaction(s) to this type of situation.

a) You think you are really unlucky and feel depressed about it. You say to yourself that no matter what you do, you'll never make it to this standard of living.

b) To overcome your jealousy, you do something that you enjoy and/or that makes you feel better about yourself.

c) Once you get home, you mull over your situation. You feel the gap between their life and yours is unfair.

d) You're going to do everything you can to get a place like that. You draw up a plan of action and stick to it.

e) Once you get home, you seek comfort from your partner or a friend. You tell them what you have experienced and what you feel about it.

f) You are unable to stop your jealously from showing. During the conversation, your jealousy prompts you to throw out a few barbed comments.

g) To get over your jealousy and the stress it has caused, you allow yourself to consume a few relaxing products (alcohol, marijuana, medication, etc.).

h) You were pleased to see your old friend again. Even though your apartment is not as luxurious, you are happy for them. You are also sure that one day you too will be able to have a lovely place of your own. In the meantime, you tell yourself that there are other sources of happiness in your life that are just as important. 
14. Today you are taking part in a morning of presentations going through the results of your company. There are a number of you due to present on stage in front of the projection screen. You hate this type of situation. You feel that all of your colleagues are better, more interesting and more at ease than you are. After your presentation, you return to sit down in the audience. Just in front of you, two of your colleagues who didn't see you sit down, whisper to one another, "just as well Eric is a good presenter, it makes up for the one before (i.e. yours)." to which the other person agrees, smiling. You feel yourself blushing with shame.

From the following options, please markin the response sheet the reaction(s) that most accurately reflect your reaction(s) to this type of situation.

a) To ensure this never happens again, you draw up a plan of action to follow for your next presentation. You plan stages to get you to the point of making a good presentation (content, attitude, posture, etc.).

b) You go away saying nothing. You feel a loser. Unfortunately, there's nothing you can do to change the situation, giving presentations is simply not your "thing".

c) You sit there behind them, without saying a word. You mull over what you have just heard. On the one hand, you think they may be right. But on the other, you're really angry at them. You replay the scene repeatedly in your head, wondering how you can put them in their place, how you can regain your honour, etc.

d) You confide in a close friend and explain just how ashamed you are to have made a fool of yourself in from of all your colleagues.

e) In the days that follow, you try to avoid your co-workers.

f) To get rid of this feeling of shame, you use substances to help you unwind (alcohol, marijuana, medication, etc.).

g) Following on from this rather unpleasant moment, you feel you want to forget about it and so you do something you enjoy.

h) It's true that your presentation was not a total success. Nevertheless, you try to see the positive side of things. For you it was something new, you learnt something from it and will make sure you are better at it next time. 
15. A friend of yours has just won a fantastic trip for two people to a paradise island. They ask you if you would like to go with them. You actually need a holiday, and you are extremely grateful.

From the following options, please mark in the response sheet the reaction(s) that most accurately reflect your reaction(s) to this type of situation.

a) Even though you are pleased with this offer, your current preoccupations (e.g. personal or job-related concerns, stress, etc.) prevent you from taking advantage of it right now.

b) You allow yourself to show your gratitude and affection (e.g. thanks, hugs, invitation to a restaurant, etc.).

c) Even before you leave, you are already dreading coming back to reality. This week away will soon be gone, and you will certainly not have such a good holiday again for ages.

d) You fully enjoy the offer.

e) You are very grateful to your friend. However, over the next few days, you can't help thinking of certain negative features that prevent you from being entirely happy (e.g. this is not really the place you would have chosen, the dates oblige you to reorganise your schedule, you will have to pay your friend back, etc.).

f) You think how lucky you are to have such a good friend, and you realise that this offer strengthens your friendship. You start to anticipate the pleasant things you will be able to do during this trip.

g) You tell your friends and family about the trip, and you praise the generosity of your friend.

h) You wish you could fully express your gratitude, but various reasons (e.g. embarrassment, fear of making a fool of yourself, shyness, etc.) prevent you from being demonstrative. 
16. After routine medical tests, your doctor tells you that you need to have an operation. Your health is not in direct danger, but if you do nothing, the situation could worsen in the near future. Even though your doctor is confident about the operation, it is quite a serious one and you are frightened by it.

From the following options, please mark in the response sheet the reaction(s) that most accurately reflect your reaction(s) to this type of situation.

a) You feel the need to talk about this operation with friends and family or with people who have already undergone the same sort of surgery.

b) You cancel the operation. You'd prefer not to be operated on for the time being; you've lived like that for years, so why have an operation now?

c) The prospect of an operation depresses you, and you are afraid of what might happen. You feel as though fate has dealt you a bad hand and there is nothing you can do about it.

d) You try to put things in perspective by telling yourself that people have operations every day and the risk of anything going wrong is really small. You also remind yourself of the major benefits for your health.

e) You can't help thinking about the operation and imagine everything that could go wrong.

f) You try to stop thinking about it until the day of the operation. As soon as the fear returns, you try to think of something else by launching yourself into activities to take your mind off it.

g) You use substances (e.g. alcohol, medication, drugs, etc.) to help you relax, as well as reduce your stress and fear levels.

h) You look at the problem logically and envisage the various solutions. Having an operation is the best solution. You set milestones to achieve before and after the operation, so that everything goes well. 


\section{Appendix C: Adapted Emotion Regulation Flexibility Scale}

Instruction: The following items describe some situations you might encounter. Please indicate how these situations apply to you by using the following scale:

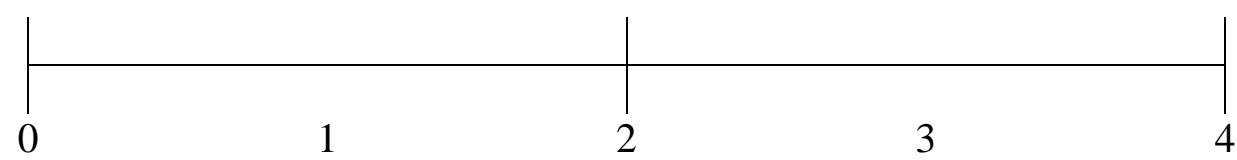

Not applicable $\begin{gathered}\text { Somewhat } \\ \text { applicable }\end{gathered} \quad$ Applicable $\quad \begin{gathered}\text { Very } \\ \text { applicable }\end{gathered} \quad \begin{gathered}\text { Extremely } \\ \text { applicable }\end{gathered}$

1. I only use certain ways to cope with stress. (R)

2. I am aware of how successful or unsuccessful my attempts to cope with stress have been.

3. I fail to notice when I have been unable to cope with stress. (R)

4. If I feel that I have failed to cope with stress, I change the way in which I deal with stress.

5. After coping with stress, I think about how well my ways of coping with stress worked or did not work.

6. I only use certain ways to enhance my positive mood. (R)

7. I am aware of how successful or unsuccessful my attempts to enhance my positive mood have been.

8. I fail to notice when I have been unable to enhance my positive mood. (R)

9. If I feel that I have failed to enhance my positive mood, I change the way of mood enhancement.

10. After enhancing my positive mood, I think about how well my ways of mood enhancement worked or did not work.

Reverse-coded item are denoted with (R). 


\section{Appendix D: Alcohol, Smoking, and Substance Involvement Screening Test}

The following questions ask you about your experience of using different substances across your lifetime and in the past 3 months. These substances can be smoked, swallowed, snorted, inhaled, injected or taken in the form of pills. Some of the substances listed may be prescribed by a doctor. For this study, please only indicate if you have taken the listed substance for reason other than prescription, or taken them more frequently or at higher dose than prescribed. Please be assured that information on such use will be kept strictly confidential.

Question 1 (Within each drug class, please circle the specific types of drugs you have used)

\begin{tabular}{|l|l|l|}
\hline $\begin{array}{l}\text { Inyourlife,whichofthefollowing substanceshaveyou } \\
\text { everused? (NON-MEDICAL USEONLY) }\end{array}$ & No & Yes \\
\hline a. Tobaccoproducts(cigarettes, chewing tobacco,cigars,etc.) & 0 & 3 \\
\hline b. Alcoholicbeverages(beer,wine, spirits,etc.) & 0 & 3 \\
\hline c. Cannabis(marijuana,pot,grass,hash,etc.) & 0 & 3 \\
\hline d. Cocaine(coke,crack,etc.) & 0 & 3 \\
\hline e.Amphetaminetypestimulants(speed,dietpills,ecstasy,etc.) & 0 & 3 \\
\hline f. Inhalants(nitrous, glue,petrol, paint thinner,etc.) & 0 & 3 \\
\hline g. SedativesorSleepingPills(Valium,Serepax,Rohypnol,etc.) & 0 & 3 \\
\hline h. Hallucinogens(LSD,acid,mushrooms,PCP,SpecialK,etc.) & 0 & 3 \\
\hline i. Opioids(heroin,morphine,methadone,codeine,etc.) & 0 & 3 \\
\hline j. Dimethyltryptamine (DMT) & 0 & 3 \\
\hline k. Other -specify: & 0 & 3 \\
\hline
\end{tabular}




\section{Question 2}

\begin{tabular}{|c|c|c|c|c|c|}
\hline $\begin{array}{l}\text { Inthepastthreemonths, howoftenhaveyouused } \\
\text { thesubstancesyoumentioned(FIRSTDRUG, } \\
\text { SECONDDRUG,ETC)? }\end{array}$ & 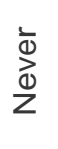 & 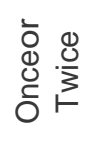 & 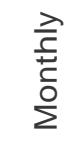 & 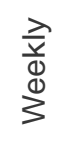 & 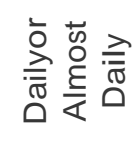 \\
\hline a. Tobaccoproducts(cigarettes, chewing tobacco,cigars,etc.) & 0 & 12 & & 4 & \\
\hline b. Alcoholicbeverages(beer, wine, spirits,etc.) & 0 & 12 & & 4 & \\
\hline c. Cannabis(marijuana,pot,grass,hash,etc.) & 0 & 12 & & 4 & \\
\hline d. Cocaine(coke,crack,etc.) & 0 & 12 & & 4 & \\
\hline e.Amphetaminetypestimulants(speed,dietpills, ecstasy,etc.) & 0 & 12 & & 4 & \\
\hline f. Inhalants(nitrous, glue,petrol, paint thinner,etc.) & 0 & 12 & & 4 & \\
\hline g. SedativesorSleepingPills(Valium,Serepax,Rohypnol,etc.) & 0 & 12 & & 4 & \\
\hline h. Hallucinogens(LSD,acid,mushrooms,PCP,SpecialK,etc.) & 0 & 12 & & 4 & \\
\hline i. Opioids(heroin,morphine, methadone,codeine,etc.) & 0 & 12 & & 4 & \\
\hline j. Dimethyltryptamine (DMT) & 0 & 12 & & 4 & \\
\hline k. Other -specify: & 0 & 12 & & 4 & \\
\hline
\end{tabular}




\section{Question 3}

\begin{tabular}{|c|c|c|c|c|c|}
\hline $\begin{array}{l}\text { Duringthepastthreemonths, howoftenhaveyou } \\
\text { hadastrongdesireorurgetouse(FIRSTDRUG,SECOND } \\
\text { DRUG,ETC)? }\end{array}$ & $\begin{array}{l}\frac{1}{d} \\
\frac{1}{Z}\end{array}$ & 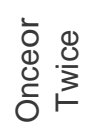 & & $\begin{array}{l}\frac{\lambda}{0} \\
\stackrel{0}{\infty} \\
3\end{array}$ & \multirow[t]{2}{*}{ 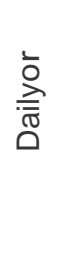 } \\
\hline a. Tobaccoproducts(cigarettes, chewing tobacco,cigars,etc.) & 0 & & 23 & 4 & \\
\hline b. Alcoholicbeverages(beer, wine, spirits,etc.) & 0 & & 23 & 4 & \\
\hline c. Cannabis(marijuana,pot,grass, hash,etc.) & 0 & 1 & 23 & 4 & \\
\hline d. Cocaine (coke,crack,etc.) & 0 & 1 & 23 & 4 & \\
\hline e.Amphetaminetypestimulants(speed, dietpills,ecstasy,etc.) & 0 & 1 & 23 & 4 & \\
\hline f. Inhalants(nitrous, glue, petrol, paint thinner,etc.) & 0 & 1 & 23 & 4 & \\
\hline g. SedativesorSleepingPills(Valium,Serepax,Rohypnol,etc.) & 0 & 1 & 23 & 4 & \\
\hline h. Hallucinogens(LSD, acid,mushrooms,PCP,SpecialK,etc.) & 0 & 1 & 23 & 4 & \\
\hline i. Opioids(heroin,morphine, methadone,codeine,etc.) & 0 & 1 & 23 & 4 & \\
\hline j. Dimethyltryptamine (DMT) & 0 & 1 & 23 & 4 & \\
\hline k. Other-specify: & 0 & 1 & 23 & 4 & \\
\hline
\end{tabular}




\section{Question 4}

\begin{tabular}{|c|c|c|c|c|c|}
\hline $\begin{array}{l}\text { Duringthepastthreemonths, howoftenhasyour } \\
\text { useof(FIRSTDRUG,SECONDDRUG,ETC) } \\
\text { ledtohealth,social,legalorfinancialproblems? }\end{array}$ & $\begin{array}{l}\stackrel{亠}{\Phi} \\
\stackrel{\circlearrowright}{Z}\end{array}$ & 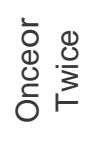 & & $\begin{array}{l}\frac{\lambda}{x} \\
\stackrel{\Phi}{3}\end{array}$ & 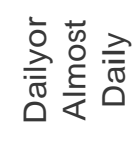 \\
\hline a. Tobaccoproducts(cigarettes, chewing tobacco,cigars,etc.) & 0 & & 23 & 4 & \\
\hline b. Alcoholicbeverages(beer, wine, spirits,etc.) & 0 & 1 & 23 & 4 & \\
\hline c. Cannabis(marijuana,pot,grass, hash,etc.) & 0 & 1 & 23 & 4 & \\
\hline d. Cocaine(coke,crack,etc.) & 0 & 1 & 23 & 4 & \\
\hline e.Amphetaminetypestimulants(speed,dietpills,ecstasy,etc.) & 0 & 1 & 23 & 4 & \\
\hline f. Inhalants(nitrous, glue,petrol, paint thinner,etc.) & 0 & 1 & 23 & 4 & \\
\hline g. SedativesorSleepingPills(Valium,Serepax,Rohypnol,etc.) & 0 & 1 & 23 & 4 & \\
\hline h. Hallucinogens(LSD,acid,mushrooms,PCP,SpecialK,etc.) & 0 & 1 & 23 & 4 & \\
\hline i. Opioids(heroin,morphine, methadone,codeine,etc.) & 0 & 1 & 23 & 4 & \\
\hline j. Dimethyltryptamine (DMT) & 0 & 1 & 23 & 4 & \\
\hline k. Other -specify: & 0 & 1 & 23 & 4 & \\
\hline
\end{tabular}




\section{Question 5}

\begin{tabular}{|c|c|c|c|c|c|}
\hline $\begin{array}{l}\text { Duringthepastthreemonths, howoftenhaveyoufailed } \\
\text { todowhatwasnormallyexpectedofyoubecauseof } \\
\text { youruseof(FIRSTDRUG,SECONDDRUG,ETC)? }\end{array}$ & \multirow[t]{2}{*}{$\frac{\bar{D}}{\stackrel{亠}{亠}}$} & \multirow{2}{*}{\multicolumn{2}{|c|}{ 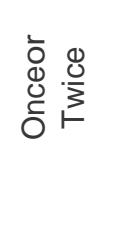 }} & \multirow[t]{2}{*}{ 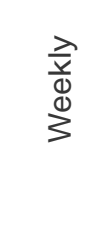 } & \multirow[t]{2}{*}{ 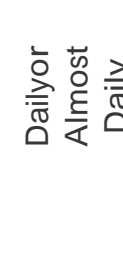 } \\
\hline a. Tobaccoproducts & & & & & \\
\hline b. Alcoholicbeverages(beer, wine, spirits,etc.) & 0 & 1 & 23 & 4 & \\
\hline c. Cannabis(marijuana,pot,grass, hash,etc.) & 0 & 1 & 23 & 4 & \\
\hline d. Cocaine(coke,crack,etc.) & 0 & 1 & 23 & 4 & \\
\hline e.Amphetaminetypestimulants(speed, dietpills, ecstasy,etc.) & 0 & 1 & 23 & 4 & \\
\hline f. Inhalants(nitrous, glue, petrol, paint thinner,etc.) & 0 & 1 & 23 & 4 & \\
\hline g. SedativesorSleepingPills(Valium,Serepax,Rohypnol,etc.) & 0 & 1 & 23 & 4 & \\
\hline h. Hallucinogens(LSD, acid,mushrooms,PCP,SpecialK,etc.) & 0 & 1 & 23 & 4 & \\
\hline i. Opioids(heroin,morphine, methadone,codeine,etc.) & 0 & 1 & 23 & 4 & \\
\hline j. Dimethyltryptamine (DMT) & 0 & 1 & 23 & 4 & \\
\hline k. Other -specify: & 0 & 1 & 23 & 4 & \\
\hline
\end{tabular}




\section{Question 6}

\begin{tabular}{|c|c|c|c|}
\hline 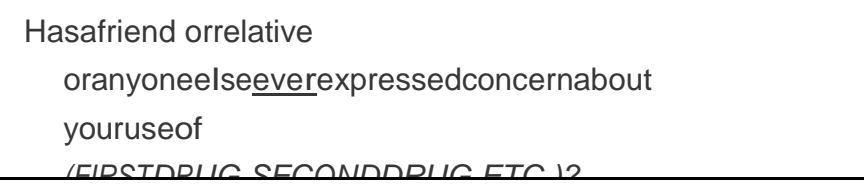 & $\begin{array}{l}\frac{1}{d} \\
\stackrel{d}{Z} \\
0^{-}\end{array}$ & 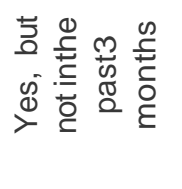 & 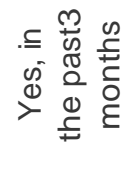 \\
\hline a. Tobaccoproducts(cigarettes, chewing tobacco,cigars,etc.) & 0 & 1 & 2 \\
\hline b. Alcoholicbeverages(beer, wine, spirits,etc.) & 0 & 1 & 2 \\
\hline c. Cannabis(marijuana,pot,grass, hash,etc.) & 0 & 1 & 2 \\
\hline d. Cocaine(coke,crack,etc.) & 0 & 1 & 2 \\
\hline e.Amphetaminetypestimulants(speed, dietpills,ecstasy,etc.) & 0 & 1 & 2 \\
\hline f. Inhalants(nitrous, glue,petrol, paint thinner,etc.) & 0 & 1 & 2 \\
\hline g. SedativesorSleepingPills(Valium,Serepax,Rohypnol,etc.) & 0 & 1 & 2 \\
\hline h. Hallucinogens(LSD, acid,mushrooms,PCP,SpecialK,etc.) & 0 & 1 & 2 \\
\hline i. Opioids(heroin,morphine, methadone,codeine,etc.) & 0 & 1 & 2 \\
\hline j. Dimethyltryptamine (DMT) & 0 & 1 & 2 \\
\hline k. Other -specify: & 0 & 1 & 2 \\
\hline
\end{tabular}




\section{Question 7}

\begin{tabular}{|c|c|c|c|}
\hline $\begin{array}{l}\text { Haveyouevertriedandfailedtocontrol, cutdown orstopusing } \\
\quad(\text { FIRSTDRUG, SECONDDRUG,ETC.)? }\end{array}$ & $\begin{array}{l}\bar{\phi} \\
\sum_{0}^{1} \\
0^{\circ}\end{array}$ & 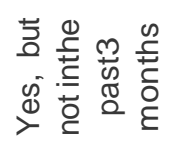 & 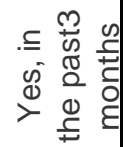 \\
\hline a. Tobaccoproducts(cigarettes, chewing tobacco,cigars,etc.) & 0 & 1 & 2 \\
\hline b. Alcoholicbeverages(beer, wine, spirits,etc.) & 0 & 1 & 2 \\
\hline c. Cannabis(marijuana,pot,grass, hash,etc.) & 0 & 1 & 2 \\
\hline d. Cocaine(coke,crack,etc.) & 0 & 1 & 2 \\
\hline e.Amphetaminetypestimulants(speed, dietpills,ecstasy,etc.) & 0 & 1 & 2 \\
\hline f. Inhalants(nitrous, glue, petrol, paint thinner,etc.) & 0 & 1 & 2 \\
\hline g. SedativesorSleepingPills(Valium,Serepax,Rohypnol,etc.) & 0 & 1 & 2 \\
\hline h. Hallucinogens(LSD, acid,mushrooms,PCP,SpecialK,etc.) & 0 & 1 & 2 \\
\hline i. Opioids(heroin,morphine, methadone,codeine,etc.) & 0 & 1 & 2 \\
\hline j. Dimethyltryptamine (DMT) & 0 & 1 & 2 \\
\hline k. Other -specify: & 0 & 1 & 2 \\
\hline
\end{tabular}

\section{Question 8}

Haveyoueverusedanydrug byinjection? (NON-MEDICAL USEONLY)

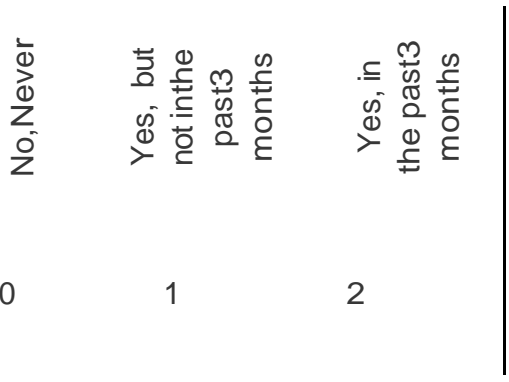




\section{Appendix E: Inventory of Drug-Taking Situations - 8}

What are your top three substance of choice (besides tobacco)?

Think about your substance use over the past year in each of the following situations. If you NEVER used the chosen substance in that situation, you would circle "0". If you ALMOST ALWAYS used the chosen substance in that situation, you would circle " $100 \%$ ". If your answer falls somewhere in between, place an $\mathrm{X}$ along the line so that it shows about how close to $0 \%$ or $100 \%$ you think is appropriate.

Over the past year, I used (top choice of substance) when I was experiencing:

1. unpleasant emotions (e.g., when I was angry, frustrated, bored, sad or anxious)

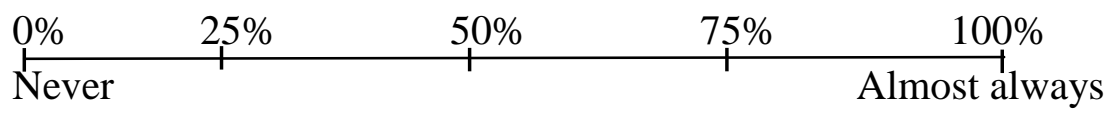

2. physical discomfort (e.g., when I was feeling ill or in pain)

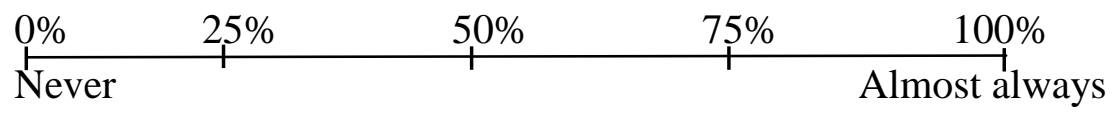

3. pleasant emotions (e.g., when I was enjoying myself or just feeling happy)

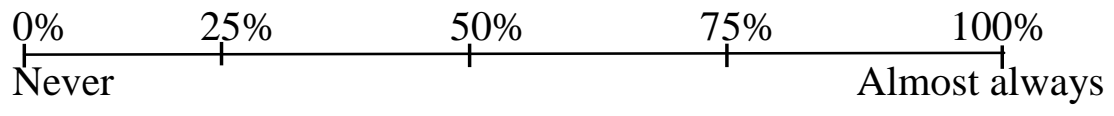

4. testing personal control (e.g., when I started to believe I could handle the drug)

$\begin{array}{lllll}0 \% & 25 \% & 50 \% & 75 \% & 100 \% \\ \text { Never } & & & \text { Almost always }\end{array}$

5. urges and temptations (e.g., when I walked by a pub or saw something that reminded me of drug use)
$\stackrel{0 \%}{\stackrel{1}{N} \text { ever }}$
$25 \%$
$50 \%$
$75 \%$
$100 \%$
Almost always

6. conflict with others (e.g., when I had an argument or was not getting along with someone)

$0 \%$\begin{tabular}{lllc}
$25 \%$ & $50 \%$ & $75 \%$ & $100 \%$ \\
\cline { 2 - 2 } & & & Almost always
\end{tabular}

7. social pressures (e.g., when someone offered drugs)
$\stackrel{0 \%}{\mathrm{~N} \text { Never }}$
$50 \%$
$75 \%$
$100 \%$
Almost always

8. pleasant times with others (e.g., when I was out with friends or at a party)
$\stackrel{0 \%}{\mathrm{~N} \text { Never }}$
$50 \%$
$75 \%$
$100 \%$
Almost always 
Over the past year, I used (second choice of substance) when I was experiencing:

1. unpleasant emotions (e.g., when I was angry, frustrated, bored, sad or anxious)

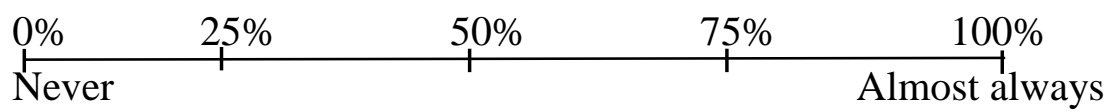

2. physical discomfort (e.g., when I was feeling ill or in pain)

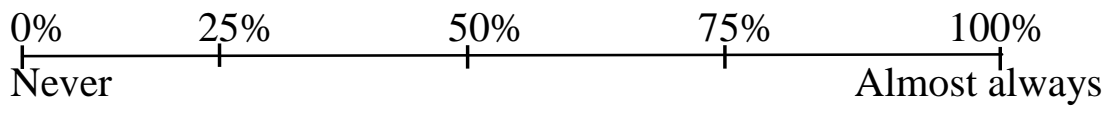

3. pleasant emotions (e.g., when I was enjoying myself or just feeling happy)

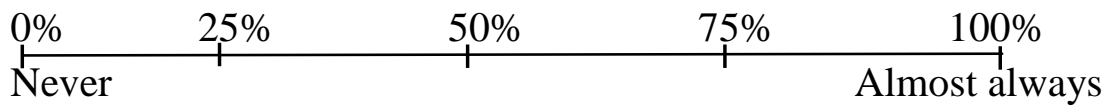

4. testing personal control (e.g., when I started to believe I could handle the drug)

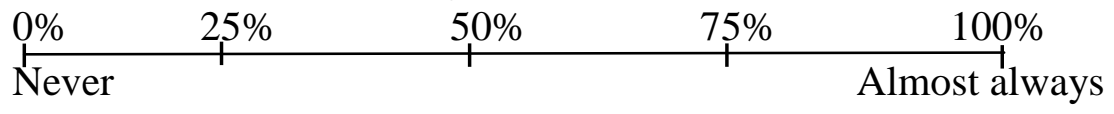

5. urges and temptations (e.g., when I walked by a pub or saw something that reminded me of drug use)

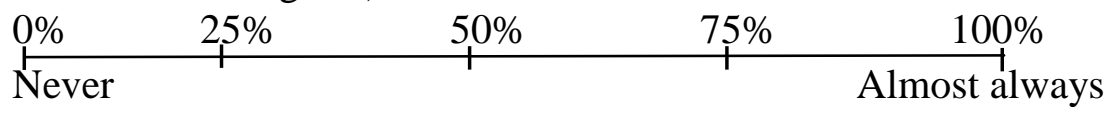

6. conflict with others (e.g., when I had an argument or was not getting along with someone)

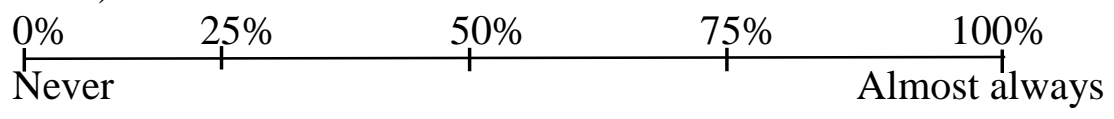

7. social pressures (e.g., when someone offered drugs)

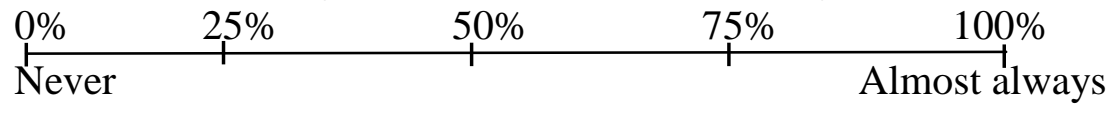

8. pleasant times with others (e.g., when I was out with friends or at a party)

$\begin{array}{lllll}0 \% & 25 \% & 50 \% & 75 \% & 100 \% \\ \text { Never } & & & \text { Almost always }\end{array}$


Over the past year, I used (third choice of substance) when I was experiencing:

1. unpleasant emotions (e.g., when I was angry, frustrated, bored, sad or anxious) $\begin{array}{lllll}0 \% & 25 \% & 50 \% & 75 \% & 100 \% \\ \stackrel{+}{N} \text { Never } & & & \text { Almost always }\end{array}$

2. physical discomfort (e.g., when I was feeling ill or in pain)

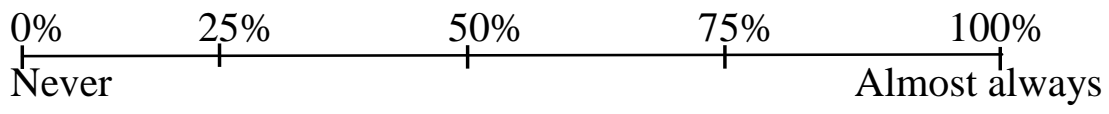

3. pleasant emotions (e.g., when I was enjoying myself or just feeling happy)

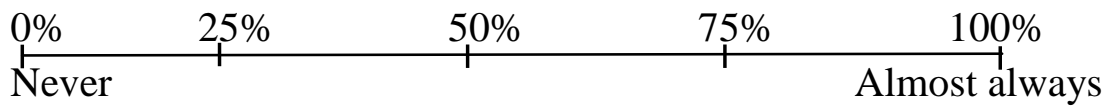

4. testing personal control (e.g., when I started to believe I could handle the drug)

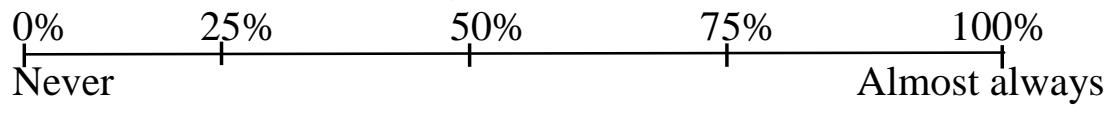

5. urges and temptations (e.g., when I walked by a pub or saw something that reminded me of drug use)

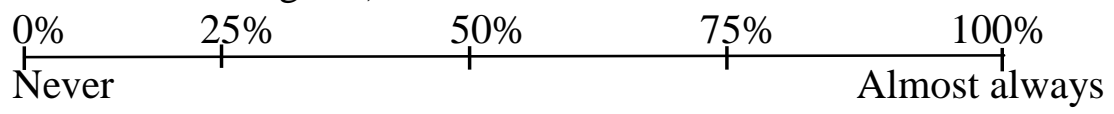

6. conflict with others (e.g., when I had an argument or was not getting along with someone)

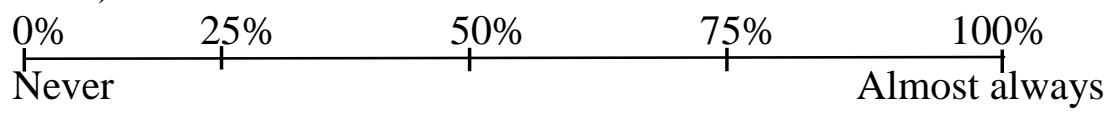

7. social pressures (e.g., when someone offered drugs)

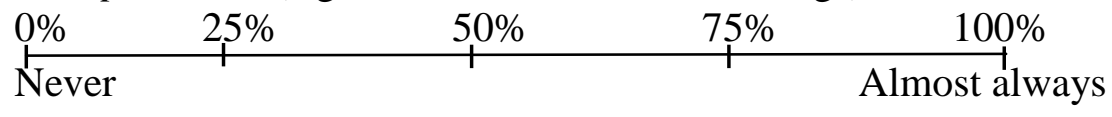

8. pleasant times with others (e.g., when I was out with friends or at a party)

$\begin{array}{lllll}0 \% & 25 \% & 50 \% & 75 \% & 100 \% \\ \text { Never } & & & \text { Almost always }\end{array}$




\section{AppendixF: Typical Mood Survey}

Below are some words that describe feelings and moods. Read each word carefully and then indicate to what extent the adjectives describe your typical mood. Please use the following scale to indicate your responses (with positive states in bold).

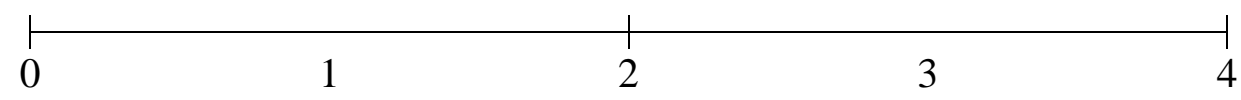

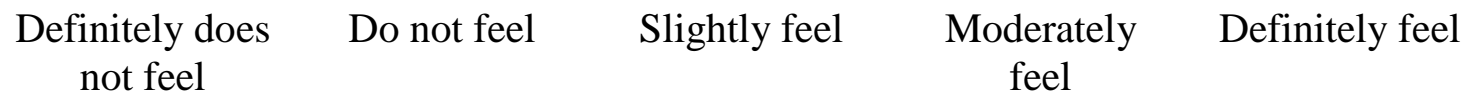

1. Over the course of a typical week, I usually feel...

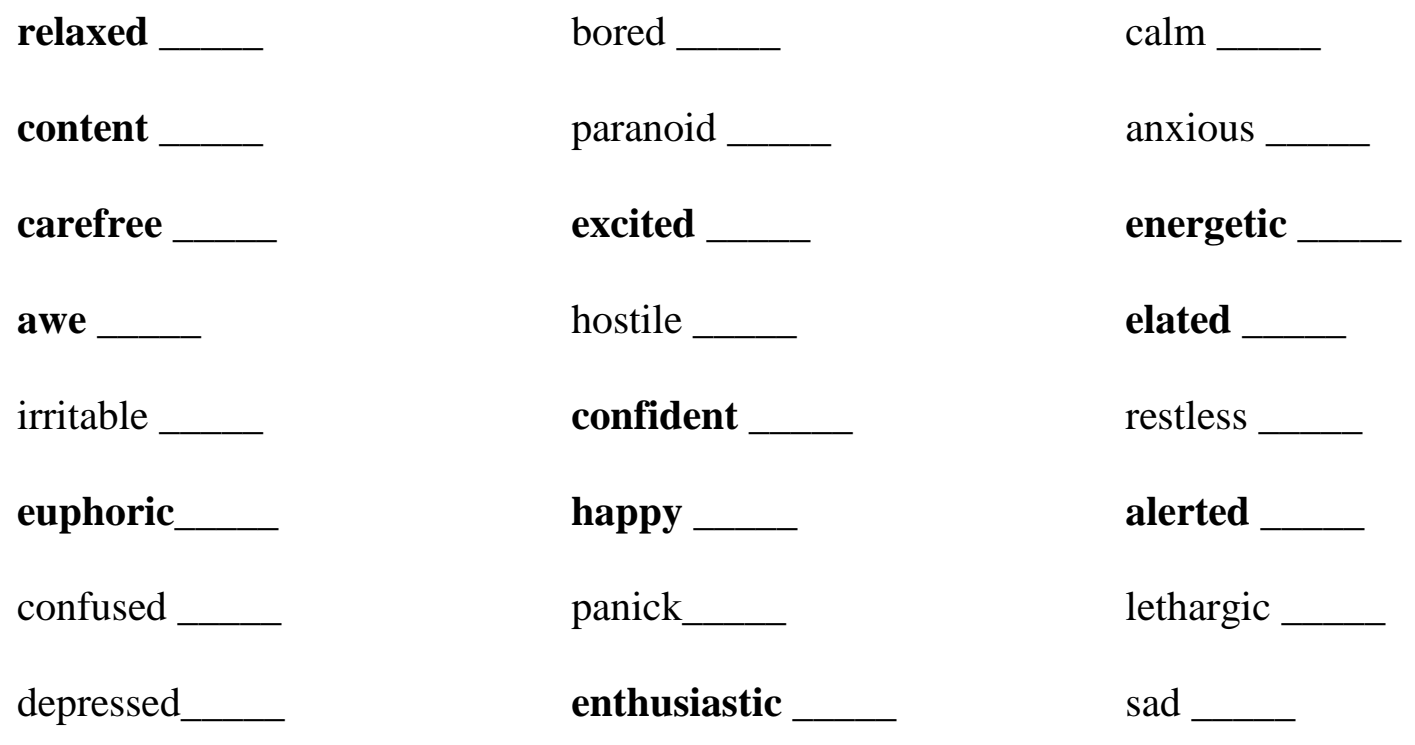




\section{AppendixG: Adult Temperament Questionnaire}

Directions: On the following pages, you will find a series of statements that individuals can use to describe themselves. Please read each statement carefully and give your best estimate of how well it describes you. Circle the appropriate number below to indicate how well a given statement describes you. If one of the statements does not apply to you (for example, if it involves driving a car and you don't drive), then circle "X" (not applicable). Check to make sure that you have answered every item.

\begin{tabular}{ll} 
circle \#: & if the statement is: \\
\hline 1 & extremely untrue of you \\
3 & quite untrue of you \\
4 & slightly untrue of you \\
5 & neither true nor false of you \\
6 & slightly true of you \\
7 & quite true of you \\
& extremely true of you
\end{tabular}

1. I become easily frightened.

$\begin{array}{llllllll}1 & 2 & 3 & 4 & 5 & 6 & 7 & \mathrm{X}\end{array}$

2 Sometimes minor events cause me to feel intense happiness.
12
3
45
$6 \quad 7$
$\mathrm{X}$

3. I rarely become annoyed when I have to wait in a slow moving line.

$\begin{array}{llllllll}1 & 2 & 3 & 4 & 5 & 6 & 7 & \mathrm{X}\end{array}$

4. I would not enjoy the sensation of listening to loud music with a laser light show.

$\begin{array}{llllllll}1 & 2 & 3 & 4 & 5 & 6 & 7 & \mathrm{X}\end{array}$

5. I rarely feel sad after saying goodbye to friends or relatives.
1
3
4
5
6
$7 \quad X$

6. Looking down at the ground from an extremely high place would make me feel uneasy.

$\begin{array}{llllllll}1 & 2 & 3 & 4 & 5 & 6 & 7 & \mathrm{X}\end{array}$

7. I would not enjoy a job that involves socializing with the public.
1
2
3
$4 \quad 5$
6
7
$\mathrm{X}$

8. I sometimes seem to be unable to feel pleasure from events and activities that I should enjoy.
1
2
34
5
6
7
X

9. I find it very annoying when a store does not stock an item that I wish to buy.
1
2
3
4
5
6
7
X

10. I usually like to talk a lot. 

1
2
3
$4 \quad 5$
6
7
X

11. I seldom become sad when I watch a sad movie.
$1 \quad 2$
3
45
$\begin{array}{ll}6 & 7\end{array}$
X

12. When I am enclosed in small places such as an elevator, I feel uneasy.
12
3
4
5
6
7
X

13. When listening to music, I usually like turn up the volume more than other people.
12
3
$4 \quad 5$
6
7
$\mathrm{X}$

14. Sometimes minor events cause me to feel intense sadness.
12
3
45
6
7
X

15. I rarely ever have days where I don't at least experience brief moments of intense happiness.
1
3
45
6
7
X

16. I would probably enjoy playing a challenging and fast paced video-game that makes lots of noise and has lots of flashing, bright lights.
1
2
3
45
$6 \quad 7$
X

17. Whenever I have to sit and wait for something (e.g., a waiting room), I become agitated.

$\begin{array}{llllllll}1 & 2 & 3 & 4 & 5 & 6 & 7 & \mathrm{X}\end{array}$

18. I seldom become sad when I hear of an unhappy event.

$\begin{array}{llllllll}1 & 2 & 3 & 4 & 5 & 6 & 7 & \mathrm{X}\end{array}$

19. I like conversations that include several people.
12
3
45
6
7
$\mathrm{X}$

20. I am usually a patient person.

$\begin{array}{llllllll}1 & 2 & 3 & 4 & 5 & 6 & 7 & \mathrm{X}\end{array}$

21. I would probably not enjoy a fast, wild carnival ride.
12
3
45
6
7
X

22. I sometimes feel sad for longer than an hour.

$\begin{array}{lllllllll}1 & 2 & 3 & 4 & 5 & 6 & 7 & \mathrm{X}\end{array}$

23. I rarely enjoy socializing with large groups of people.

$\begin{array}{llllllll}1 & 2 & 3 & 4 & 5 & 6 & 7 & \mathrm{X}\end{array}$

24. It doesn't take very much to make feel frustrated or irritated.
12
3
45
6
7
X

25. It doesn't take much to evoke a happy response in me. 

1
2
3
$4 \quad 5$
6
7
X

26. Sometimes, I feel a sense of panic or terror for no apparent reason.
12
3
4
5
6
7
X

27. I often feel sad.
12
3
$4 \quad 5$
6
7
X

28. I usually remain calm without getting frustrated when things are not going smoothly for me.

$\begin{array}{llllllll}1 & 2 & 3 & 4 & 5 & 6 & 7 & \mathrm{X}\end{array}$

29. Loud noises sometimes scare me.

$\begin{array}{llllllll}1 & 2 & 3 & 4 & 5 & 6 & 7 & \mathrm{X}\end{array}$

30. I would enjoy watching a laser show with lots of bright, colorful flashing lights.
12
3
$4 \quad 5$
6
7
$\mathrm{X}$

31. When I hear of an unhappy event, I immediately feel sad.

$\begin{array}{llllllll}1 & 2 & 3 & 4 & 5 & 6 & 7 & \mathrm{X}\end{array}$

32. I usually like to spend my free time with people.

$\begin{array}{llllllll}1 & 2 & 3 & 4 & 5 & 6 & 7 & \mathrm{X}\end{array}$

33. It does not frighten me if I think that I am alone and suddenly discover someone close by.
1
2
3
45
6
7
$\mathrm{X}$

34. It takes a lot to make me feel truly happy.

$\begin{array}{llllllll}1 & 2 & 3 & 4 & 5 & 6 & 7 & \mathrm{X}\end{array}$

35. I especially enjoy conversations where I am able to say things without thinking first.

$\begin{array}{llllllll}1 & 2 & 3 & 4 & 5 & 6 & 7 & \mathrm{X}\end{array}$

36. When I try something new, I am rarely concerned about the possibility of failing.
1
2
3
4
5
6
7
$\mathrm{X}$

37. I would not enjoy the feeling that comes from yelling as loud as I can.

$\begin{array}{llllllll}1 & 2 & 3 & 4 & 5 & 6 & 7 & \mathrm{X}\end{array}$




\section{Appendix H: UPPS-P Impulsive Behavior Scale}

Below are a number of statements that describe ways in which people act and think. For each statement, please indicate how much you agree or disagree with the statement. Be sure to indicate your agreement or disagreement for every statement below, using the following scale:

$1=$ Agree strongly; 2 = Agree somewhat; 3 = Disagree somewhat; $4=$ Disagree Strongly

1. I have trouble controlling my impulses.

2. When I am very happy, I can't seem to stop myself from doing things that 1 can have bad consequences.

3. I have trouble resisting my cravings (for food, cigarettes, etc.).

4. When I am in great mood, I tend to get into situations that could cause me problems.

5. I often get involved in things I later wish I could get out of.

6. When I am very happy, I tend to do things that may cause problems in my life.

7. When I feel bad, I will often do things I later regret in order to make myself feel better now.

8. I tend to lose control when I am in a great mood.

9. Sometimes when I feel bad, I can't seem to stop what I am doing even though it is making me feel worse.

10. When I am really ecstatic, I tend to get out of control.

11. When I am upset I often act without thinking.

12. Others would say I make bad choices when I am extremely happy about something.

13. When I feel rejected, I will often say things that I later regret.

14. Others are shocked or worried about the things I do when I am feeling very excited.

15. It is hard for me to resist acting on my feelings.

16. When I get really happy about something, I tend to do things that can have bad consequences.

17. I often make matters worse because I act without thinking when I am upset.

18. When overjoyed, I feel like I can’t stop myself from going overboard.

1

2

3

3

4

1

1

$\begin{array}{llll}1 & 2 & 3 & 4 \\ 1 & 2 & 3 & 4\end{array}$

1

2

3

3

4

4

1

2

3

4

$\begin{array}{llll}1 & 2 & 3 & 4 \\ 1 & 2 & 3 & 4\end{array}$

1

1

1

$\begin{array}{llll}1 & 2 & 3 & 4 \\ 1 & 2 & 3 & 4 \\ 1 & 2 & 3 & 4\end{array}$

1

1

2

2

3

3

4 
19. When I am really excited, I tend not to think of the consequences of my actions.

20. In the heat of an argument, I will often say things that I later regret.

21. I tend to act without thinking when I am really excited.

22. I always keep my feelings under control.

23. When I am really happy, I often find myself in situations that I

1
normally wouldn't be comfortable with.

24. When I am very happy, I feel like it is ok to give in to cravings or

1

-

1

2

2

3

4

2

3

4

2

34

2

34
overindulge.

25. Sometimes I do impulsive things that I later regret.

26. I am surprised at the things I do while in a great mood.

2

3

4

1

1

2

2

3

4

34


Appendix I: Center for Epidemiologic Studies Depression Scale

Below is a list of the ways you might have felt or behaved. Please tell me how often you have felt this way during the past week.

\begin{tabular}{|c|c|c|c|c|}
\hline & $\begin{array}{l}\text { Rarely or } \\
\text { none of the } \\
\text { time (less } \\
\text { than } 1 \text { day) }\end{array}$ & $\begin{array}{l}\text { Some or a } \\
\text { little of the } \\
\text { time (1-2 } \\
\text { days) }\end{array}$ & $\begin{array}{l}\text { Occasionally or } \\
\text { a moderate } \\
\text { amount of the } \\
\text { time (3-4 days) }\end{array}$ & $\begin{array}{l}\text { Most or all } \\
\text { of the time } \\
\text { (5-7 days) }\end{array}$ \\
\hline $\begin{array}{l}\text { 1) I was bothered by things } \\
\text { that usually don't bother me }\end{array}$ & 0 & 1 & 2 & 3 \\
\hline $\begin{array}{l}\text { 2) I did not feel like eating; } \\
\text { my appetite was poor }\end{array}$ & 0 & 1 & 2 & 3 \\
\hline $\begin{array}{l}\text { 3) I felt that I could not shake } \\
\text { off the blues even with help } \\
\text { from my family and friends }\end{array}$ & 0 & 1 & 2 & 3 \\
\hline $\begin{array}{l}\text { 4) I felt that I was just as good } \\
\text { as other people }\end{array}$ & 0 & 1 & 2 & 3 \\
\hline $\begin{array}{l}\text { 5) I had trouble keeping my } \\
\text { mind on what I was doing }\end{array}$ & 0 & 1 & 2 & 3 \\
\hline 6) I felt depressed & 0 & 1 & 2 & 3 \\
\hline $\begin{array}{l}\text { 7) I felt that everything I did } \\
\text { was an effort }\end{array}$ & 0 & 1 & 2 & 3 \\
\hline $\begin{array}{l}\text { 8) I felt hopeful about the } \\
\text { future }\end{array}$ & 0 & 1 & 2 & 3 \\
\hline $\begin{array}{l}\text { 9) I thought my life had been } \\
\text { a failure }\end{array}$ & 0 & 1 & 2 & 3 \\
\hline 10) I felt fearful & 0 & 1 & 2 & 3 \\
\hline 11) My sleep was restless & 0 & 1 & 2 & 3 \\
\hline 12) I was happy & 0 & 1 & 2 & 3 \\
\hline 13) I talked less than usual & 0 & 1 & 2 & 3 \\
\hline 14) I felt lonely & 0 & 1 & 2 & 3 \\
\hline 15) People were unfriendly & 0 & 1 & 2 & 3 \\
\hline 16) I enjoyed life & 0 & 1 & 2 & 3 \\
\hline 17) I had crying spells & 0 & 1 & 2 & 3 \\
\hline 18) I felt sad & 0 & 1 & 2 & 3 \\
\hline $\begin{array}{l}\text { 19) I felt that people disliked } \\
\text { me }\end{array}$ & 0 & 1 & 2 & 3 \\
\hline 20) I could not get "going" & 0 & 1 & 2 & 3 \\
\hline
\end{tabular}




\section{Appendix J: Supplementary Moderation Analyses}

The moderation analyses were examined by including the interaction terms between the three indices of ER flexibility and each of the three moderators in the structural models, controlling for the participants' gender and depressive symptom. All continuous predictors and moderators were grant-mean centered. Model fit was assessed with the same fit indices, and modification indices were examined to determine if the models needed to be trimmed or expanded to improve model fit. Because the main effects of the moderators were presented in the main document, only the moderating effects were reported below.

The initial moderation model with negative mood did not fit the data well, $\chi 2$ (39) = $271.21, \chi 2 / \mathrm{df}=6.98, p<.001, \mathrm{CFI}=.75, \mathrm{RMSEA}=.12$. Informed by the modification indices, depressive symptom was allowed to covary with ER repertoire for negative emotions and negative mood. The modified model provided better fit to the data, $\chi 2(37)=71.62, \chi 2 / \mathrm{df}=1.94$, $p=.001, \mathrm{CFI}=.96, \mathrm{RMSEA}=.05$. The results indicated that negative mood did not moderate the associations between the indices of negative ER flexibility and the substance use outcomes.

The initial model for moderation by negative emotionality did not provide a good fit to the data, $\chi 2(39)=187.70, \chi 2 / \mathrm{df}=4.81, p<.001, \mathrm{CFI}=.82$, RMSEA $=.09$. Based on the suggestion of the modification indices, modifications were made to allow depressive symptom to covary with repertoire for regulating negative emotions and with negative emotionality. Gender was also allowed to covary with negative emotionality. The revised model provided adequate fit to the data, $\chi^{2}(36)=98.24, \chi 2 / \mathrm{df}=2.73, p<.001, \mathrm{CFI}=.93, \mathrm{RMSEA}=.06$ according to more lenient cutoffs for CFI (.90 or higher), and RMSEA (.08 or lower; Byrne (2010). In contrast to the hypotheses, negative emotionality did not moderate the association between the indices of negative ER flexibility and the substance use outcomes.

The initial moderation model for negative urgency did not fit the data well, $\chi 2$ (39) $=$ $125.94, \chi 2 / \mathrm{df}=3.23, p<.001, \mathrm{CFI}=.89, \mathrm{RMSEA}=.07$. The model fit was improved by allowing depressive symptoms to covary with repertoire for regulating negative emotions and negative urgency. Two of the fit indices suggested good fit of the modified model, $\chi^{2}(37)=$ $82.17, \chi 2 / \mathrm{df}=2.22, p<.001, \mathrm{CFI}=.94, \mathrm{RMSEA}=.05$. The results revealed that the moderating effect of negative urgency on the association between repertoire for regulating negative emotions and substance-related problems was significant $(\beta=.09, \mathrm{C} . \mathrm{R} .=2.02, p=.04)$. No other moderating effects were found. The results of simple slope analyses suggested that a larger repertoire for regulating negative emotions was significantly associated with more substancerelated problems for individuals with higher levels of negative urgency $(\mathrm{B}=0.58, \mathrm{~S} . \mathrm{E} .=0.18, p$ $=.001)$, but not for those with lower levels of negative urgency $(\mathrm{B}=-0.21, \mathrm{~S} . \mathrm{E} .=0.18, p=.23)$. Partly consistent with the hypotheses, the association between ER repertoire for negative emotions and substance-use problems was more pronounced among individuals with higher levels of negative urgency, although the association was in the opposite direction as expected. The reduced model for moderation by negative urgency and the interaction graph are shown in Figure $\mathrm{J} 1$ and $\mathrm{J} 2$.

Two of the fit indices indicated that the initial model for moderation by positive mood provided a good fit to the data, $\chi 2(29)=65.20, \chi 2 / \mathrm{df}=2.25, p<.001, \mathrm{CFI}=.93$, RMSEA $=.05$. Positive mood marginally moderated the association between responsiveness to feedback of positive ER and levels of substance use $(\beta=-.10$, C.R. $=-1.95, p=.051)$. No other significant moderating effects of positive mood were found. Simple slope analyses suggested that higher levels of responsiveness to feedback of positive ER was significantly associated with lower 
levels of substance for individuals who reported higher levels of positive mood $(B=-0.63, S$.E. $=0.23, p=.01)$, but not for those who reported lower levels of positive $\operatorname{mood}(\mathrm{B}=0.15, \mathrm{~S} . \mathrm{E} .=$ $0.23, p=.52$ ), which was contrary to expectations. The full model for moderation by positive mood and the interaction graph are shown in Figure $\mathrm{J} 3$ and $\mathrm{J} 4$.

The fit indices for the initial model involving moderation by positive emotionality was good, $\chi 2(29)=37.10, \chi 2 / \mathrm{df}=1.28, p=.14, \mathrm{CFI}=.99$, RMSEA $=.03$. The positive association between repertoire for regulating positive emotions and levels of substance use was significant ( $\beta$ $=.12$, C.R. $=2.41, p=.02$ ), but the association between repertoire for regulating positive emotions and tendency to use substance in positive situations was not significant $(\beta=-.09$, C.R. $=-1.83, p=.067)$. Positive emotionality significantly moderated the association between repertoire for regulating positive emotions and tendency of using substance in positive situations $(\beta=.11$, C.R. $=2.18, p=.03)$. In contrast to prediction, however, the simple slope effect was significant for individuals with lower levels $(\mathrm{B}=-10.27$, S.E. $=1.56, p<.001)$, but not for those with higher levels of positive emotionality $(\mathrm{B}=-.36, \mathrm{~S} . \mathrm{E} .=.1 .48, p=.81)$. The full model for moderation by positive emotionality and the interaction graph are shown in Figure J5 and J6.

The initial model for moderation by positive urgency provided a good fit to the data, $\chi 2$ $(29)=40.98, \chi 2 / \mathrm{df}=1.41, p=.07, \mathrm{CFI}=.98, \mathrm{RMSEA}=.03$. Based on the modification indices, depressive symptoms were allowed to covary with repertoire for regulating positive emotions. Two of the fit indices met the conservative cutoff values for good model fit in the modified model, $\chi 2(38)=76.74, \chi 2 / \mathrm{df}=2.02, p<.001, \mathrm{CFI}=.94, \mathrm{RMSEA}=.05$. The restuls revealted that positive urgency did not moderate the association between positive ER flexibility and illicit substance use.

\section{Discussion of the Moderation Analyses}

Overall, the results of the moderation analyses provided evidence that individuals with higher levels of positive mood and a higher levels of responsiveness to feedback aboutpositiveER may be less likely to use substances, whereas those with lower levels of positive emotionality and those with higher levels of negative urgency were more susceptibility to the effect of ER repertoire on illicit substance use, whereas

\section{Moderations by Positive Mood}

There was a significant moderating effect of positive mood on the association between responsiveness to feedback of positive ER and levels of substance use. Contrary to prediction though, higher levels of responsiveness to feedback of positive ER was associated with lower levels of substance use for individuals who reported higher levels of positive mood over the course of a typical week, not for those who reported lower levels of positive mood.Based on the interaction graph (see Figure J4), it appeared that participants with high responsiveness to feedback of positive ER reported lower levels of substance use, regardless of their positive mood. However, for those lower in responsiveness to feedback, only those who reported more positive mood had elevated levels of use. Perhaps these individuals with higher levels of positive mood are also likely to be more extraverted (Lucas \& Baird, 2004) and may be more often in situations with peers that involve alcohol or illicit drugs. Thus, if they spend more time with substance-using peers but are less flexible in managing emotions, they may be at risk for using more substances (possibly to regulate emotions or for other reasons). 


\section{Moderations by Positive Emotionality}

Interesting, positive emotionality also moderated the association between ER repertoire for positive emotions and substance use in positive situations, though not in the expected way. Having a larger ER repertoire for positive emotions was hypothesized to be associated with lower tendency to use substances in positive situations for those higher in positive emotionality. However, the results indicated that for those with lower levels of positive emotionality, lower repertoire was related to higher use of substances in positive situations. Having a larger ER repertoire may provide more alternatives to enhance the emotions in positive situations without resorting to substance use. Thus, for people who tend to feel infrequent or less intense positive affect and who have few ways to effectively feel better or more positive, they may be at risk for using substance to further enhance their positive emotions when they do feel positively. Another explanation could be that individuals who endorse using drugs when they feel positive may be indicating that it is one of the few times they feel good (because they also indicated low trait PA and few other ways they try to enhance positive emotions).

\section{Moderations by Negative Urgency}

With regard to the interactive effects, the main effect of negative ER repertoire on substance-related problems was qualified by the significant moderating effect of negative urgency. Specifically, a larger ER repertoire for negative emotions was significantly associated with more substance related problems only for individuals with higher levels for negative urgency, but not for those with mean or lower levels of negative urgency. The lower levels of problems for those with high urgency but a lower repertoire seemed to be driving the effect, which is counter to the hypothesis. Given how the repertoire variable was computed in the present study, individuals who had to deploy more regulatory strategies across various contexts may not be strategically matching their strategies to situational demand and may be less effective in regulating their emotions. 


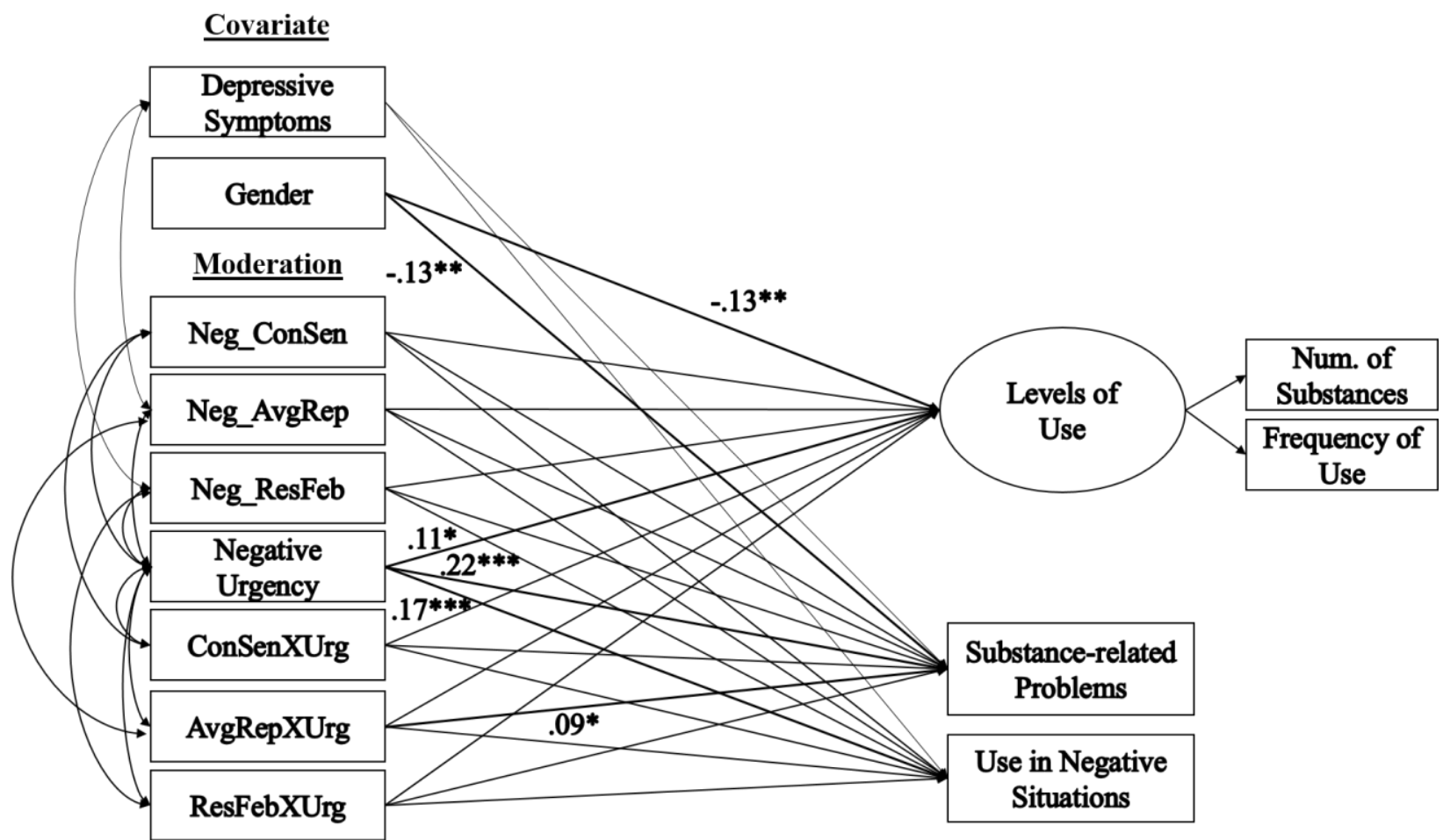

Figure J1. Model for Moderation by Negative Urgency on Negative Emotion Regulation Flexibility and Illicit Substance Use (Modified) 


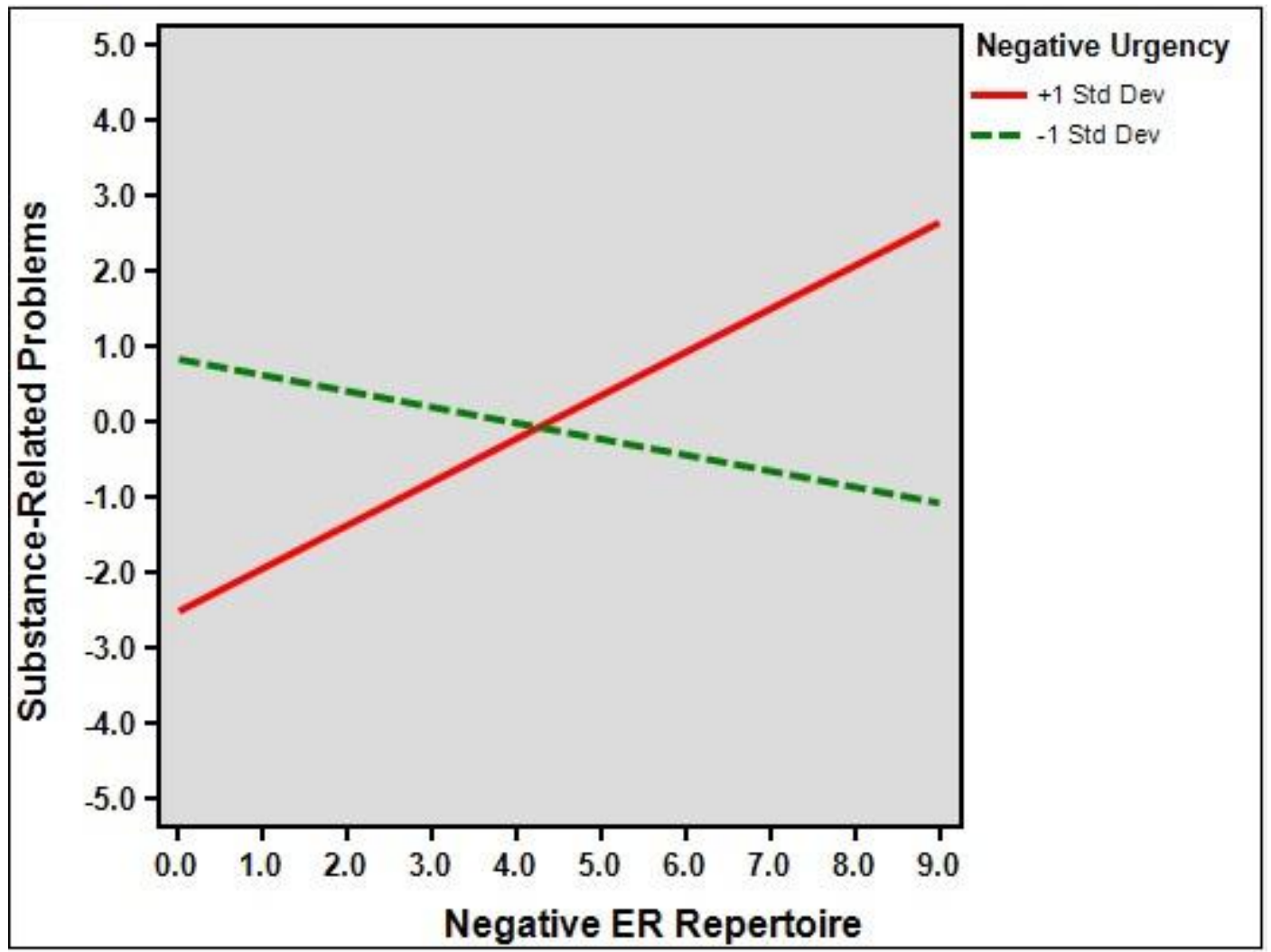

Figure J2. Negative Urgency by Repertoire for Negative Emotion Regulation Interaction on Substance-related Problems 


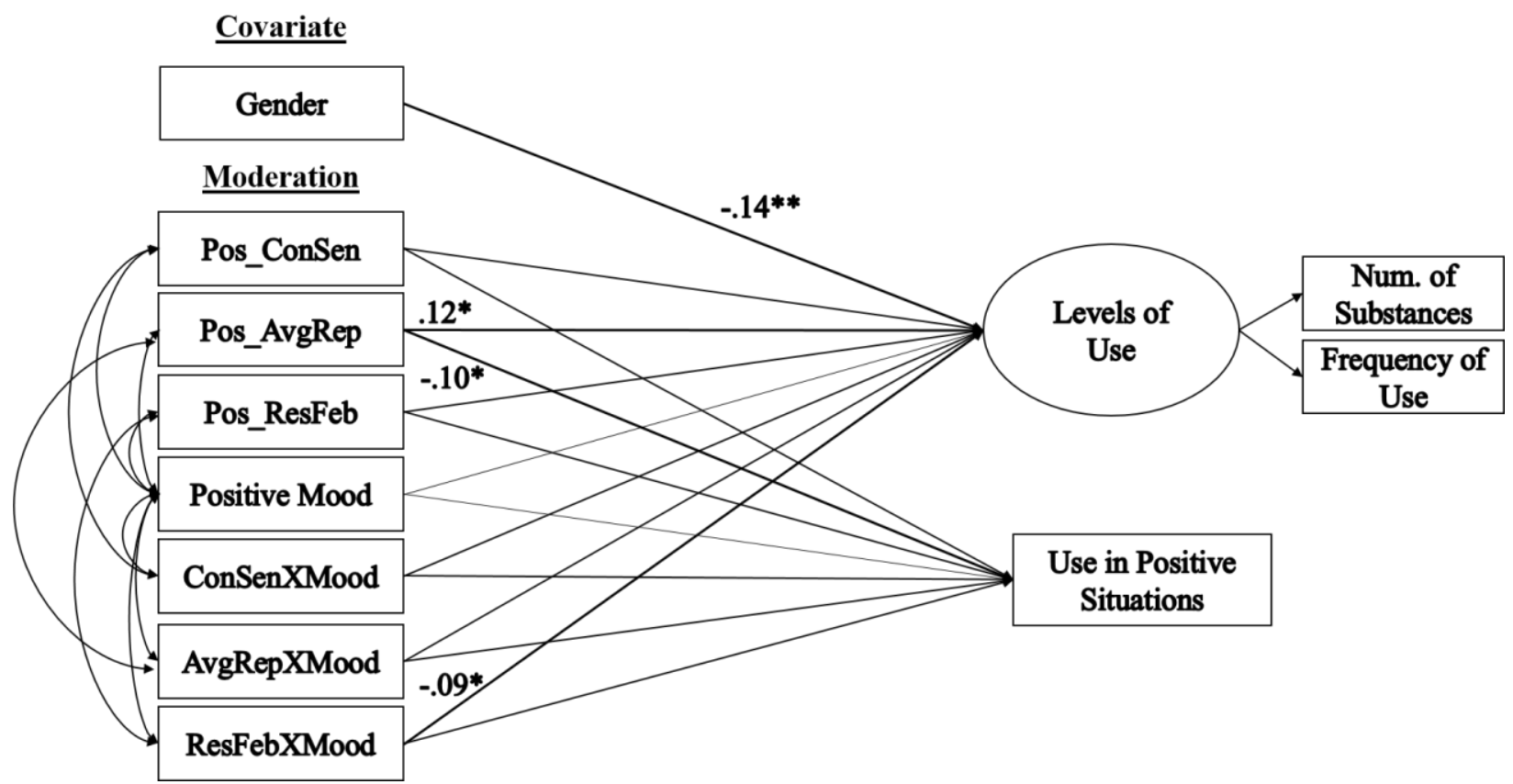

Figure J3. Model for Moderation by Positive Mood on Positive Emotion Regulation Flexibility and Illicit Substance Use 


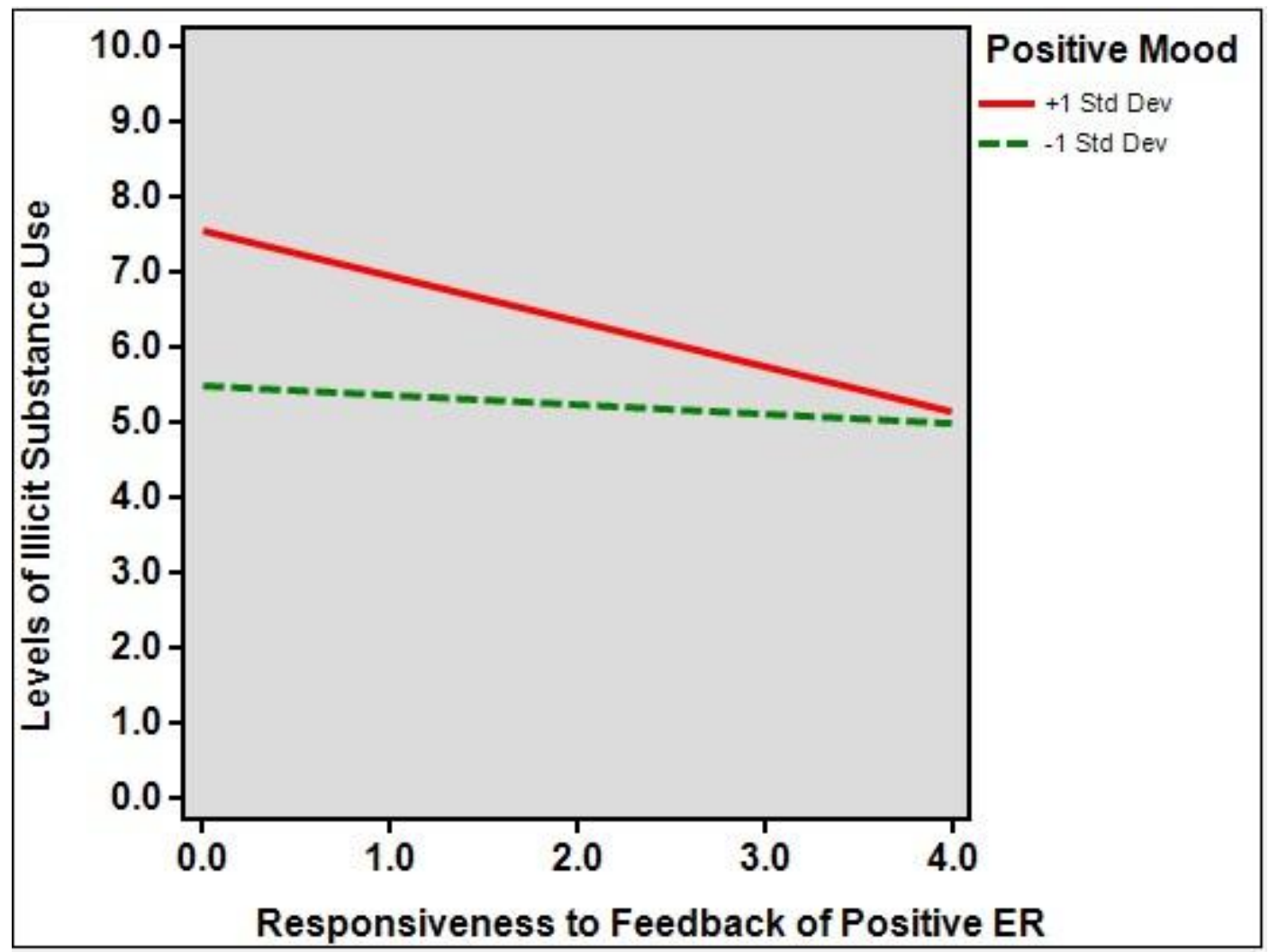

Figure J4. Positive Mood by Responsiveness to Feedback about Positive Emotion Regulation Interaction on Levels of Substance Use 


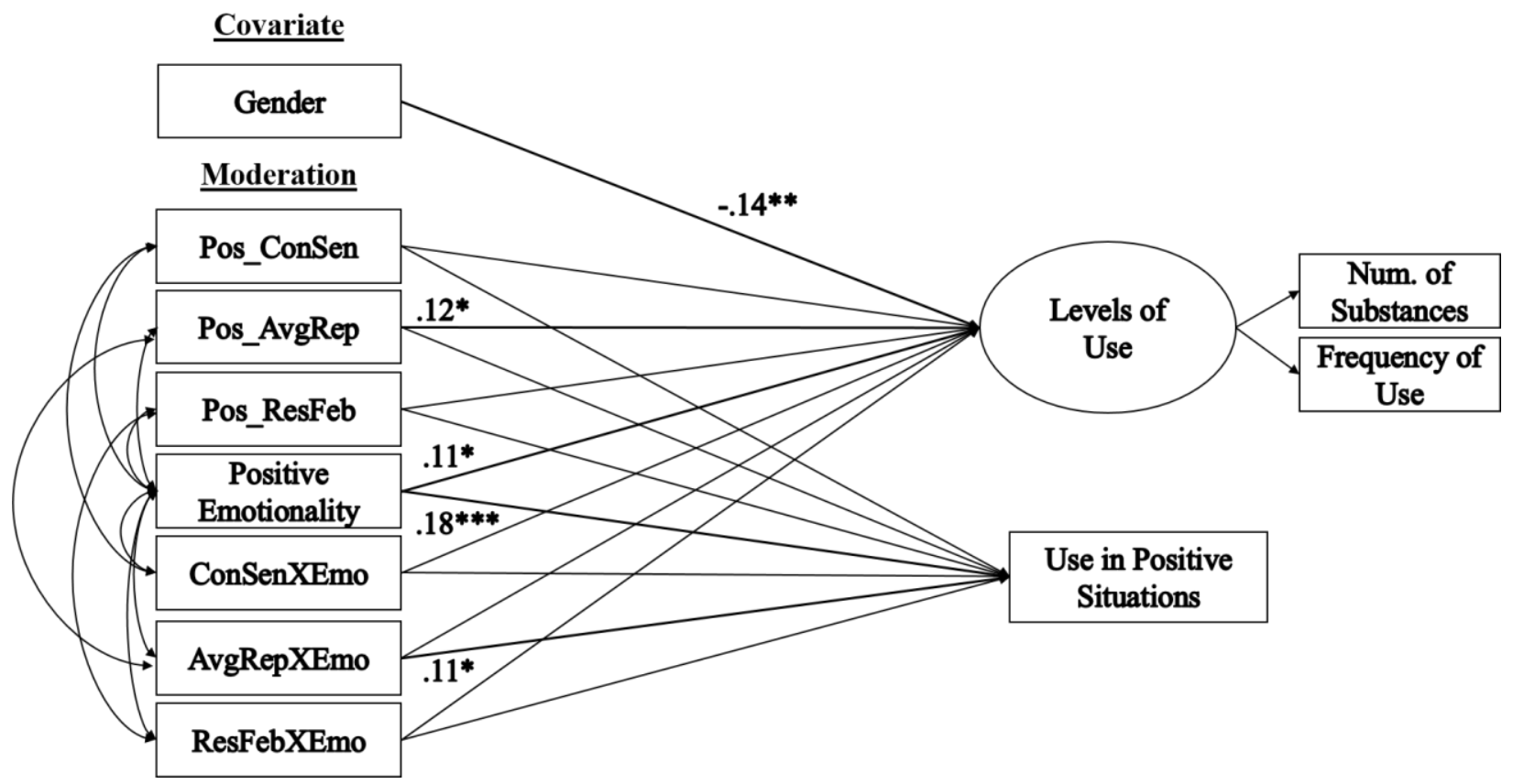

Figure J5. Model for Moderation by Positive Emotionality on Positive Emotion Regulation Flexibility and Illicit Substance Use 


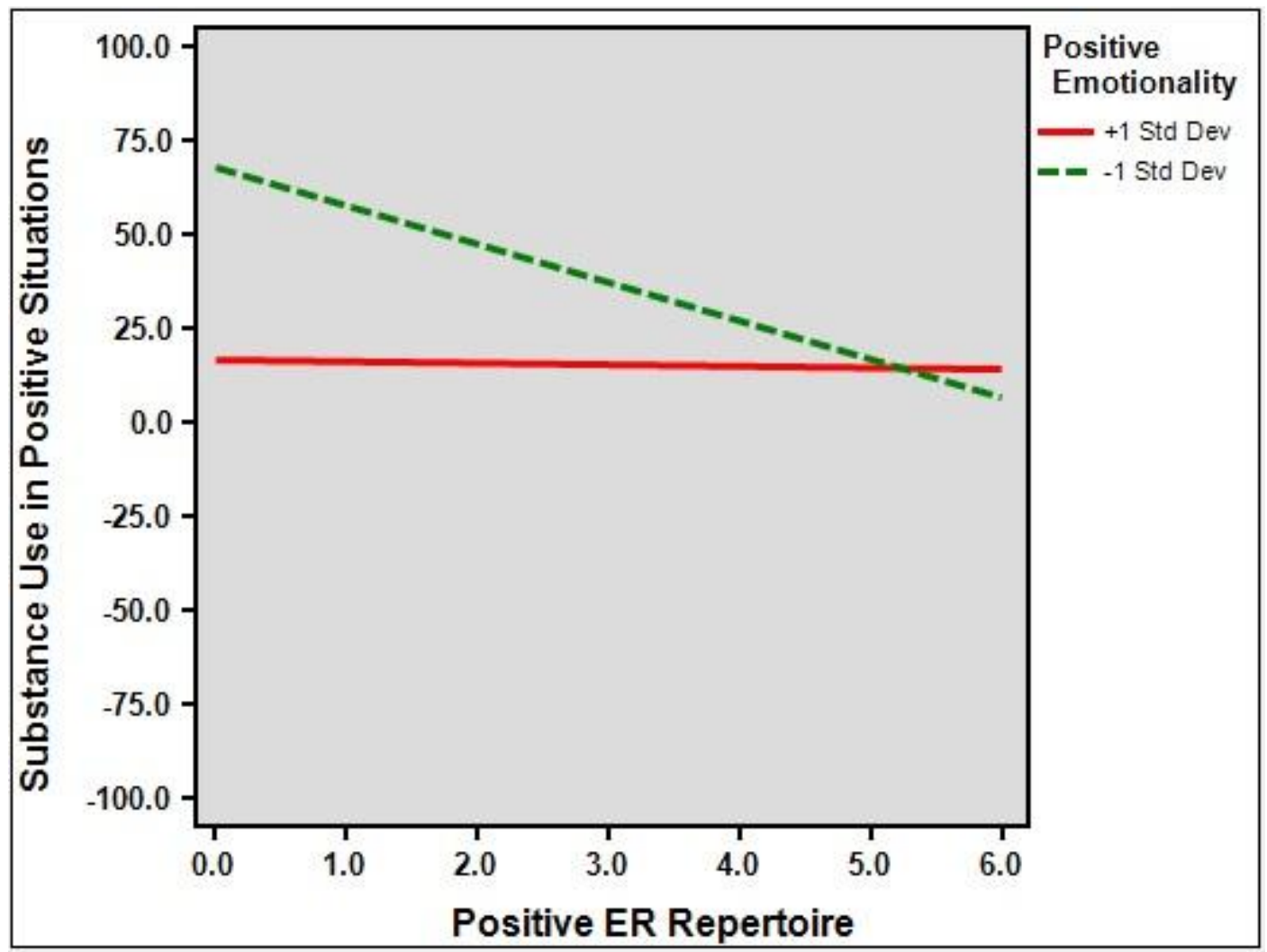

Figure J6. Positive Emotionality by Repertoire for Positive Emotion Regulation Interaction on Substance Use in Positive Situations 